UNIVERSIDADE DE SÃO PAULO

ESCOLA DE ENGENHARIA DE SÃO CARLOS

INSTITUTO DE FÍSICA DE SÃO CARLOS

INSTITUTO DE QUÍMICA DE SÃO CARLOS

GUSTAVO TARGINO VALENTE

Fotogeração, migração e dissociação do éxciton em filmes de Polifluorenos (amorfos e ordenados) próximos de interface orgânica/inorgânica 

GUSTAVO TARGINO VALENTE

\title{
Fotogeração, migração e dissociação do éxciton em filmes de Polifluorenos (amorfos e ordenados) próximos de interface orgânica/inorgânica
}

\author{
Versão Corrigida, Original na Unidade
}

Dissertação apresentada ao programa de PósGraduação Interunidades em Ciência e Engenharia de Materiais da Universidade de São Paulo, para obtenção do título de Mestre em Ciência e Engenharia de Materiais.

Área de concentração: Desenvolvimento, Caracterização e Aplicação de Materiais.

Orientador: Prof. Dr. Francisco Eduardo Gontijo Guimarães

São Carlos

2012 


\begin{abstract}
AUTORIZO A REPRODUÇÃO E DIVULGAÇÃO TOTAL OU PARCIAL DESTE TRABALHO, POR QUALQUER MEIO CONVENCIONAL OU ELETRÔNICO, PARA FINS DE ESTUDO E PESQUISA, DESDE QUE CITADA A FONTE.
\end{abstract}

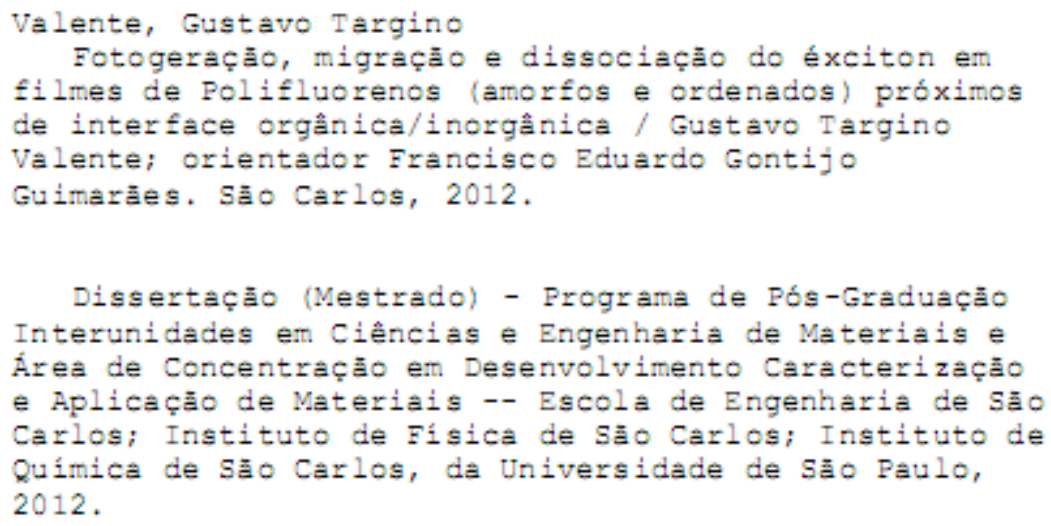

1. Migraçăo do éxciton. 2. dissociação do éxciton. 3. polifluoreno. 4. dióxido de titânio. I. Título. 
Este exemplar foi revisado e alterado em relação ao original seguindo as orientações da comissão julgadora, sob a exclusiva responsabilidade do autor. 
A minha família, Joaquim, Luzia, Guilherme e Josiane por todo amor e carinho 


\section{AGRADECIMENTOS}

À Josiane pelo amor, companheirismo e apoio durante esses mais de quatro anos juntos. Você é muito especial para mim. Admiro e amo muito você.

Aos meus pais, Joaquim e Luzia, por todo amor, carinho e ensinamentos que carregarei por toda minha vida. Além disso, agradeço por todo suporte durante esses anos aqui em São Carlos. Amo vocês.

Ao meu irmão Guilherme e minha cunhada Tatianna Melo por todo carinho e ajuda concedida durante esses anos aqui em São Carlos. Em especial ao Guilherme que desde a graduação sempre mostrou quais os caminhos profissionais eu poderia seguir. Amo vocês.

Ao professor Francisco Guimarães pelos ensinamentos que contribuíram para minha formação profissional e pela amizade construída durante o mestrado.

Ao Raphael Caface, Nirton Cristi e Ângelo Faceto pela grande amizade e contribuições no trabalho.

Ao Grupo de Polímero Bernad Cross, em especial a Débora Baloch e ao Bruno Bassi.

A equipe da Biblioteca e da gráfica do IFSC e da coordenação do programa de Pósgraduação em Ciência e Engenharia de Materiais.

Á Coordenação de Aperfeiçoamento de Pessoal de Nível Superior (CAPES) pelo auxílio financeiro.

Ao meu grande amigo Fernando, e agora compadre também, pelos ótimos momentos de convivência e companheirismo desde a graduação. Agradeço também a Aline que em suas vindas para São Carlos sempre trouxe alegria e descontração.

À Carla (Carlita) que me recebeu aqui em São Carlos com muito carinho. Nos primeiros dias de convivência já construímos uma grande amizade que espero ter por toda a vida.

Ao Willian Marcondes (Throll) e Filipe da Silva pela grande amizade e os momentos inesquecíveis que passamos juntos.

À Idelma Terra pela inestimável amizade e por todos os momentos compartilhados.

Aos amigos Mike Mello, Vinícius Heck e Edson Fernandes por todos os momentos inesquecíveis que compartilhamos. 
Aos amigos (as) de grupo, Alessandra Figueiredo, Izabela Gitierrez, Fernando Tissutae, Fran Araújo e Vitor Coletta pelo ótimo convívio.

Aos amigos, Christiane Tragante, Gustavo D'alóia e Rafael Cabral que me receberam muito bem aqui em São Carlos.

Aos amigos Manolo Sanches e Kiko Titico pela preciosa amizade.

Muito obrigado a todos! 


\section{RESUMO}

VALENTE, G. T. Fotogeração, migração e dissociação do éxciton em filmes de Polifluorenos (amorfos e ordenados) próximos de interface orgânica/inorgânica. 2012. 113 p. Dissertação (Mestrado) - Instituto de Física de São Carlos, Instituto de Química de São Carlos, Escola de Engenharia de São Carlos, Universidade de São Paulo, São Carlos, 2012.

Neste trabalho, foram investigados os processos de migração e dissociação do éxciton em filmes ultrafinos de poli(9,9 dioctilfluoreno) (PFO) com espessura menores que o raio típico de migração excitônica $(10 \mathrm{~nm})$ próximos de interface semicondutora orgânica e inorgânica. Os filmes de PFO foram produzidos utilizando a técnica de spin-coating a partir de soluções de PFO em clorofórmio e em tolueno. Sabe-se que ao se utilizar o clorofórmio como solvente, os filmes de PFO apresentam uma estrutura amorfa. Com isso foi possível obter filmes com espessuras menores que o raio de migração do éxciton com qualidades ideais para o estudo de processos fotofísicos. Esses filmes foram depositados sobre uma camada de nanopartículas de dióxido de titânio $\left(\mathrm{TiO}_{2}\right)$ formando assim uma interface orgânica/inorgânica. Técnicas espectroscópicas, tais como, microscopia confocal de fluorescência (LSCM), microscopia de imagem do tempo de vida (FLIM), fotoluminescência de onda contínua e resolvida no tempo bem como espectroscopia de absorção foram utilizadas no presente trabalho. Inicialmente o espectro de fotoluminescência dos filmes de PFO foram caracterizados através da dependência da intensidade da transição puramente eletrônica $I$, largura da linha a meia altura $\Gamma_{\mathrm{o}}$, energia da transição puramente eletrônica $E$ e parâmetro de Huang-Rhys $S$ variando a temperatura. Verificou-se que a intensidade pode ser descrita em termos da ativação térmica da migração do éxciton. Além disso, a temperatura introduz uma desordem térmica que afeta diretamente o tamanho dos segmentos conjugados que é observado em termos dos parâmetros, $\Gamma_{\mathrm{o}}, E$ e $S$. Com os filmes de PFO produzidos com o solvente tolueno foi observado que frações de fase $\beta$ já são induzidas nesses filmes e que esta fase não está dispersa na matriz amorfa e sim em forma de domínios formados por moléculas na fase $\beta$ que correspondente ao ordenamento nos anéis aromáticos do PFO. Também foi observado que nos filmes com espessura menor que $10 \mathrm{~nm}$ preparados em clorofórmio, a fase $\beta$ é induzida e sugerimos que isso ocorre devido a forte interação filme/substrato. Além disso, outros métodos bem conhecidos na literatura, tais como, tratamento a vapor de tolueno e ciclos térmicos de resfriamento/aquecimento foram utilizados para induzir a fase $\beta$ em filmes de PFO amorfo. Com relação aos filmes contendo a interface $\mathrm{TiO}_{2} / \mathrm{PFO}$, a dissociação do éxciton na interface foi observada através da redução da intensidade da fotoluminescência. Em filmes ultrafinos, a eficiência do processo de dissociação do éxciton na interface é superior a $90 \%$. A partir desses resultados, obteve-se que o raio de migração do éxciton no PFO é de $(13 \pm 3)$ $\mathrm{nm}$. Além disso, devido à alta fluência $\left(\sim 10^{25}\right.$ fótons $\left./ \mathrm{cm}^{2} \mathrm{~s}\right)$, efeitos de autoaniquilamento de éxcitons em filmes ultrafinos foram observados nas medidas de tempo de decaimento radiativo. Por fim, em filmes de PFO (contendo a fase $\beta$ ) depositados sobre o $\mathrm{TiO}_{2}$, somente os éxcitons das regiões amorfas migram até a interface do $\mathrm{TiO}_{2}$ e são dissociados por ela. A energia térmica a temperatura ambiente promove uma maior eficiência da dissociação do éxciton do que em baixas temperaturas $(\sim 5 \mathrm{~K})$. No entanto, mesmo em temperatura ambiente, as moléculas de fase $\beta$ atuam como centros de captura dos éxcitons competindo com o processo de dissociação. A partir desses resultados, obteve-se que o raio de transferência de energia no PFO é igual a $(3,5 \pm 0,5) \mathrm{nm}$.

Palavras-chave: Migração do éxciton, dissociação do éxciton, polifluoreno, $\mathrm{TiO}_{2}$. 


\begin{abstract}
VALENTE, G. T. Photogeneration, migration and dissociation of the exciton in polymer films (amorphous and ordered) near organic/inorganic interface. 2012. 113 p. Dissertação (Mestrado) - Instituto de Física de São Carlos, Instituto de Química de São Carlos, Escola de Engenharia de São Carlos, Universidade de São Paulo, São Carlos, 2012.
\end{abstract}

In this work, we investigated the process of exciton dissociation and migration in ultra-thin films of poly (9,9 dioctilfluoreno) (PFO) with a thickness smaller than the typical radius of excitonic migration $(10 \mathrm{~nm})$ and near to organic and inorganic semiconductor interface. The PFO films were produced using the spin-coating technique from a PFO solution in chloroform and toluene. It is known that when using chloroform as solvent, the PFO films have an amorphous structure. Thus, it was possible to obtain films that have thicknesses smaller than the radius of the exciton migration qualities, which is ideal to study photophysical processes. These films were deposited on the titanium dioxide $\left(\mathrm{TiO}_{2}\right)$ nanoparticles layer forming an organic/inorganic interface. Spectroscopic techniques such as fluorescence confocal microscopy (LSCM), fluorescence lifetime imaging microscopy (FLIM), continuous wave photoluminescence and time resolved and absorption spectroscopy were used in this study. First, the photoluminescence spectrum of PFO films were characterized by the dependence of the purely electronic transition intensity $I$, full width at half maximum $\Gamma_{\mathrm{o}}$, purely electronic transition energy $E$ and Huang-Rhys parameter $S$ with the temperature. It was showed that the intensity can be described according to thermal activation of the exciton migration. Furthermore, the temperature introduces a thermal disorder affecting directly the conjugated segment length which is observed according to the parameters, $\Gamma_{\mathrm{o}}, E$ e $S$. The PFO films produced with the solvent toluene analysis showed that the fractions of $\beta$ phase are already induced and that this phase is not dispersed in the amorphous matrix. On the order hand, they are shaped domains formed by $\beta$ phase molecules that are related to the PFO aromatic rings organization. It was also observed that the films with thickness smaller than $10 \mathrm{~nm}$ prepared using chloroform, the $\beta$ phase is induced, which may be occurring due to the strong interaction observed between film and substrate. Other methods reported in the literature, such as toluene steam treatment and thermal cycles of cooling/heating were used to induce $\beta$ phase in amorphous PFO films as well. The exciton dissociation at the interface in films containing $\mathrm{TiO}_{2} / \mathrm{PFO}$ interface were observed by reduction of photoluminescence intensity; and this same efficiency in ultra-thin films is higher than $90 \%$. From these results, it was reported that the exciton migration radius in PFO is (13 \pm 3$) \mathrm{nm}$. Furthermore, effects of excitons annihilation in ultra-thin films were observed in the decay time radiative measurements due to high fluency $\left(\sim 10^{25}\right.$ photons $/ \mathrm{cm}^{2} \mathrm{~s}$ ). Finally, in PFO films (with the $\beta$ phase) deposited on the $\mathrm{TiO}_{2}$ just the exciton of amorphous regions migrates to the $\mathrm{TiO}_{2}$ interface, which dissociates them. The thermal energy at room temperature promotes higher efficiency than the exciton dissociation at low temperatures $(\sim 5 \mathrm{~K})$. However, even at room temperature, the $\beta$ phase molecules act as the most important molecules to capture exciton, competing to the exciton dissociation process. These results conducted to conclude that the energy transfer radius in PFO is equal to $(3.5 \pm 0.5) \mathrm{nm}$.

Keywords: Exciton migration, exciton dissociation, polyfluorene, $\mathrm{TiO}_{2}$. 


\section{Lista de Figuras}

Figura 1.1: Ilustração dos processos de fotogeração de carga em uma interface polímero/nanopartícula semicondutora na qual ocorre basicamente 1) a geração de um éxciton pela absorção de um fóton; 2) a migração ou difusão do éxciton; 3) a dissociação do éxciton por transferência de carga na interface; 4) a coleta de carga pelos eletrodos. Em baixo, os mesmos processos considerando o diagrama energético e as eficiências de cada um.

Figura 1.2: Diagrama energético mostrando a: (a) Transferência de carga e (b) transferência de energia. BV é a banda de valência, $B C$ a banda de condução, $S^{0}$ é o estado fundamental e $S^{*}$ o estado eletrônico excitado.

Figura 1.3: Esquema ilustrativo das propriedades gerais desses materiais e da interface, bem como efeitos de tratamentos na organização molecular.

Figura 2.1: Estrutura química de polímeros conjugados. (a) poli( $p$-fenileno) e (b) poli( $p$ fenileno vinileno) (KIESS, 1992).

Figura 2.2: Ilustração da cadeia do poli(fenileno vinileno) (PPV). A figura acima (vermelha) apresenta a desordem conformacional na cadeia e a figura abaixo ilustra a quebra da conjugação. Adaptado de (SCHOLES, 2006).

Figura 2.3: Ilustração das ligações covalentes da molécula de benzeno. (a) orbitais localizados $(\sigma)$ e (b) orbitais moleculares não localizados $(\pi)$. Adaptado de (ALONSO \& FINN, 1968).

Figura 2.4: Ilustração do comprimento dos segmentos conjugados do polímero com seus respectivos gap's de energia. Quando maior o segmento conjugado menor é o gap de energia.

Figura 2.5: Lacuna de energia do PFO em função do comprimento da conjugação. Valores obtidos de (SRIWICHITKAMOL et al., 2006). A linha vermelha é o ajuste com a eq. (1)....31

Figura 2.6: Diagrama configuracional considerando o acoplamento elétron - fônon. hv é a energia de fônon.

Figura 2.7: Processos de absorção, relaxamento vibracional e fotoluminescência ilustrados no diagrama configuracional. $E_{d}$ é a energia de reorganização (relaxamento).

Figura 2.8: Transferência de energia segundo o mecanismo de Förster. Adaptado de FACETO (2007).

Figura 2.9: Taxa de transferência de energia $k_{T}$ em função de $R / R_{0}$ e comparação com as taxas $k_{R}$ e $k_{F}($ FACETO, 2007).

Figura 2.10: Migração do estado excitado resultado da transferência de energia entre os segmentos conjugados.

Figura 2.11: Forma de linha Gaussiana com os parâmetros, $I\left(E_{0}\right), E_{0}$ e $\Gamma$ que podem ser utilizados para caracterizar uma transição puramente eletrônica. Em destaque a função gaussiana. 
Figura 3.1: Foto do substrato de quartzo (Qtz) no qual metade deste contém uma camada de nanopartículas de $\mathrm{TiO}_{2}\left(\mathrm{Qtz} / \mathrm{TiO}_{2}\right)$.

Figura 3.2: Curva do tratamento térmico realizado com as camadas de $\mathrm{TiO}_{2}$ depositadas sobre o quartzo.

Figura 3.3: Estrutura química do PFO (ADS129BE) utilizado no presente trabalho. 43

Figura 3.4: Formação do filme polimérico por spin-coating. (a) Solução polimérica depositada sobre o substrato de quartzo. (b) No início da rotação do substrato com a solução polimérica ocorre perda de material polimérico e há a formação do filme. (c) Diminuição da espessura do filme pela evaporação do solvente durante o intervalo em que a amostra é rotacionada. (d) Filme polimérico formado ao término da rotação.

Figura 3.5: Ilustração do processo de absorção mostrando a radiação incidente $\left(\mathrm{I}_{0}\right)$ e transmitida (I) num material.

Figura 3.6: Ilustração da configuração experimental da espectroscopia de fotoluminescência de onda contínua. 46

Figura 3.7: (a) Diagrama dos principais componentes ópticos da microscopia confocal de fluorescência de varredura a laser. (b) Ilustração do bloqueio das fluorescências fora de foco realizada pelo pinhole, nesta figura os espelhos de varredura foram omitidos para facilitar a visualização da imagem. Adaptado de (HIBBS, 2004).

Figura 3.8: Ilustração bidimensional de uma gota sobre uma superfície e as tensões interfaciais em equilíbrio no eixo horizontal que resultam na equação de Young (TADMOR, 2004). 49

Figura 3.9: Ilustração do funcionamento básico da técnica AFM (BORGES, 2005) 50

Figura 4.1: (a) Espectro de absorção de um filme de PFO amorfo (espessura de $41 \mathrm{~nm}$ ) e no canto superior direito a estrutura química de um mero do PFO.

Figura 4.2: Espectro de absorção e fotoluminescência do filme de PFO $(41 \mathrm{~nm})$ medidos a temperatura ambiente. Na medida de fotoluminescência a amostra foi excitada em $325 \mathrm{~nm}$ utilizando laser de $\mathrm{He}-\mathrm{Cd}$.

Figura 4.3: Espectro de fotoluminescência do filme de PFO $(41 \mathrm{~nm})$ medidos em diferentes temperaturas. Excitação em $325 \mathrm{~nm}$ utilizando laser de $\mathrm{He}-\mathrm{Cd}$. 54

Figura 4.4: (a) Intensidade normalizada, (b) largura a meia altura da transição 0-0, (c) posição energética do pico da transição 0-0 e (d) fator $S$. Em (a), (b), (c) e (d) a linha vermelha é o ajuste dos dados experimentais com a equação em destaque na figura.

Figura 4.5: Ilustração da difusão espectral em diferentes temperaturas. DOS é a densidade de estados, $E_{\max }$ a energia máxima da DOS e $E_{P L}$ a energia final de emissão. Adaptado de (HOFFMANN et al., 2010). 58 
Figura 4.6: Intensidade normalizada dos picos da $\mathrm{PL}$ a $5 \mathrm{~K}$ em função dos modos vibracionais $m$. A linha vermelha é o ajuste dos dados utilizando apresentada no canto superior da figura.

Figura 4.7: (a) PL do filme de PFO amorfo com a intensidade da PL na escala logarítmica em função da energia da emissão. Medida realizada a $5 \mathrm{~K}$, excitação em $325 \mathrm{~nm}$ utilizando laser de He-Cd. (b) Ilustração do diagrama de energia das transições eletrônicas envolvidas na PL ao longo da coordenada de configurações (q).

Figura 4.8: (a) Espectros de absorção normalizados do filme de PFO contendo a fase $\beta$ (linha preta contínua $\mathrm{A}_{\beta}$ ) e do mesmo filme após tratamento térmico (linha vermelha pontilhada $\mathrm{A}$ ). (b) Diferença entre os espectros de absorção $\mathrm{A}_{\beta}$ e A da Figura 4.8(a).

Figura 4.9: Espectro de absorção e fotoluminescência do filme de PFO contendo a fase $\beta$ medidos a temperatura ambiente. Na medida de fotoluminescência a amostra foi excitada em $325 \mathrm{~nm}$ utilizando laser de $\mathrm{He}-\mathrm{Cd}$.

Figura 4.10: (a) PL normalizada do filme de PFO amorfo e contendo fase $\beta$. (b) ilustração dos LUMO's (Lowest Unoccupied Molecular Orbital) da região amorfa e da fase $\beta$ mostrando a transferência de energia entre essas regiões. Excitação em $325 \mathrm{~nm}$ utilizando laser de $\mathrm{He}$ Cd.

Figura 4.11: Espectro de absorção dos filmes de PFO na região do visível e monitoramento em $390 \mathrm{~nm}$ do crescimento linear da absorção em função da concentração da solução de PFO utilizada para produzir os filmes. Medidas realizadas a temperatura ambiente.

Figura 4.12: Absorbância em função da espessura medida por AFM das amostras $41 \mathrm{~nm}, 17$ $\mathrm{nm}$ e 5,9 $\mathrm{nm}$. A linha vermelha é o ajuste utilizando a equação da Lei de Beer-Lambert.

Figura 4.13: Ângulo de contato de filmes de PFO (amorfo) depositados sobre o quartzo com diferentes espessuras. (a) Imagem da gota de água sobre: $\left(\mathrm{a}_{1}\right)$ quartzo, $\left(\mathrm{a}_{2}\right)$ filme PFO (solução 0,3 g/L), ( $\left.a_{3}\right)$ filme PFO (0,6 g/L), ( $\left.a_{4}\right)$ filme PFO (1,25 g/L), ( $\left.a_{5}\right)$ filme PFO (2,50 g/L) e ( $\left.a_{5}\right)$ filme PFO $(5,00 \mathrm{~g} / \mathrm{L})$. (b) Comportamento do ângulo de contato em função das concentrações das soluções poliméricas utilizadas para produzir os filmes. A linha vermelha é somente um guia para os olhos.

Figura 4.14: Imagens de microscopia confocal no modo espectral de filmes de PFO sobre o quartzo produzido a partir das seguintes concentrações poliméricas: (a) 0,30 g/L, (b) 0,60 g/L, (c) 1,25 g/L (5,9 nm de espessura), (d) 2,50 g/L (17 nm de espessura) e (e) (41 nm de espessura). Excitação em $405 \mathrm{~nm}$. Cada figura mostra também o perfil de intensidade ao longo de uma linha (cor branca na imagem) ao longo do filme, a distribuição de intensidades (frequência absoluta pela intensidade) sobre da área sondada, assim como espectros de PL avaliado sobre três pontos ao longo da diagonal da imagem. 73

Figura 4.15: Imagens de microscopia de força atômica (AFM) no modo de contato de filmes de PFO sobre o quartzo produzido a partir das seguintes concentrações poliméricas: (a) 0,30 $\mathrm{g} / \mathrm{L}$, (b) 0,60 g/L, (c) 1,25 g/L (5,9 $\mathrm{nm}$ de espessura), (d) 2,50 g/L (17 nm de espessura) e (e) (41 nm de espessura). (f) Variação da rugosidade RMS (Rq) com a concentração de PFO 
(espessura) dos mesmos filmes e para a superfície do substrato de quartzo (concentração zero, não mostrado)..

Figura 4.16: (a) Comparação entre espectros normalizados de emissão de cada um dos filmes contendo diferentes espessuras (concentrações) estudadas acima medidos por microscopia confocal. A escala semi-log no eixo das ordenadas e energética no eixo das abscissas foram utilizados para melhor visualização. As medidas realizadas a temperatura ambiente. As mudanças nestes espectros podem ser visualizadas através (b) da energia da transição $0-0$, (c) do parâmetro $\mathrm{S}$ e (d) da energia de fônon em função da concentração da solução de PFO utilizada para depositar os filmes. 77

Figura 4.17: Ilustração da influência da tensão na formação de filmes ultrafinos e de filme finos......

Figura 4.18: Espectros de emissão de um filme de PFO ultrafino (0,6 g/L em clorofórmio) durante o último ciclo de 4 ciclos de resfriamento (a) de $297 \mathrm{~K}$ a $5 \mathrm{~K}$ e aquecimento lento (b) $\left(\sim 1^{\circ} \mathrm{C} / \mathrm{min}\right)$.

Figura 4.19: Evolução temporal dos espectros de absorbância medidas em intervalos de tempo entre 0 e 20 minutos para (a) um filme com espessura menor que $10 \mathrm{~nm}$ (preparado com solução de PFO em clorofórmio $0,3 \mathrm{~g} / \mathrm{L}$ ) e (b) outro com espessura de aproximadamente $41 \mathrm{~nm}$ (preparado com solução de PFO em clorofórmio 5,0 g/L). 82

Figura 4.20: Espectros de luminescência medidos a (a) $5 \mathrm{~K}$ em um espectrômetro convencional através de excitação em $325 \mathrm{~nm}$ e (b) a $297 \mathrm{~K}$ em um microscópio confocal utilizando luz de excitação de $405 \mathrm{~nm}$ para os filmes spin-coating preparados com clorofórmio (não tratados ou n/T) mostrados na Figura 4.16 e que sofreram posteriormente tratamento com vapor de tolueno $(\mathrm{c} / \mathrm{T})$ por 20 minutos. As barras horizontais posicionam as transições envolvendo fônons longitudinais com energias entre $1200-1600 \mathrm{~cm}^{-1}$. As setas verticais posicionam as transições sem acoplamento com fônon. As linhas verdes são ajustes gaussianos destas transições 83

Figura 4.21: Imagens obtidas por MEV da camada de nanopartículas de $\mathrm{TiO}_{2}$ depositada a partir da pasta de $\mathrm{TiO}_{2}$ sobre substrato de quartzo...... 86

Figura 4.22: PL da camada de nanopartículas de $\mathrm{TiO}_{2}$ medidas a $297 \mathrm{~K}$ e 5 K. Excitação em $325 \mathrm{~nm}$ utilizando um laser de $\mathrm{He}-\mathrm{Cd}$.

Figura 4.23: (a) Estrutura de banda energética do $\mathrm{TiO}_{2}$ (REEJA-JAYAN, 2010) e do PFO (LIAO, 2000). (b) Absorbância do $\mathrm{TiO}_{2}$, dados retirados de (CHEN, 2007), e PL do filme do PFO ambos a temperatura ambiente. Na PL excitação em $325 \mathrm{~nm}$ utilizando laser de He-Cd.

Figura 4.24: (a) Foto da amostra utilizada no presente trabalho. Imagens de microscopia confocal de fluorescência da região indica com foco em: (b) interface $\mathrm{TiO}_{2} / \mathrm{PFO}$ e (c) filme de PFO sobre o quartzo. Melhorar legenda de acordo com o texto corrigido acima.....

Figura 4.25: Resultados de microscopia confocal de fluorescência par filmes com diferentes espessuras: (a) 0,30 g/L, (b) 0,60 g/L, (c) 1,25 g/L (5,9 nm de espessura), (d) 2,50 g/L (17 nm de espessura) e (e) (41 nm de espessura). Medidas realizadas a temperatura ambiente com 
excitação em $405 \mathrm{~nm}$. Cada figura mostra a imagem no modo espectral do filme de PFO sobre o quartzo (PFO) e sobre o $\mathrm{TiO}_{2}\left(\mathrm{TiO}_{2} / \mathrm{PFO}\right)$, o perfil de intensidade em $434 \mathrm{~nm}$ ao longo da linha de cor branca na imagem, a distribuição de intensidades (frequência absoluta pela intensidade) sobre da área sondada e o espectro de PL avaliado sobre os pontos marcados com cruzes bancas e vermelhas nas imagens espectrais.

Figura 4.26: Razão I/Io entre as intensidades médias avaliadas das distribuições das Figuras 4.24 sobre o $\mathrm{TiO}_{2}$ e sobre o quartzo em função da espessura dos filmes de PFO (pontos pretos). A linha vermelha representa um ajuste sigmoidal dos dados experimentais e a linha preta tracejada representa o caso ideal em que a intensidade sobre o quartzo Io é igual a intensidade medida sobre o $\mathrm{TiO}_{2}$ I para espessuras do filme de PFO muito maiores que $13 \mathrm{~nm}$. Medidas realizadas a temperatura ambiente. 92

Figura 4.27: Imagens FLIM do filme de PFO preparado com clorofórmio (amostra espessa, 5 $\mathrm{g} / \mathrm{L}$ ) medida sobre uma região próxima à interface $\mathrm{TiO}_{2} /$ Quartzo (a) e sobre uma área do $\mathrm{TiO}_{2}$ (b). Comparação entre os decaimentos temporais da fluorescência (c) tomado sobre a superfície de quartzo para o filme de PFO espesso preparado com solução de clorofórmio a 5 $\mathrm{g} / \mathrm{L}$ (linha branca); para o mesmo filme sobre $\mathrm{TiO}_{2}$ (linha amarela), e para o filme de PFO mais fino sobre $\mathrm{TiO}_{2}$ preparado a $0.3 \mathrm{~g} / \mathrm{L}$ (linha verde). Comparação entre as distribuições da contagem normalizadas do tempo de decaimento médio $\tau(\mathrm{d})$ calculadas para o filme de PFO espesso preparado $(5 \mathrm{~g} / \mathrm{L})$ e para o filme de PFO mais fino $(0.3 \mathrm{~g} / \mathrm{L})$.

Figura 4.28: Dependência de $\tau_{1}$ e $\tau_{2}$ com a espessura do filme de PFO (com a concentração do PFO em clorofórmio) sobre as superfícies de quartzo (linha preta) e sobre o $\mathrm{TiO}_{2}$ (linha vermelha).

Figura 4.29: Fotoluminescência do filme de PFO contendo fase $\beta$ sobre o quartzo (linha preta) e sobre o $\mathrm{TiO}_{2}$ (linha vermelha). Medida realizada a (a) $5 \mathrm{~K}$ e (b) $297 \mathrm{~K}$. Excitação em $325 \mathrm{~nm}$ utilizando laser de $\mathrm{He}-\mathrm{Cd}$.

Figura 4.30: Simulações de sistema polimérico obtidos utilizando o método de Monte Carlo realizado por Faceto (2012). (a), (c) e (e) são mapas de migração do éxciton em um polímero amorfo, amorfo com interface de $\mathrm{TiO}_{2}$ e amorfo com domínios ordenados e interface de $\mathrm{TiO}_{2}$, respectivamente. Em (a) as posições P1 e P2 indicam regiões de baixa e alta migração, respectivamente. (b), (d) e (f) são os eventos de emissão para a mesma configuração de (a), (c) e (f) respectivamente. Em (e) e (f) as setas indicam os domínios ordenados. 102

Figura 4.31: Perfil de migração do éxciton em um sistema polimérico contendo uma interface de $\mathrm{TiO}_{2}$ obtida a partir do método Monte Carlo (FACETO, 2012). 103 
XVIII 


\section{SUMÁRIO}

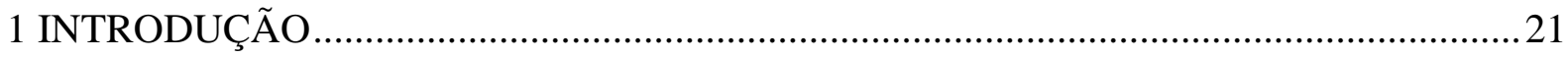

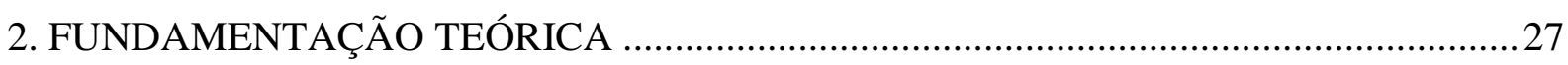

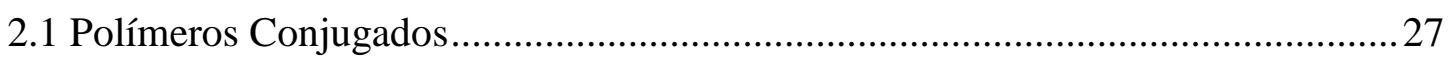

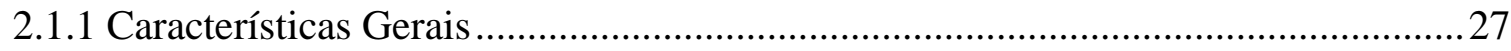

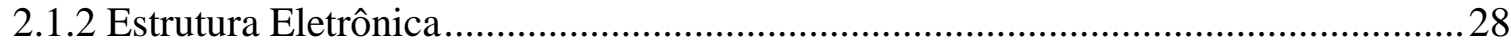

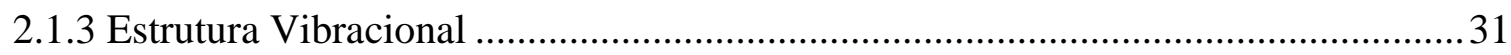

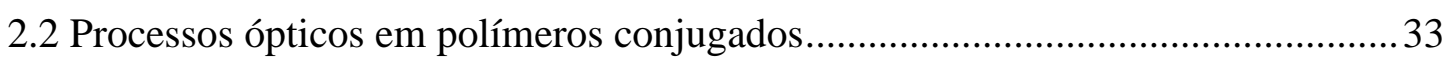

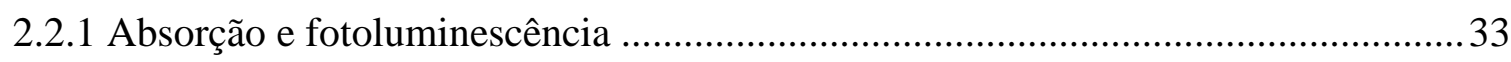

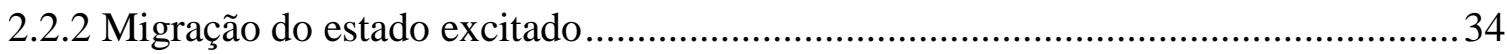

2.2.3 Propriedades fotoluminescência de polímeros conjugados..................................... 37

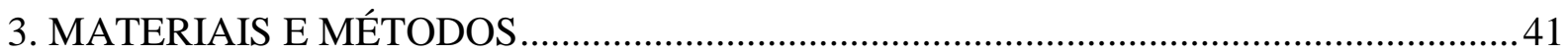

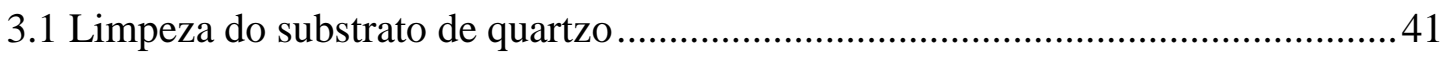

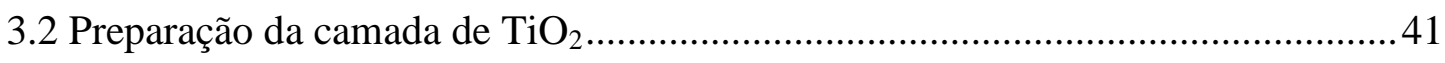

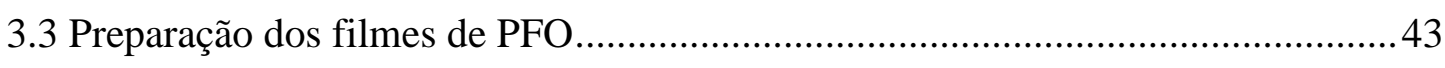

3.4 Espectroscopia de Absorção UV/Vis ................................................................ 44

3.5 Espectroscopia de fotoluminescência................................................................ 45

3.6 Microscopia Confocal de fluorescência de varredura a laser (LSCM) ..................46

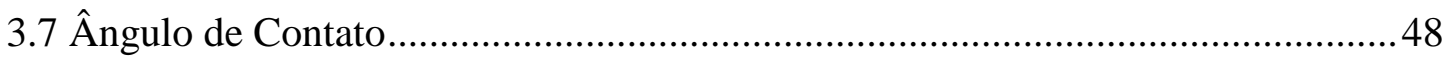

3.8 Microscopia de Força Atômica ....................................................................... 49

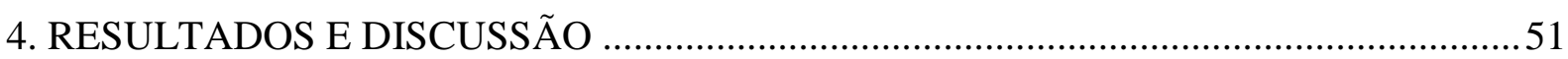

4.1 Caracterização espectroscópica de filmes de PFO amorfo ..................................51

4.2 Caracterização espectroscópica de filmes de PFO com fase $\beta$............................62

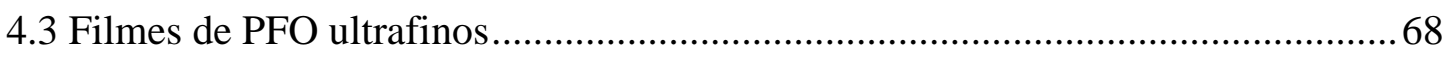

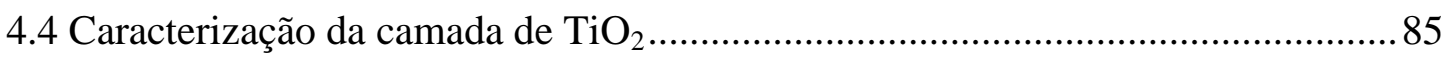

4.5 Processos fotofísicos nas proximidades da interface $\mathrm{TiO}_{2} / \mathrm{PFO}$..........................8 87

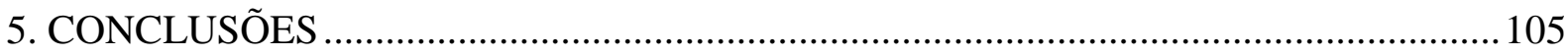

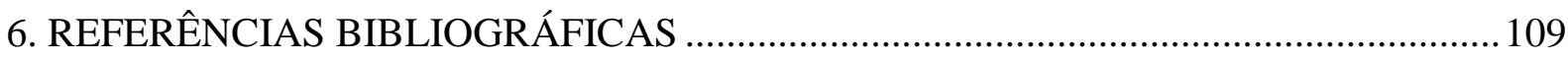


XX 


\section{INTRODUÇÃO}

Polímeros semicondutores $\pi$-conjugados combinados com semicondutores inorgânicos apresentam um potencial de aplicação em sistemas de conversão de energia como, células fotovoltaicas e de catálise, transistor de efeito de campo e em diodos emissores de luz (OLEDs) (FACCHETTI, 2011; HAINS et al., 2010; SESSOLO et al., 2011). Os polímeros semicondutores são promissores pelas propriedades opto-eletrônicas, baixo custo, versatilidade na funcionalização, fácil processamento e por ser um material flexível. Estes são os componentes essenciais para se produzir células fotovoltaicas orgânicas que sejam alternativas promissoras aos dispositivos inorgânicos. A eficiência das células orgânicas ainda é baixa ( 8-10\%) (WU, 2012), mas apresenta um grande potencial para competir com as células fotovoltaicas comerciais inorgânicas. Para que isso aconteça, ainda é preciso estudar de forma detalhada os processos responsáveis pelo aumento da eficiência nas células orgânicas. Este é o foco das extensas pesquisas nessa área atualmente (HAINS et al., 2010; CLARKE et al., 2010; FACCHETTI, 2011).

A compreensão e o controle dos processos que envolvem a formação e migração do estado excitado formado por éxcitons nas proximidades das interfaces de materiais orgânico/inorgânico, bem como a dissociação dos mesmos por transferência de carga e/ou energia pode contribuir para o melhoramento dos dispositivos ópto-eletrônicos citados acima. Além disso, estes processos estão intimamente relacionados com a estrutura molecular do polímero e, portanto, uma compreensão desta relação se torna importante. Nesse contexto, entendemos ser fundamental desenvolver experimentos e metodologias que permitam investigar os processos de geração, migração e dissociação dos éxcitons nas proximidades de interface. Estes processos estão esquematizados na Figura 1.1.

Alcançar uma eficiente fotogeração de cargas em uma região espectral que compreende o ultravioleta próximo, o visível e o infravermelho têm sido um dos desafios vitais em células solares orgânicas. Por exemplo, os primeiros dispositivos fotovoltaicos orgânicos eram formados por uma camada polimérica simples entre dois eletrodos de diferentes funções trabalho (ANTONIADIS et al., 1994; RIESS et al., 1994). Os dispositivos atuais são formados por estruturas de multicamadas, cada uma absorvendo luz em comprimentos de ondas específicos e possuindo o conceito de bicamadas doadoras/aceitadoras interpenetrantes (CLARKE et al., 2010). A diferença nas afinidades eletrônicas (ou potencial de ionização) entre os materiais que compõe as bicamadas cria um deslocamento energético (offset) na sua interface que favorece a dissociação do éxciton 
através da transferência de carga do material doador (absorvedor) para o aceitador (CLARKE et al., 2010; BERNÈDE, 2008). No entanto, a eficiência dos dispositivos de bicamadas é limitada pelo comprimento de migração/difusão do éxciton $(\sim 10 \mathrm{~nm})$ que se processa desde a sua fotogeração e dissociação. A bem conhecida separação de fase entre materiais poliméricos distintos tem sido usada como metodologia para produzir heterojunções em escala nanoscópica formando uma rede contínua interpenetrante e de alta área superficial, reduzindo as distâncias de migração e favorecendo a dissociação do éxciton. Esta é a ideia da heterojunção de volume (YU et al., 1995). Além disso, existe um esforço significativo para produzir materiais orgânicos e estruturas que aumentam o raio de migração do éxciton, favorecendo sua difusão e guiando o mesmo até a interface (FAVARIM et al., 2007). Outro problema aparece após a dissociação do éxciton: elétrons e buracos exibem atração Coulombiana significante mesmo estando separados em materiais diferentes, o que resulta na formação de estados de transferência de carga de tempo de vida longo na interface (CLARKE et al., 2010).

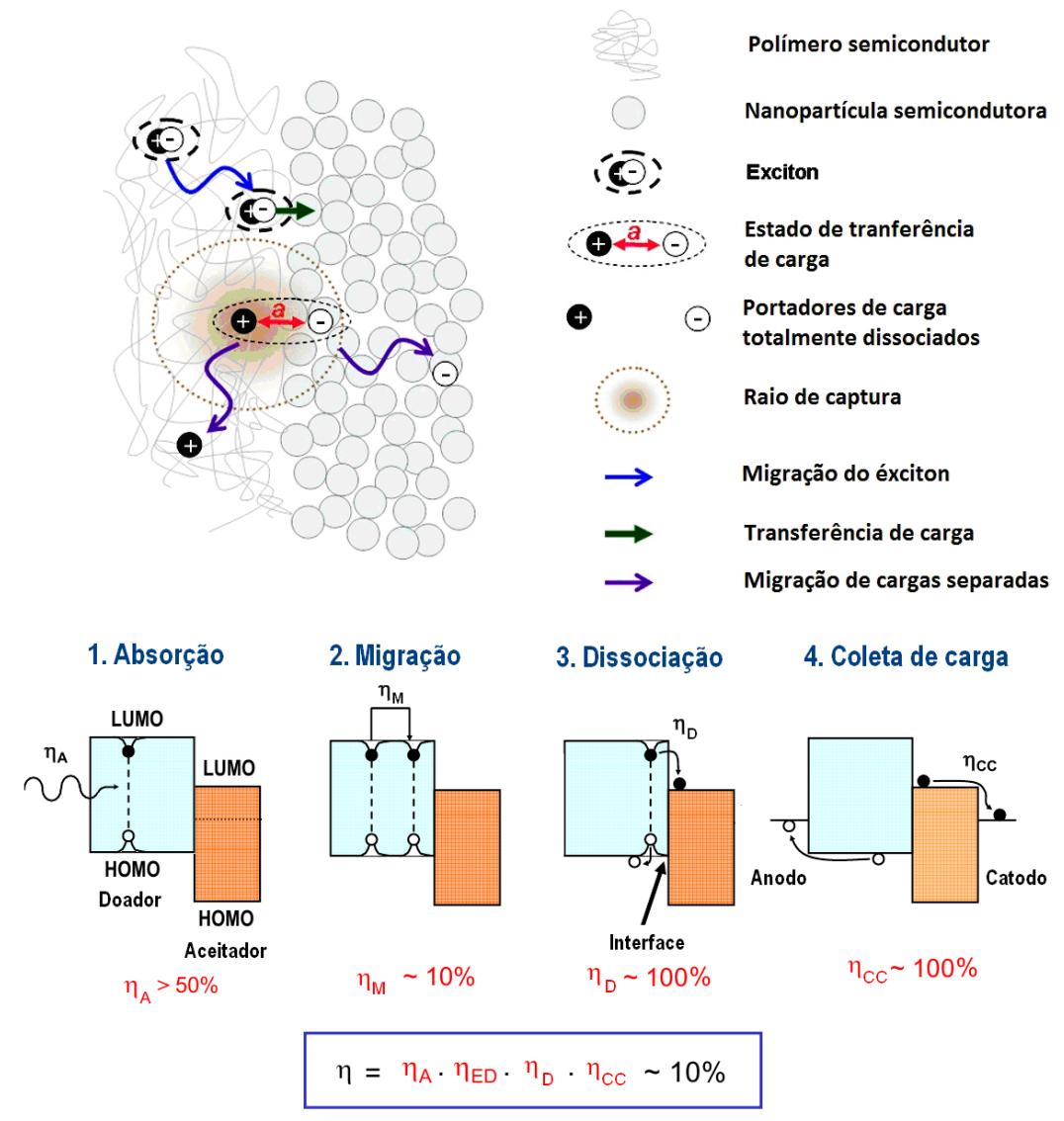

Figura 1.1: Ilustração dos processos de fotogeração de carga em uma interface polímero/nanopartícula semicondutora na qual ocorre basicamente 1) a geração de um éxciton pela absorção de um fóton; 2) a migração ou difusão do éxciton; 3) a dissociação do éxciton por transferência de carga na interface; 4) a coleta de carga pelos eletrodos. Embaixo, os mesmos processos considerando o diagrama energético e as eficiências de cada um (CLARKE et al., 2010). 
A Figura 1.1 também ilustra o diagrama energético e uma estimativa da eficiência de cada processo envolvido na fotogeração de cargas em uma heterojunção semicondutora do tipo doadora/aceitadora. Nesse esquema, assumimos uma eficiência maior que $50 \%$ na fotogeração do éxciton, considerando um comprimento de absorção dada pela espessura típica da camada doadora da ordem de $100 \mathrm{~nm}$. Desses éxcitons fotogerados, consideramos que apenas $10 \%$ alcançam a interface, já que o comprimento típico de migração é da ordem de 10 nm (HWANG et al., 2011). Perdas por processos não radiativos não foram computados nessa etapa. Uma vez na interface, a dissociação do éxciton por transferência de carga é extremamente eficiente $(100 \%)$ para a condição em que a diferença de energia entre os LUMOS's (Lowest Unoccupied Molecular Orbital) do material doador e o material aceitador é maior do que a energia de ligação do éxciton do material doador (BERNÈDE, 2008), para polímeros conjugados a energia dos éxcitons é da ordem de 0,1-1eV, (KNUPFER, 2003; BARFORD, 2005). O polifluoreno investigado no presente trabalho é o poli(9,9 dioctil fluoreno) (PFO) e a energia de ligação do éxciton é igual a 0,3 eV (ALVARADO et al., 1998). Já a etapa final de coleta de carga pelos eletrodos pode ser um fator limitante. Porém, vamos assumir uma eficiência de $100 \%$ desse processo. Assim, uma estimativa por alto da eficiência de um dispositivo de heterojunção é de 5-10 \%, que é uma conseqüência dos limites impostos pela fotogeração e migração do éxciton na estrutura. Portanto, há muito ainda a ser investigado em relação aos mecanismos de fotogeração e migração do éxciton para que sejam alcançadas eficiências maiores de geração de carga em dispositivos de heterojunção.

Neste trabalho, portanto, daremos ênfase à fotogeração, à migração e à dissociação do éxciton nas proximidades de uma interface híbrida orgânica/inorgânica. Sendo assim, elaboramos experimentos e metodologias específicas para entender melhor os processos mencionados acima. A interface escolhida para o presente estudo é híbrida, ou seja, é uma junção formada entre um polímero semicondutor emissor de luz e nanopartículas semicondutoras inorgânicas na forma de filme. Além disso, o modelo de interface deve conter fundamentos que encontram aplicação direta nos dispositivos citados acima. As propriedades desses materiais devem ser tais que todos os processos de geração, de migração até a interface e a possível dissociação do éxciton por transferência de carga e/ou energia sejam detectados e, principalmente, distinguidos.

Assim, a geração do éxciton deve ser realizada em um material livre de defeitos e impurezas que agem como armadilhas ou dissociam o éxciton, de modo a garantir a sobrevivência desse estado excitado por tempos próximos ao seu tempo de vida $\tau$. A sua 
constante dielétrica deve ser baixa de modo que a energia de ligação do par elétron-buraco seja alta o suficiente para não ser dissociado à temperatura ambiente antes do tempo $\tau$. Sistemas moleculares suficientemente puros possuem essas características. Éxcitons de Frenkel (MOLITON, 2006) (assim chamados em homenagem a Yakov Frenkel) em materiais orgânicos são localizados basicamente em uma única molécula e, por isso, têm energias de ligação típicas da ordem de 0,1 a $1 \mathrm{eV}$ muito maiores que a energia térmica $k_{\mathrm{B}} \mathrm{T}$ à temperatura ambiente.

Além da estabilidade térmica, a migração do éxciton em sistemas moleculares é extremamente efetiva por ser mediada por interações dipolares de longo alcance que possibilitam transferência de energia do tipo Förster entre estados de duas moléculas de uma mesma espécie (FAVARIM et al., 2007). Nesses sistemas, os raios médios de migração típicos $R_{m}$ são da ordem de 1 a $20 \mathrm{~nm}$. Consequentemente, as dimensões do semicondutor orgânico devem ser iguais ou menores que $R_{m}$ para que a migração do éxciton até a interface seja garantida e observada. Filmes ultrafinos de polímero conjugado emissor de luz com espessuras da ordem ou menores que $R_{m}$ foram preparados e suas propriedades estruturais e ópticas foram estudadas separadamente para que estes fossem utilizados como um dos materiais da interface e responsáveis pela geração do éxciton.

$\mathrm{O}$ outro material de interface deve ser um semicondutor bom receptor (doador) de elétrons (buracos) que garanta a dissociação de éxciton por transferência de carga (TC) entre os materiais (Figura 1.2(a)) ou que possua níveis de energia na banda de valência e de condução ressonantes com estados moleculares que favoreçam a aniquilação do éxciton por transferência de energia (TE) não radiativa entre eles (Figura 1.2(b)). O estado final (2) no primeiro caso corresponde a elétrons e buracos separados em materiais diferentes. No segundo caso, o estado final (3) é formado por um éxciton em um dos materiais e é o caso do sistema metal/semicondutor orgânico (BORGES, 2005). 


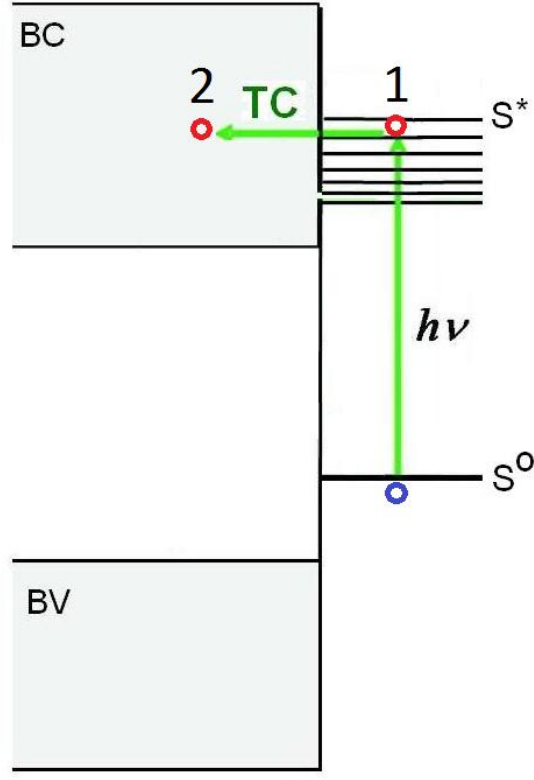

a)

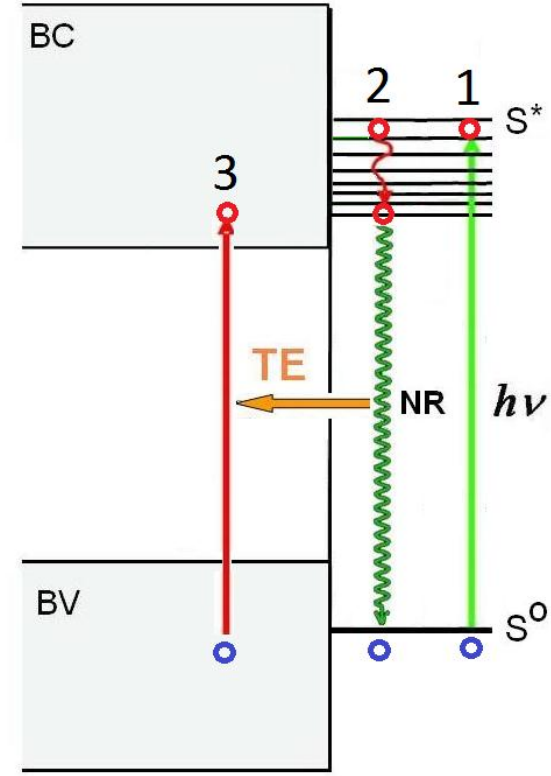

b)

Figura 1.2: Diagrama energético mostrando a: (a) Transferência de carga e (b) transferência de energia. BV é a banda de valência, $\mathrm{BC}$ a banda de condução, $S^{0}$ é o estado fundamental e $S^{*}$ o estado eletrônico excitado.

No presente trabalho, estudamos a dissociação do éxciton por separação de carga na interface descrita na Figura 1.2(a) usando o dióxido de titânio $\left(\mathrm{TiO}_{2}\right)$ como semicondutor aceitador de elétrons e um polifluoreno (PFO) que absorve no ultravioleta em que os portadores são gerados. Um esquema ilustrativo das propriedades gerais desses materiais e da interface é mostrado na Figura 1.3. Evidentemente, nanopartículas de $\mathrm{TiO}_{2}$ foram usadas para aumentar a área interfacial e, consequentemente, aumentar a probabilidade de dissociação do éxciton na interface. Além de todas as propriedades acima, os PFO's são materiais poliméricos de alta pureza, altamente solúveis em solventes orgânicos e, portanto, apresentam alta eficiência quântica. Os filmes de PFO sobre vidro ou quartzo possuem alta qualidade morfológica e aderência. Além disso, este polímero pode apresentar a coexistência de um material amorfo (fases amorfa) e domínios ordenados (fase $\beta$ ) (GRELL et al., 1999) com lacunas de energias distintas o que pode alterar significantemente a migração do éxciton nesse material. A partir dessas características do PFO, investigamos a influência da organização molecular (regiões amorfas e ordenadas) deste polímero no processo de migração e dissociação do éxciton em filmes de PFO, com espessuras menores que o raio típico de migração, próximos da interface de nanopartículas de $\mathrm{TiO}_{2}$. 


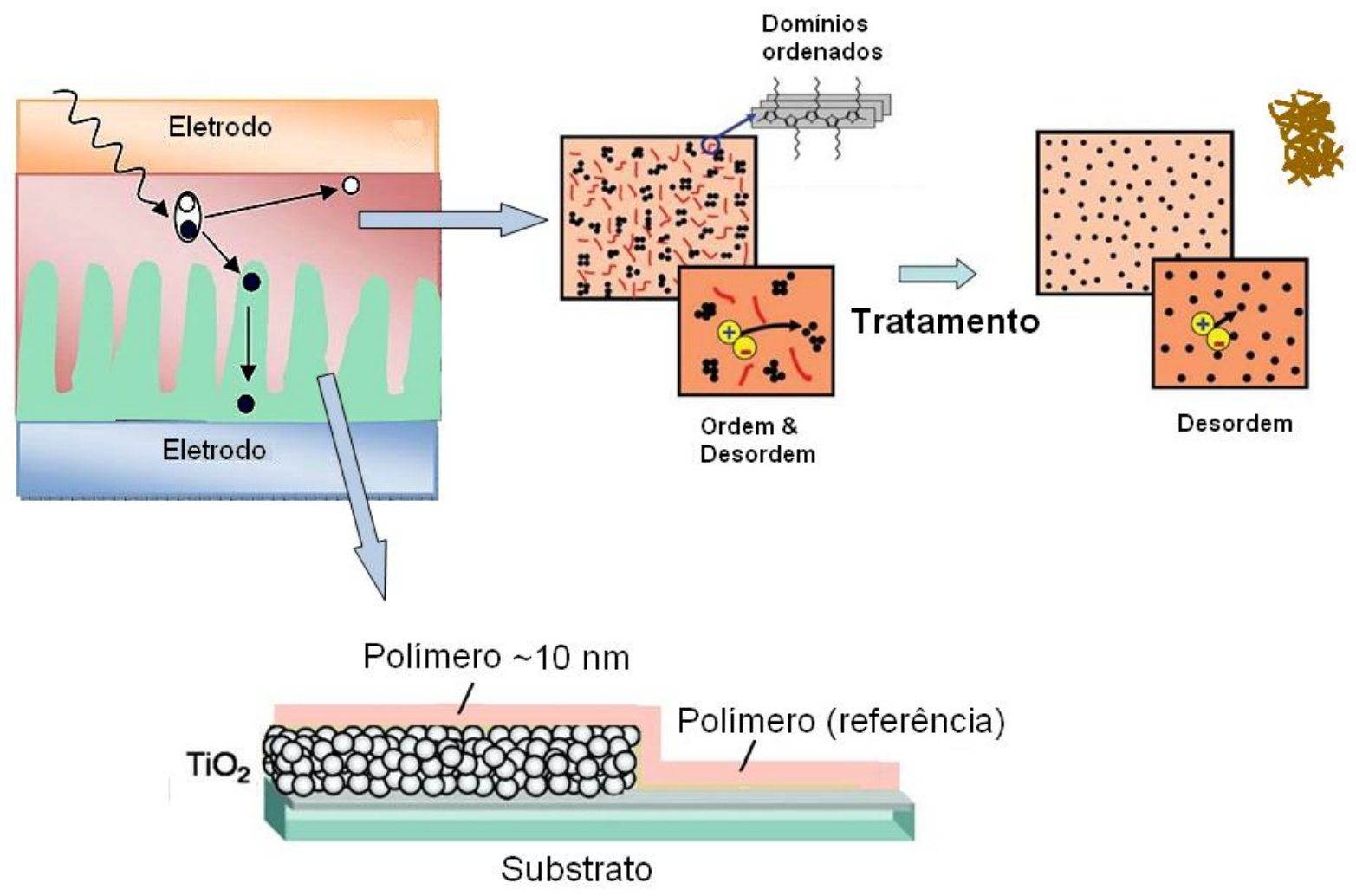

Figura 1.3: Esquema ilustrativo das propriedades gerais desses materiais e da interface, bem como efeitos de tratamentos na organização molecular.

Essa dissertação está organizada da seguinte forma. No Capítulo 2 é feita uma introdução das características gerais dos polímeros conjugados bem como de suas propriedades ópticas. Na sequência, o Capítulo 3 apresenta os materiais utilizados, os procedimentos de limpeza dos substratos, os métodos de produção dos filmes e detalhes das técnicas experimentais utilizadas. No Capítulo 4, nas quatro primeiras seções são apresentados os resultados da caracterização espectroscópica de cada material envolvido neste trabalho, na última seção são apresentados os resultados referentes aos processos fotofísicos na interface $\mathrm{TiO}_{2} /$ polímero. Por fim, no Capítulo 5 as conclusões do trabalho são apresentadas. 


\section{FUNDAMENTAÇÃO TEÓRICA}

\subsection{Polímeros Conjugados}

\subsubsection{Características Gerais}

Polímeros (do grego poli (muitos) e meros (partes)) são macromoléculas formadas por repetições de unidades idênticas menores. Esses materiais são obtidos por meio de vários processos químicos de polimerização a partir de unidades menores denominadas monômeros (CALLISTER, 2008). O tamanho e interconectividade das cadeias poliméricas influência diretamente as propriedades mecânicas e reológicas desses materiais, que podem ser muito diferentes das propriedades dos monômeros que os constituem. Muitos materiais naturais importantes são polímeros orgânicos, incluindo a celulose (a partir de monómeros de açúcar), a lignina, a borracha, proteínas (a partir de aminoácidos) e os ácidos nucleicos (a partir de nucleotídeos). Polímeros orgânicos sintéticos incluem vários plásticos, incluindo polietileno, os nylons, poliuretanos, poliésteres, vinil (por exemplo, PVC) e borrachas sintéticas. Os silicones, polímeros com uma cadeia principal inorgânica de silício e de oxigênio e grupos de átomos secundários orgânicos, estão entre os mais importantes compostos híbridos orgânicoinorgânicos. Em muitos polímeros orgânicos a cadeia principal é constituída basicamente de hidrocarbonetos, podendo ou não apresentar ramos laterais ou cadeias secundárias. Dentre esses, um grupo de polímeros, chamados polímeros conjugados, possuem propriedades optoeletrônicas interessantes que têm sido exploradas nas últimas décadas.

Quando os átomos de carbono na cadeia polimérica são unidos através de ligações simples e duplas de forma alternada o polímero é dito conjugado, dois exemplos de polímeros desse tipo são apresentados na Figura 2.1 (KIESS, 1992). Os elétrons de fronteira que participam dessas ligações são denominados elétrons $\sigma$ (sigma) e $\pi$ (pi). Os elétrons $\sigma$ são fortemente localizados entre átomos de carbono adjacentes enquanto que os elétrons $\pi$ são mais fracamente ligados e podem se estender por toda a região conjugada.
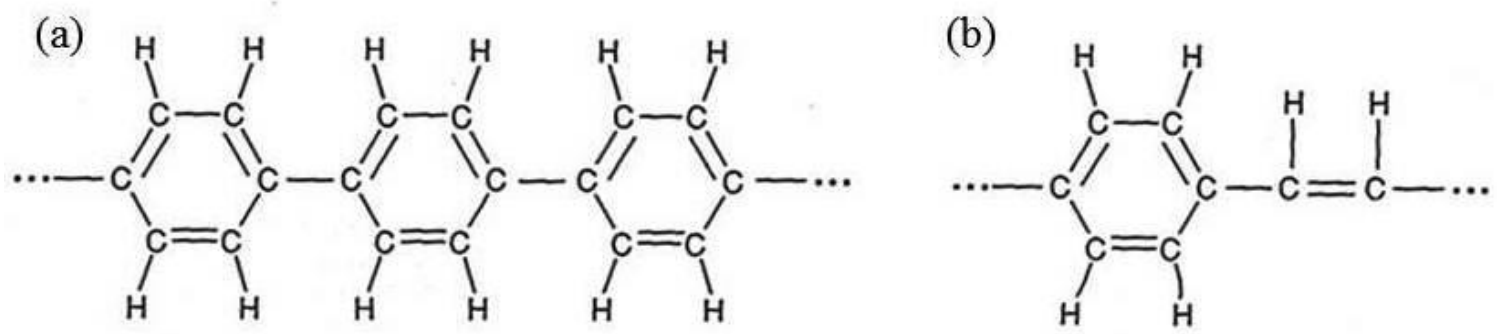

Figura 2.1: Estrutura química de polímeros conjugados. (a) poli( $p$-fenileno) e (b) poli( $p$-fenileno vinileno) (KIESS, 1992). 
As ligações alternadas em um sistema conjugado produzem uma região de sobreposição de orbitais $p$ unindo as ligações simples interjacentes. Isso permite a deslocalização de elétrons $\pi$ nos orbitais $p$ adjacentes alinhados, fazendo com que os elétrons $\pi$ não pertençam a uma única ligação ou átomo, mas sim a um grupo de átomos na região conjugada, mas para uma descrição mais precisa de um sistema polimérico conjugado deve-se considerar os defeitos estruturais, por exemplo, defeitos químicos e os movimentos de torções que a cadeia polimérica está sujeita promovem uma desordem conformacional no material. Como resultado disso, há uma quebra das conjugações do polímero, formando segmentos conjugados com diferentes tamanhos entremeados por quebras de conjugação. Como exemplo, a Figura 2.2 ilustra uma cadeia conjugada do poli(vinileno fenileno) (PPV) sujeita à torções que levam a formação de segmentos conjugados (SCHOLES et al., 2006). O comprimento de conjugação é um parâmetro que influência diretamente as propriedades ópticas dos polímeros conjugados. Assim, o modelo físico de um polímero conjugado desordenado no estado sólido pode ser descrito, em primeira aproximação, por um conjunto de segmentos com diversos tamanhos, orientações e posições distribuídas no material.

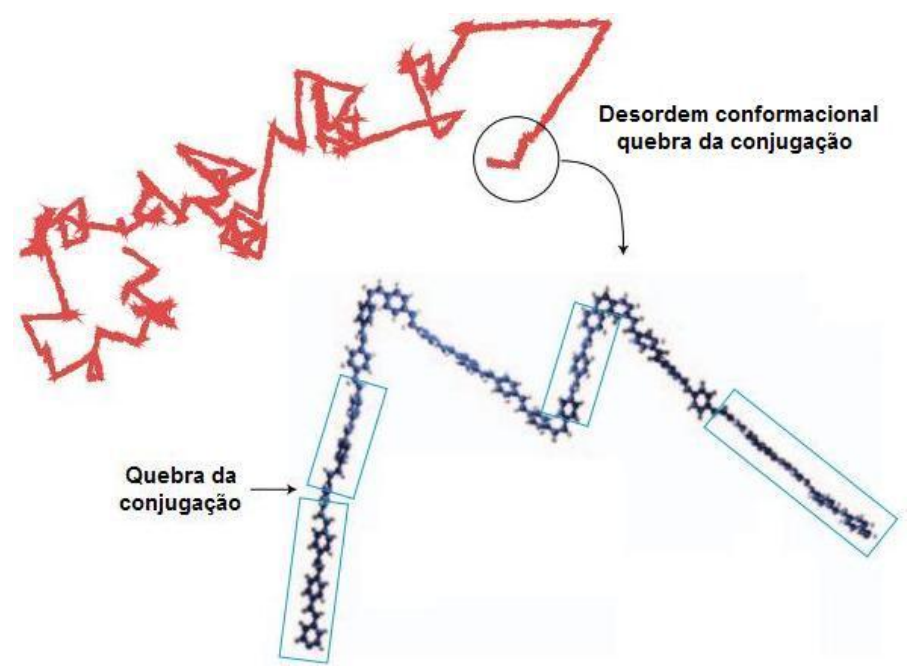

Figura 2.2: Ilustração da cadeia do poli(fenileno vinileno) (PPV). A figura acima (vermelha) apresenta a desordem conformacional na cadeia e a figura abaixo ilustra a quebra da conjugação. Adaptado de (SCHOLES et al., 2006).

\subsubsection{Estrutura Eletrônica}

Em geral, as ligações químicas dos átomos de polímeros conjugados são formadas pela hibridização $s p^{2}$. Em moléculas à base de carbono, basicamente uma hibridização $s p^{2}$ é a sobreposição entre os orbitais atômicos $2 s, 2 p_{x}, 2 p_{y}$. Isso resulta em três orbitais híbridos $s p^{2}$ por átomo de carbono e um orbital livre $2 p_{z}$ (BARFORD, 2005). O tipo de ligação covalente, $\sigma$ ou $\pi$, entre os átomos depende da maneira que ocorre a sobreposição entre os orbitais 
envolvidos.

Se a sobreposição dos orbitais ocorre ao longo do eixo inter-nuclear a ligação é denominada de $\sigma$. Já, se a sobreposição dos orbitais ocorre através da aproximação de orbitais perpendiculares ao eixo inter-nuclear, a ligação é denominada de $\pi$. Para uma melhor visualização das sobreposições desses orbitais, a Figura 2.3 ilustra as ligações $\sigma$ e $\pi$ de uma molécula pequena, o benzeno. Os elétrons do orbital $\sigma$ estão localizados entre os dois átomos de carbono, elas são responsáveis pela rigidez das ligações covalente. Enquanto que os elétrons do orbital $\pi$ são não localizados, ou seja, se estendem por toda região conjugada da molécula.
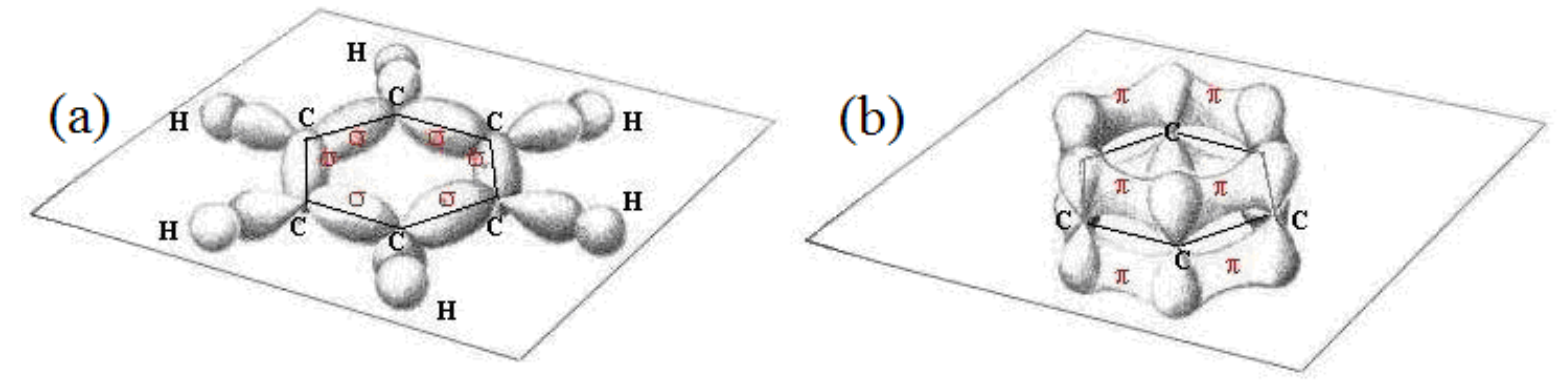

Figura 2.3: Ilustração das ligações covalentes da molécula de benzeno. (a) orbitais localizados $(\sigma)$ e (b) orbitais moleculares não localizados $(\pi)$. Adaptado de (ALONSO \& FINN, 1968).

Nos polímeros conjugados as ligações covalentes na cadeia polimérica são responsáveis pela coesão da molécula, enquanto que as interações intermoleculares ocorrem por meio de interações de Van der Walls e são muito mais fracas.

A superposição entre os orbitais livres $2 p_{z}$ na região conjugada dá origem a orbitais moleculares com caráter ligante e antiligante. Como resultado dessa superposição duas regiões energéticas são formadas, uma banda de orbitais ligante (banda $\pi$ ) e uma banda de orbitais antiligante (banda $\pi^{*}$ ). $\mathrm{O}$ orbital da banda $\pi$ que possui energia mais elevada é denominado de HOMO (Highest Occupied Moleulcar Orbital) e o orbital da banda $\pi *$ que possui menor energia é denominado de LUMO (Lowest Unoccupied Molecular Orbital). A diferença de energia entre o HOMO e o LUMO é denominada de lacuna de energia $E_{g}$ (ou gap de energia), e em geral corresponde à transição eletrônica opticamente ativa de menor energia no sistema.

A lacuna de energia depende do nível de deslocalização dos elétrons $\pi$ e estes estão relacionados com o comprimento de conjugação do segmento. Investigações teóricas e experimentais mostram que a lacuna de energia é inversamente proporcional ao comprimento 
da conjugação. A Figura 2.4 ilustra a relação entre o comprimento e a lacuna de energia e comprimento da conjugação.

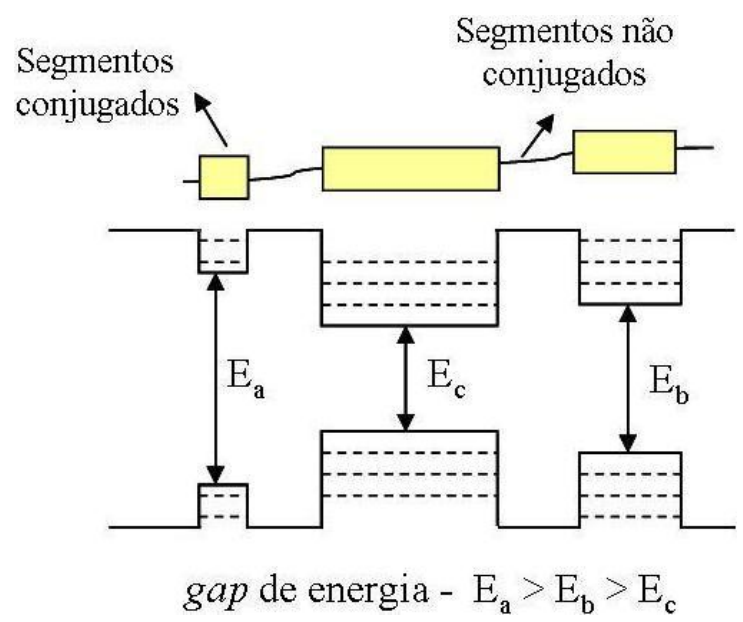

Figura 2.4: Ilustração do comprimento dos segmentos conjugados do polímero com seus respectivos gap's de energia. Quando maior o segmento conjugado menor é o gap de energia.

O comportamento da lacuna de energia em função do comprimento de conjugação pode ser descrito pela seguinte equação, (GIERSCHNER et al., 2002; SRIWICHITKAMOL et al., 2006; CHANG et al., 2000)

$$
E_{g(n)}=E_{g(n \rightarrow \infty)}+\frac{\varepsilon_{1}}{n}
$$

onde $n$ é o comprimento da conjugação, $E_{g(n \rightarrow \infty)}$ é a lacuna de energia quando $n$ tende ao infinito (limite do polímero infinito) e $\varepsilon_{l}$ é a diferença entre a lacuna de energia do polímero infinito e a de um monômero com $n=1$, ou seja, $\varepsilon_{1}=E_{g(1)}-E_{g(n \rightarrow \infty)}$. Esses parâmetros são característicos de cada material.

Sriwichitkamol (et al., 2006) calcularam a lacuna de energia para diferentes comprimentos de oligômeros do PFO. Os valores da lacuna de energia obtidos por esses autores em função do inverso do tamanho do oligômero estão apresentados na Figura 2.5. A partir do ajuste dos dados com a eq. 1 foram obtidos valores de energia de gap para o polímero infinito igual a 3,2 eV e o parâmetro $\varepsilon_{l}=1,7 \mathrm{eV}$. Esses valores são importantes, pois serão utilizados na análise dos resultados. 


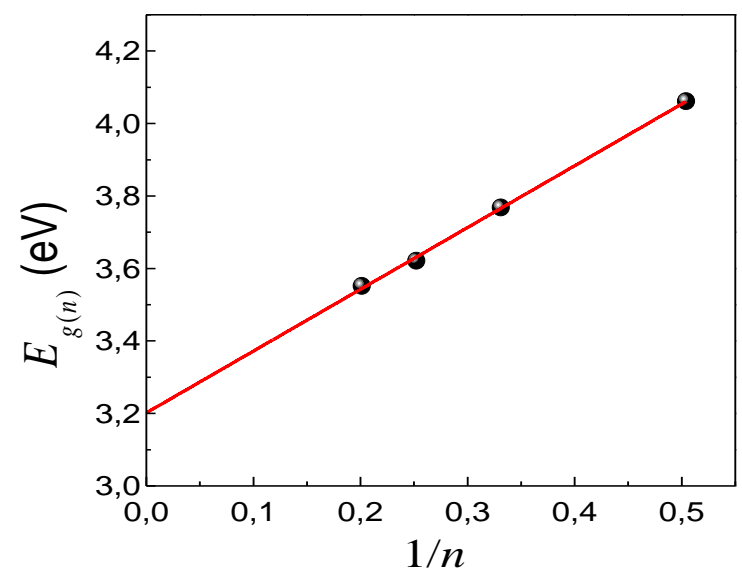

Figura 2.5: Lacuna de energia do PFO em função do comprimento da conjugação. Valores obtidos de (SRIWICHITKAMOL et al., 2006). A linha vermelha é o ajuste com a eq. (1).

\subsubsection{Estrutura Vibracional}

Polímeros conjugados apresentam um forte acoplamento entre os estados eletrônicos e o movimento dos núcleos das cadeias moleculares, denominado acoplamento elétron-fônon. Sistemas moleculares desse tipo podem ser abordados por meio da aproximação de BornOppenheimer que trata separadamente os estados eletrônicos e vibracionais. Isso permite escrever a função de onda como sendo composta por uma parte eletrônica e outra vibracional. Essa aproximação é justificada pelo fato de que o intervalo de tempo do movimento de um elétron é de $10^{-15} \mathrm{~s}$ enquanto que o tempo do movimento nuclear é de $10^{-12} \mathrm{~s}$ (MOLITON, 2006). Com isso, o estado eletrônico fundamental e os estados excitados de uma molécula estão acoplados com diversos estados vibracionais, fazendo com que os espectros de absorção e fotoluminescência apresentem réplicas das bandas eletrônicas devido a transições envolvendo os estados vibracionais.

Considerando o acoplamento elétron-fônon, as transições eletrônicas (absorção e fotoluminescência) em polímeros conjugados podem ser representadas por um diagrama configuracional como o da Figura 2.6. Este diagrama ilustra o estado eletrônico fundamental $\left(E_{i}\right)$, o estado eletrônico excitado $\left(E_{j}\right)$ e os modos vibracionais de ambos estados eletrônicos em função da coordenada de configuração (q). O deslocamento na coordenada de configuração $(\Delta)$ entre os dois mínimos dos estados eletrônicos ocorre devido à diferença de configuração que resulta em menor energia em cada um desses estados. Esse deslocamento é quem determina o quanto a função de onda vibracional do estado $E_{i}$ e a função de onda vibracional do estado $E_{j}$ estão superpostas durante a transição óptica. Essa superposição é descrita pelo fator Franck-Codon $(F)$ que fornece o peso de cada transição eletrônica- 
vibracional (BARFORD, 2005). Por exemplo, quando maior o valor de $F$, ou seja, quanto maior a superposição entre as funções de onda vibracionais dos estados eletrônicos (fundamental e excitado) maior é a probabilidade de ocorrer a transição.

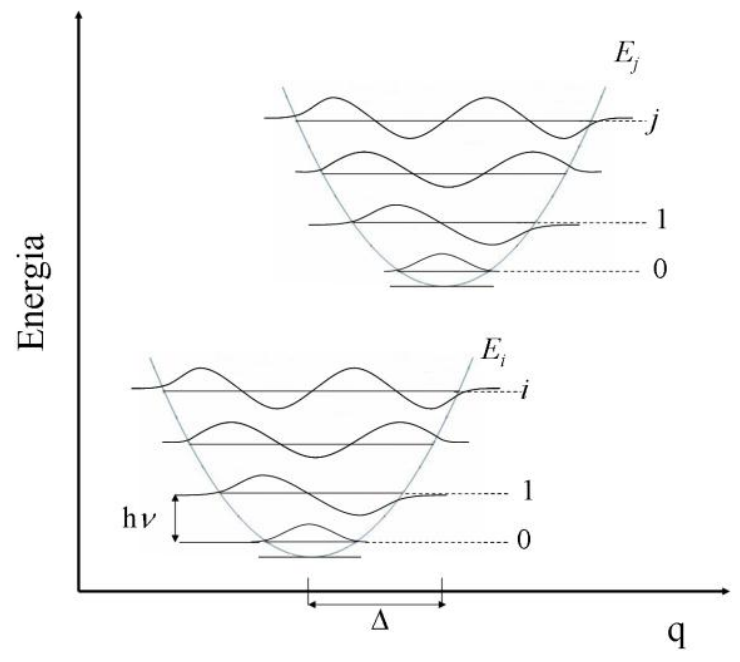

Figura 2.6: Diagrama configuracional considerando o acoplamento elétron - fônon. hv é a energia de fônon.

Para os modos vibracionais com maior acoplamento apenas o nível vibracional de menor energia do estado eletrônico fundamental está significativamente ocupado; nessas condições o fator de Franck-Condon pode ser escrito como:

$$
F_{(0, m)}=\frac{\exp (-S) S^{m}}{m !}
$$

onde $S$ é o parâmetro de Huang-Rhys, que está relacionado com a diferença de conformação da cadeia polimérica entre o estado fundamental e o excitado e $m$ representa o estado vibracional do estado excitado/fundamental $(m=0,1,2, \ldots$,$) no processo de absorção/emissão$ (BARFORD, 2005), assim $F$ pode descrever tanto o processo de absorção quanto o processo de emissão.

O parâmetro $S$ pode ser obtido a partir do espectro de fotoluminescência a partir da relação (KENNEDY et al. 2001):

$$
S=\frac{I_{0-1}}{I_{0-0}}
$$

onde $I_{0-0}$ é a intensidade da transição puramente eletrônica e $I_{0-1}$ a intensidade da transição entre o estado eletrônico excitado (que está no estado vibracional de menor energia, $m=0$ ) e o primeiro estado vibracional $(m=1)$ do estado eletrônico fundamental (primeira réplica de fônon). 


\subsection{Processos ópticos em polímeros conjugados}

\subsubsection{Absorção e fotoluminescência}

As propriedades ópticas de polímeros conjugados são determinadas principalmente pelos elétrons $\pi$. Quando um segmento conjugado de um polímero absorve um fóton com energia $h v$ ( $h$ é a constante de Planck e $v$ é a frequência da radiação) um elétron é promovido da banda $\pi$ (estado singleto, $\mathrm{S}_{0}$ ) para a banda $\pi^{*}$ (estado singleto, $\mathrm{S}_{1}$ ) deixando um buraco na banda $\pi$. Esse processo é denominado de transição interbanda $\pi-\pi^{*}$ ou simplesmente de excitação eletrônica. Após a excitação óptica, o estado molecular é conhecido por estado excitado. Neste estado o elétron e o buraco são ligados por meio da interação de Coulomb formando um par elétron-buraco denominado de éxciton.

Os processos de absorção, relaxação vibracional e fotoluminescência podem ser ilustrados no diagrama configuracional como o da Figura 2.7. A excitação de um segmento conjugados por meio da absorção de um fóton pode ser representado por,

$$
D+h v \rightarrow D^{*}
$$

onde $D$ representa o segmento conjugado, $h v$ a energia do fóton e $D^{*}$ o estado excitado. Esse processo ocorre a uma taxa constante $\left(k_{A}\right)$ da ordem de $10^{15} \mathrm{~s}^{-1}$.

Após o segmento conjugado ser excitado ocorre um rápido relaxamento energético não radioativo através dos estados vibracionais que ocorre com taxas $\left(k_{R}\right)$ em torno de $10^{12} \mathrm{~s}^{-1}$ e é representado por,

$$
D_{m}^{*} \rightarrow D_{m^{\prime}}^{*} \rightarrow D_{m}^{*}
$$

com os índices $m$ representando os níveis vibracionais do estado excitado $D^{*}$. Esse é um tipo de relaxação energética intramolecular. No entanto, o cruzamento intersistema (não mostrado na Figura 2.7) é outro processo não radiativo que compete com o relaxamento vibracional. Nesse processo o estado excitado é transferido para estado tripleto de menor energia que pode relaxar vibracionalmente para o estado fundamental ou decair radiativamente em tempos grandes, em geral maiores que $\mu$ s (fosforescência).

O estado excitado (singleto ou tripleto) pode ser desativado através de um processo radiativo denominado luminescência (emissão de fóton) ou por processos não radiativos. $\mathrm{O}$ processo de decaimento radiativo é denominado fluorescência no caso de estados singletos e fosforescência no caso de estados tripletos e podem ser representado por:

$$
D^{*} \rightarrow D+h v
$$

essa transição ocorre entre o estado vibracional de menor energia do estado excitado para os outros estados vibracionais do estado eletrônico fundamental. A taxa desse processo $\left(k_{F}\right)$ para 
estados singleto é da ordem de $10^{9} \mathrm{~s}^{-1}$.

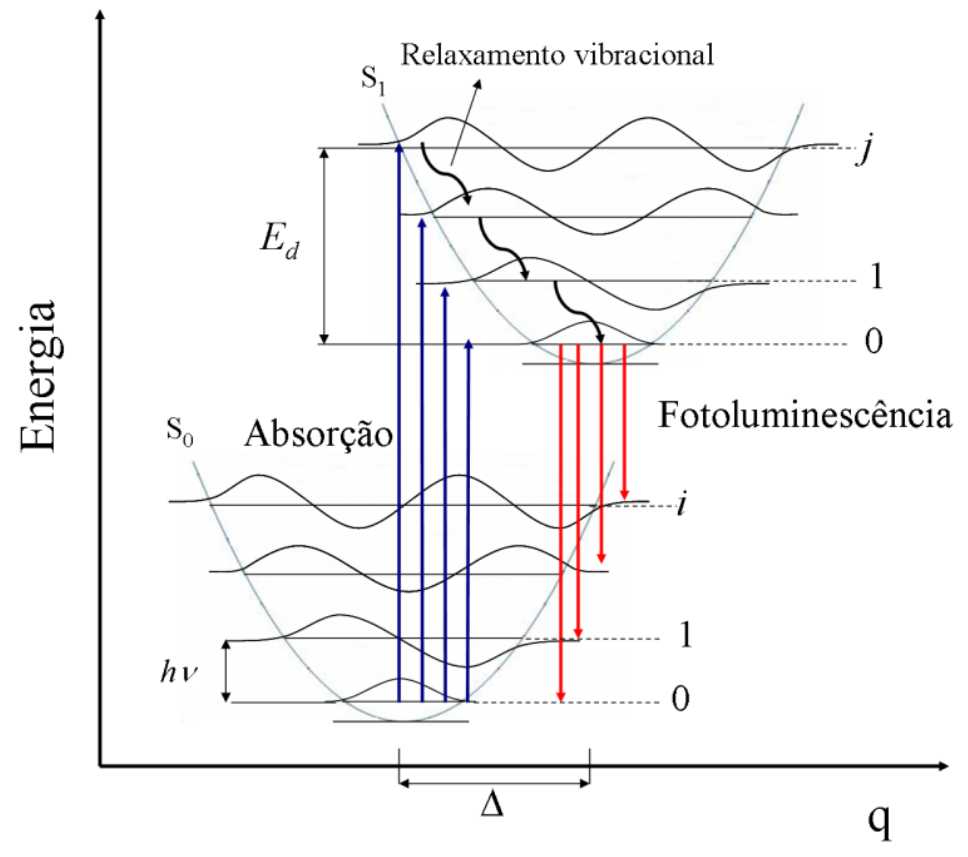

Figura 2.7: Processos de absorção, relaxamento vibracional e fotoluminescência ilustrados no diagrama configuracional. $E_{d}$ é a energia de reorganização (relaxamento).

\subsubsection{Migração do estado excitado}

Além dos processos intramoleculares de desativação, relaxamento vibracional e cruzamento intersistema, o estado eletrônico excitado de um cromóforo (molécula absorvedor de radiação) pode ser desativado através da transferência de energia incoerente, que leva à migração do estado excitado para outro cromóforo. Essa transferência pode ser entre dois cromóforos com estados eletrônicos equivalentes, neste caso a transferência é denominada de homotransferência, ou entre cromóforos distintos que é denominada de heterotransferência. Estes processos são representados por,

$$
\begin{array}{ll}
D^{*}+D \rightarrow D+D^{*} & \text { Homotransferência } \\
D^{*}+A \rightarrow D+A^{*} & \text { Heterotransferência }
\end{array}
$$

onde $A$ é o cromóforo aceitador, este processo dá origem ao deslocamento espectral para o vermelho da emissão observado em polímeros estatísticos; ou à diminuição da luminescência, no caso do aceitador ser um centro supressor ou armadilha, que é uma molécula que tem estados de menor energia com pequena probabilidade de emissão (baixa eficiência quântica).

O modelo que descreve a transferência de energia através de processos não radiativos próximos foi descrito inicialmente por Förster (1959) e é denominado muitas vezes Transferência de Energia Ressonante. Neste modelo a transferência ocorre de forma não radiativa mediada pela interação ressonante entre o dipolo de transição do segmento 
conjugado doador e o dipolo de transição do segmento conjugado aceitador (interação dipolar). A estrutura vibracional de cada estado eletrônico proporciona condições favoráveis de ressonância para que ocorra a transferência de energia antes do decaimento radiativo e com uma taxa de transferência $\left(k_{T}\right)$ que pode chegar teoricamente a $10^{12} \mathrm{~s}^{-1}$. Após a transferência de energia, o segmento doador retorna ao estado eletrônico fundamental e o segmento aceitador vai para o estado excitado, sem que ocorra efetivamente a transferência de elétrons entre os dois segmentos, por isso muitas vezes esse processo é chamado de transferência de energia, em oposição aos processos de transferência de carga. A Figura 2.8 ilustra esse processo.

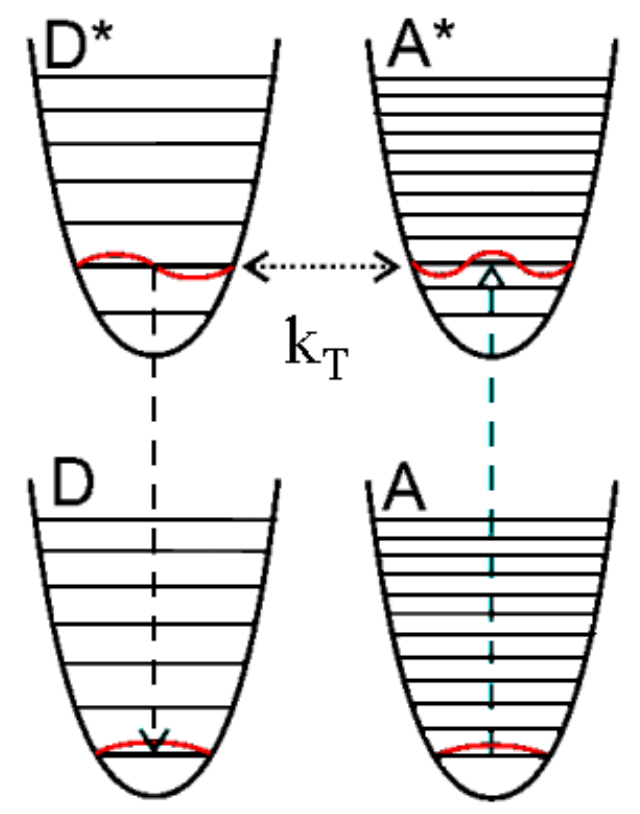

Figura 2.8: Transferência de energia segundo o mecanismo de Förster. Adaptado de FACETO (2007).

A estrutura molecular desempenha um papel importante na transferência de energia, pois, a interação dipolar depende da posição, orientação relativa e da ressonância energética entre os estados dos segmentos conjugados doadores e aceitadores. A taxa $k_{T}$ depende da distância $(R)$ entre as moléculas doadoras e a aceitadoras segundo a relação (FÖRSTER, 1959),

$$
k_{T}=k_{F} \frac{R_{0}^{6}}{R^{6}}
$$

onde $R_{O}$ é o raio de transferência de Förster que corresponde a uma distância na qual o decaimento radiativo e a transferência de energia possuem a mesma probabilidade de ocorrência para moléculas alinhadas. A Figura 2.9 mostra o comportamento de $k_{T}$ em função da razão $R / R_{0}$ e as taxas de decaimento radiativo $\left(k_{F}\right)$ e relaxamento vibracional $\left(k_{R}\right)$.

Em regiões onde $R / R_{0}$ está próximo de 0,3 as taxas de transferência de energia e a taxa 
de relaxamento vibracional possuem a mesma ordem de grandeza $\left(k_{T} \approx k_{R}\right)$ e, portanto, há uma competição entre esses dois processos para relaxar o estado excitado. Nessa região o decaimento radioativo é pouco provável.

Já em regiões onde $R / R_{0}$ está próximo de $1\left(k_{T} \approx k_{F}\right)$ a transferência de energia e o decaimento radiativo competem entre si, esses dois processos são igualmente prováveis. O resultado disso é a migração do estado excitado até essa região. Por outro lado, a transferência de energia se torna menos provável em regiões onde $R$ é pouco maior de $R_{0}$ em função da dependência $\mathrm{R}^{-6}$. Em polímeros conjugados, o raio típico de Förster é da ordem de $1 \mathrm{~nm}$.

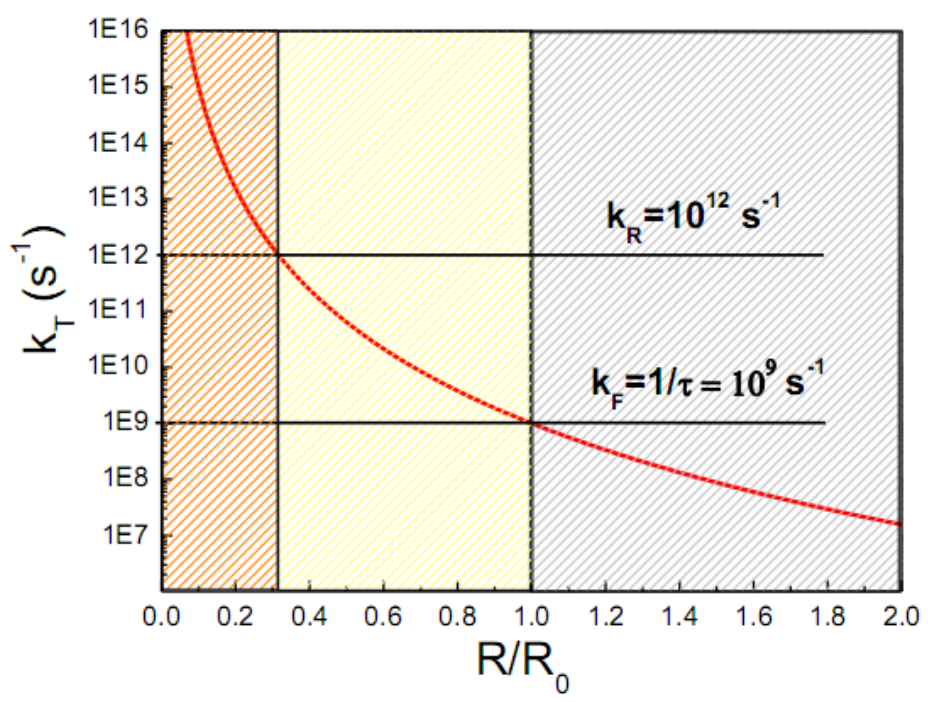

Figura 2.9: Taxa de transferência de energia $k_{T}$ em função de $R / R_{0}$ e comparação com as taxas $k_{R}$ e $k_{F}$ (FACETO, 2007).

A migração do estado excitado entre diversos cromóforos, bem como o processo de absorção, relaxamento vibracional e fotoluminescência estão representados esquematicamente na Figura 2.10. A transferência de energia ocorre preferencialmente dos segmentos conjugados de maior energia para segmentos conjugados de menor energia, ou seja, para segmentos de maior comprimento de conjugação. Assim, o estado energético alcançado no final desse processo é o de menor energia e, portanto, a fotoluminescência gerada ( $h v^{\prime}$ na Figura 2.10) possui menor energia que da radiação absorvida $(h v)$, dando origem a uma emissão mais para o vermelho. 


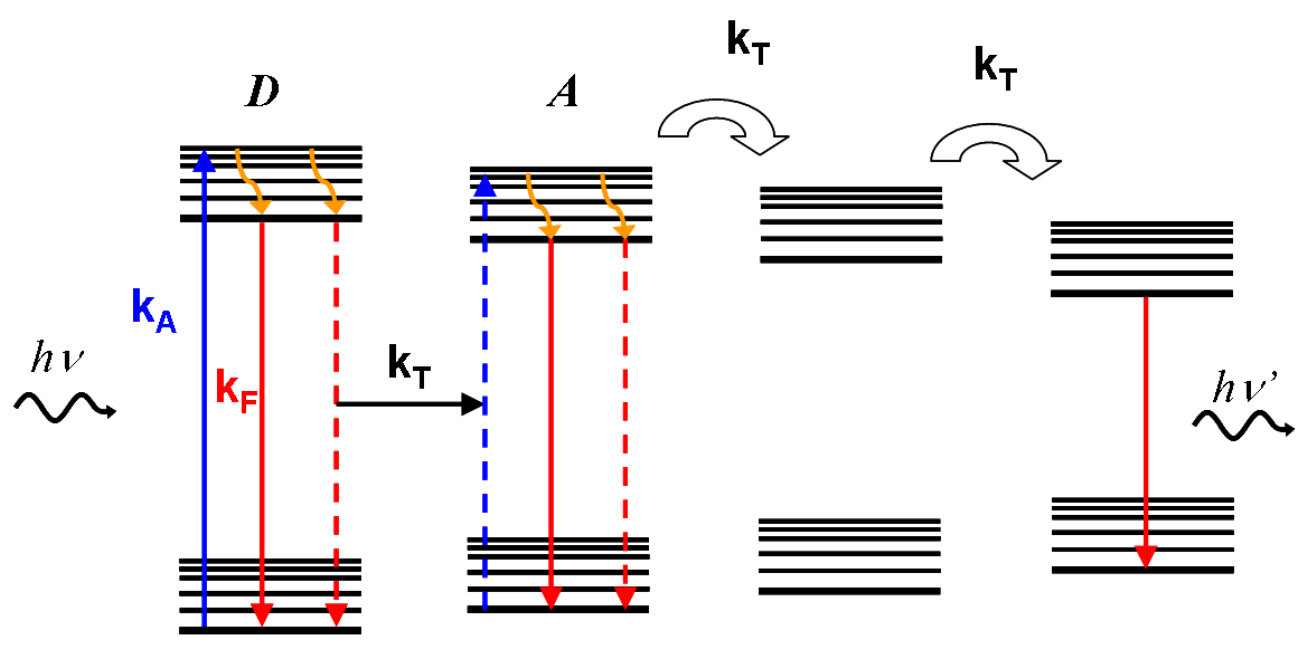

Figura 2.10: Migração do estado excitado resultado da transferência de energia entre os segmentos conjugados.

\subsubsection{Propriedades da fotoluminescência de polímeros conjugados}

A forma da linha espectral de emissão de polímeros conjugados é caracterizada pela emissão de diversos segmentos conjugados não equivalentes, entretanto a forma de linha pode ser muito bem descrita por uma distribuição energética em torno de um valor médio de energia $E_{0}$ com uma largura $\Gamma$. $\mathrm{O}$ valor $E_{0}$ corresponde à energia média da transição eletrônica que deu origem a essa linha espectral, e a largura utilizada para caracterizar o espectro é a largura na meia altura (Full width at Half-Maximum, FWHM), ou seja, largura na qual a intensidade da linha possui metade da intensidade máxima, ou seja, quando $I(E)=I\left(E_{0}\right) / 2$. Os espectros de emissão apresentam uma forma mais complexa, com diversas réplicas de fônon da transição eletrônica, mas a forma da linha $\mathrm{I}(\mathrm{E})$ do espectro de fotoluminescência de uma transição puramente eletrônica pode ser bem descrita utilizando uma função gaussiana como o da Figura 2.11.

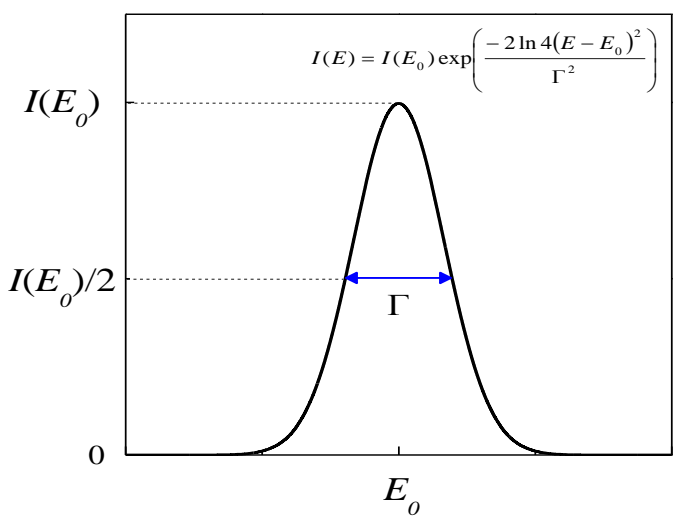

Figura 2.11: Forma de linha Gaussiana com os parâmetros, $I\left(E_{0}\right), E_{0}$ e $\Gamma$ que podem ser utilizados para caracterizar uma transição puramente eletrônica. Em destaque a função gaussiana. 
Através da dependência da energia da $E_{0-0}$ e da largura da linha espectral $\Gamma$ da transição puramente eletrônica, bem como do parâmetro $S$ com a temperatura é possível investigar efeitos de desordem conformacional na cadeia produzidas pela temperatura (BORGES, 2001). A dependência da intensidade da fotoluminescência com a temperatura é descrita pela equação (BORGES, 2001; DA SILVA et al, 2008),

$$
I(T)=\frac{I_{0}}{1+B e^{-E_{a t} / k_{B} T}}
$$

onde $T$ é a temperatura, $I_{0}$ é a intensidade quando $T$ tende a zero, $B$ é uma constante típica de cada material, $E_{a t}$ é a energia de ativação e $k_{B}$ é a constante de Boltzmann que é igual a $8,6 \times 10^{-5} \mathrm{eVK}^{-1}$.

A energia $\mathrm{E}_{0-0}$, a largura $\Gamma$ e o fator $S$ são influenciados pelo tamanho do segmento conjugado do polímero que é afetado, por sua vez, pela energia térmica do sistema (BORGES, 2001). A dependência do comprimento médio dos segmentos conjugados com a temperatura pode ser expressa pode ser expressa pela seguinte relação,

$$
n(T)=n_{0} e^{\hbar \omega / k_{B} T}
$$

$n_{0}$ é o comprimento de conjugação efetivo e $\hbar \omega$ é a energia característica de mudanças conformacionais na cadeia polimérica. Considerando a Eq.(1) e a Eq.(6) a posição da linha de transição puramente eletrônica $\left(E_{0-0}\right)$ em função da temperatura pode ser expressa por (BORGES, 2001; DA SILVA et al, 2008),

$$
E_{0-0}(T)=\varepsilon_{0}+\frac{\varepsilon_{1}}{n_{0}} e^{-\varepsilon / k_{B} T}
$$

onde $\varepsilon_{0}$ corresponde a energia da transição do polímero infinito quando $T$ tende a zero e $\varepsilon_{l}$ é característicos de cada material como apresentado na seção 2.1.

Há dois tipos de desordem energética que contribuem para a largura de linha espectral, a desordem estática e a desordem dinâmica. A primeira é resultado da não homogeneidade do sistema molecular que é provocada por imperfeições das cadeias, distorções moleculares (torções, por exemplo) ou pela falta de homogeneidade do campo local provocado pelas interações com as moléculas vizinhas (AKIRA et al., 1995). Já a desordem dinâmica resulta das flutuações térmicas na conformação da cadeia molecular, produzida principalmente por movimentos de torção, que ocorrem de modo homogêneo em cada sítio do material. Portanto, alterações de temperatura afetam somente a desordem homogênea. A largura das flutuações energéticas da desordem dinâmica em termos da temperatura pode ser descrita por (BORGES, 2001), 


$$
\Gamma(T)=\Gamma_{0}+\frac{\varepsilon_{1}}{n_{0}^{2}} e^{-2 \hbar \omega / k_{B} T}
$$

onde $\Gamma_{0}$ é o alargamento não homogêneo e $\hbar \omega$ é energia de um modo vibracional particular.

O parâmetro $S$ depende diretamente do tamanho dos segmentos conjugados do polímero e aumenta com o decréscimo de $n$. Para sistemas moleculares com alto grau de conjugação $(n>>1)$, a relação entre o fator Huang-Rhys $S$ e o tamanho de conjugação $n$ pode ser descrita por uma relação empírica dada por (BORGES, 2001; HAGLER, 1991; HEUN, 1993; DA SILVA et al, 2008),

$$
S(T)=S_{o}+\frac{S_{1}}{1+n(T)}
$$

onde $S_{\mathrm{o}}$ é o fator Huang-Rhys para $T=0 \mathrm{~K}, S_{1}$ é um parâmetro a ser determinado e $n(T)$ é descrito pela eq. 6 . 


\section{MATERIAIS E MÉTODOS}

\subsection{Limpeza do substrato de quartzo}

As lâminas de quartzo utilizadas como substrato, inicialmente foram limpas com água e detergente utilizando uma esponja macia. A última limpeza dos substratos foi realizada utilizando o método RCA ácido. Esse método promove uma hidrofilização na superfície proporcionando condições favoráveis para a formação dos filmes pela técnica spin-coating. A composição do RCA ácida é a seguinte: água ultrapura $\left(\mathrm{H}_{2} \mathrm{O}\right)$, água oxigenada $\left(\mathrm{H}_{2} \mathrm{O}_{2}\right)$ e ácido clorídrico $(\mathrm{HCl})$ na proporção de 6:1:1, respectivamente. O procedimento de limpeza utilizando método RCA consiste em aquecer a solução de RCA até a $80{ }^{\circ} \mathrm{C}$, deixar as lâminas de quartzo imersas na solução durante 15 minutos mantendo a temperatura constante de 80 ${ }^{\circ} \mathrm{C}$. Após esse tempo as lâminas devem ser exaustivamente enxaguadas com água ultrapura e secas utilizando fluxo de nitrogênio.

\subsection{Preparação da camada de $\mathrm{TiO}_{2}$}

As nanopartículas de dióxido de titânio $\left(\mathrm{TiO}_{2}\right)$ utilizadas são da marca Aldrich e possuem diâmetro $\leq 25 \mathrm{~nm}$ e fase anatase (informações do fabricante). O procedimento adotado para o preparo da solução de $\mathrm{TiO}_{2}$ foi obtido em Reeja-Jayan et al. (REEJA-JAYAN, 2010). A solução é constituída de $10 \%$ da massa de nanopartículas de $\mathrm{TiO}_{2}$ em álcool etílico. Essa solução de $\mathrm{TiO}_{2}$ foi agitada vigorosamente utilizando um agitador magnético por aproximadamente $12 \mathrm{~h}$. Com isso foi obtida uma solução concentrada de nanopartículas de $\mathrm{TiO}_{2}$.

Utilizando esta solução de $\mathrm{TiO}_{2}$ em álcool etílico, a camada de nanopartículas de $\mathrm{TiO}_{2}$ sobre o substrato de quartzo foi obtida utilizando a técnica de spin-coating (300 rpm por 60 s). A fim de preservar uma região do substrato para posteriormente depositar o polímero tanto sobre o $\mathrm{TiO}_{2}$ quanto sobre o quartzo, somente metade do substrato foi coberto com a camada de $\mathrm{TiO}_{2}$, como mostra a Figura 3.1. Esta figura também mostra as dimensões do substrato. Para obter uma região do substrato sem a camada de $\mathrm{TiO}_{2}$, antes de depositar a camada de $\mathrm{TiO}_{2}$, metade do quartzo foi coberta com uma fita adesiva (fita mágica, 3M) que foi retirada logo após a deposição da camada de $\mathrm{TiO}_{2}$. 
Figura 3.1: Foto do substrato de quartzo (Qtz) no qual metade deste contém uma camada de nanopartículas de $\mathrm{TiO}_{2}\left(\mathrm{Qtz} / \mathrm{TiO}_{2}\right)$.

Por fim as camadas de $\mathrm{TiO}_{2}$ depositadas sobre o quartzo foram tratadas termicamente a $723 \mathrm{~K}\left(450{ }^{\circ} \mathrm{C}\right.$ ) por 30 minutos (rampa de $10 \mathrm{~K} /$ minuto) como mostra a ilustração da Figura 3.2. Este procedimento foi realizado utilizando um forno mufla modelo EDGON5P da E.D.G. Equipamentos.

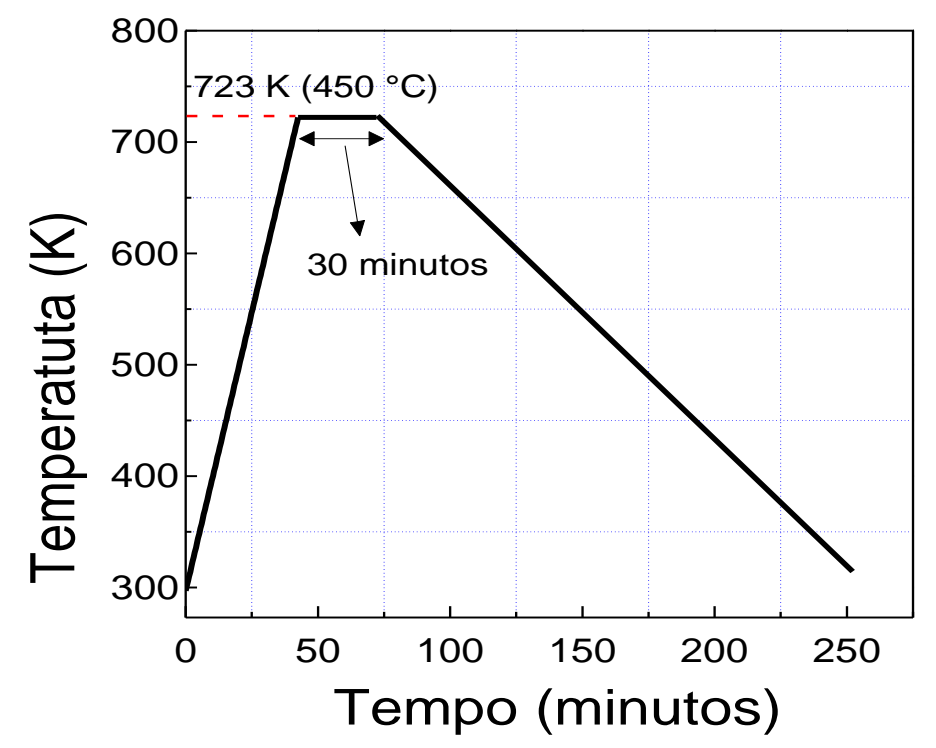

Figura 3.2: Curva do tratamento térmico realizado com as camadas de $\mathrm{TiO}_{2}$ depositadas sobre o quartzo. 


\subsection{Preparação dos filmes de PFO}

O polímero utilizado neste trabalho foi o poli(9,9 dioctilfluoreno) (ADS129BE) (PFO), Figura 3.3.

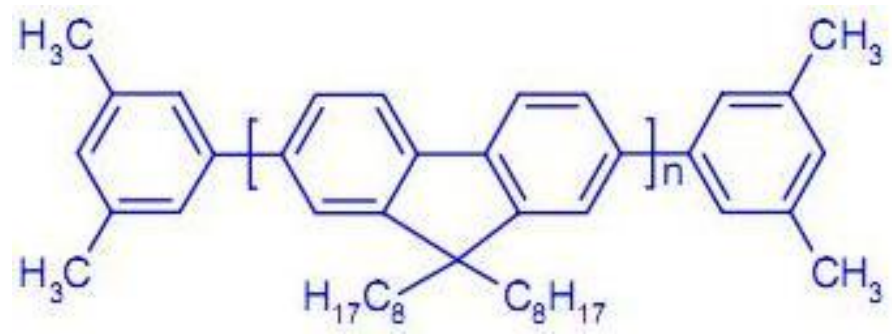

Figura 3.3: Estrutura química do PFO (ADS129BE) utilizado no presente trabalho.

Todos os filmes de PFO foram produzidos utilizando a técnica spin-coating. Nessa técnica, a formação do filme polimérico ocorre por meio de dois processos. O primeiro é um processo hidrodinâmico, no qual logo após iniciar a rotação do substrato, uma quantidade do material polimérico é perdida devido a aceleração centrífuga que o material está sujeito. Nessa etapa se inicia a formação do filme polimérico. Após isso, o segundo processo é a evaporação do solvente durante o tempo em que a amostra é rotacionada (MOKARIANTABARI et al., 2010). Durante esse processo a espessura do filme é reduzida e ao término da rotação o filme polimérico está completamente formado. A Figura 3.4 ilustra este processo.

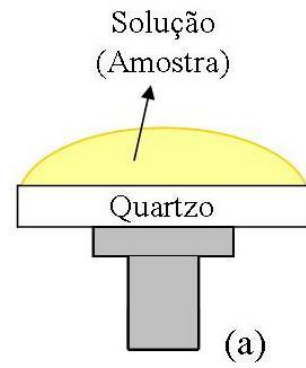

(a)

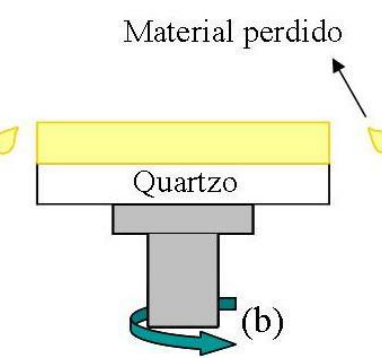
o substrato de quartzo. (b) No início da rotação do substrato com a solução polimérica ocorre perda de material polimérico e há a formação do filme. (c) Diminuição da espessura do filme pela evaporação do solvente durante o intervalo em que a amostra é rotacionada. (d) Filme polimérico formado ao término da rotação.

Utilizando a técnica spin-coating o controle da espessura dos filmes pode ser realizada através da velocidade de rotação do substrato ou através da concentração da solução polimérica. Neste trabalho, para todos os filmes poliméricos, a velocidade e o tempo de rotação foram mantidos constantes em $3000 \mathrm{rpm}$ por $60 \mathrm{~s}$ e o controle da espessura foi realizado por meio da concentração da solução polimérica. Os filmes foram produzidos a partir de uma solução de PFO diluída em clorofórmio, as concentrações utilizadas foram 0,3 
$\mathrm{g} / \mathrm{L}$, 0,6 g/L, 1,25 g/L, 2,5 g/L e 5,0 g/L. Também foram investigados filmes de PFO produzidos a partir de uma solução de PFO diluído em tolueno, neste caso, a concentração utilizada foi de $0,6 \mathrm{~g} / \mathrm{L}$.

Filmes de PFO contendo fase $\beta$ foram produzidos por dois métodos, tratamento a vapor de tolueno e por ciclos térmicos de aquecimento/resfriamento. O primeiro método consiste em manter o filme amorfo de PFO exposto à vapor de tolueno por alguns minutos ou horas. Utilizando esse método, filmes de PFO spin-coating preparados com solução de PFO em clorofórmio foram colocados no espectrômetro UV-Vis em uma câmera lacrada e com janelas por onde foi passado um fluxo contínuo de nitrogênio gasoso contendo vapor de tolueno com vazão de 30-40 Nl/h. Com isso é possível acompanhar a formação da fase $\beta$ através das medidas de absorbância. No segundo método, o filme de PFO amorfo está sujeito a ciclos de resfriamento de $297 \mathrm{~K}$ até temperaturas criogênicas ( $5 \mathrm{~K}$ ) e aquecimento lentamente até $297 \mathrm{~K}$ ( 1 K/min). Esse processo foi realizado utilizando um criostato no qual as amostras foram inseridas. A temperatura na amostra foi controlada utilizando um circuito de gás hélio e um controlador de temperatura (Neocera, modelo LTC-11) acoplados ao criostato.

\subsection{Espectroscopia de Absorção UV/Vis}

A espectroscopia de absorção baseia-se no processo de absorção óptica que promove transições eletrônicas entre o estado fundamental e excitado. Este processo está ilustrado na Figura 3.5. Uma radiação monocromática $\left(I_{0}\right)$ incide num material de espessura (L) que contém uma concentração $c$ de moléculas absorvedoras. Devido a absorção dos fótons da radiação incidente por essas moléculas uma radiação transmitida $(I)$ de menor intensidade, porém, de mesma frequência é observada.

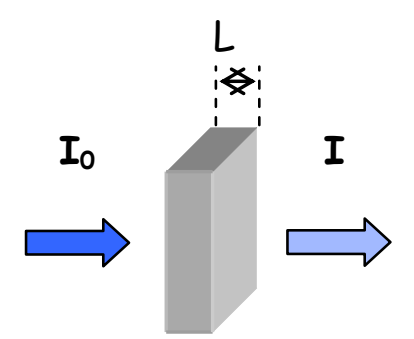

Figura 3.5: Ilustração do processo de absorção mostrando a radiação incidente $\left(\mathrm{I}_{0}\right)$ e transmitida (I) num material.

Experimentalmente observa-se que $I$ depende da espessura da amostra (L) e da concentração da espécie absorvedora (c), essa dependência é descrita pela lei de Beer- 
Lambert (ATKINS, 2004),

$$
I=I_{0} 10^{-\varepsilon c L}
$$

onde $\varepsilon$ é o coeficiente de absorção molar que depende do comprimento de onda da radiação incidente, possuindo maiores valores onde a intensidade da absorção é maior. A lei de Lambert-Beer demonstra que a intensidade da radiação incidente diminui exponencialmente com a espessura da amostra e com a concentração $c$. A partir da equação acima obtemos outra grandeza que é a absorbância $(A b s)$, dada por,

$$
A b s=\log \left(\frac{I_{0}}{I}\right)=\log \left(\frac{1}{T}\right)=\varepsilon c x
$$

onde $T=\frac{I}{I_{0}}$ é a transmitância do material.

Numa medida de absorção varre-se o comprimento de radiação incidente e obtém-se a absorbância do material em função do comprimento de onda. Nesse trabalho utilizamos o espectrofotômetro da marca Hitachi (modelo U2900), que possui um intervalo de excitação na região do ultravioleta e visível (UV/Vis) do espectro eletromagnético, de 190 a $1100 \mathrm{~nm}$. Esta técnica foi utilizada para caracterização óptica dos filmes de PFO.

\subsection{Espectroscopia de fotoluminescência}

A espectroscopia de fotoluminescência baseia-se na medida da radiação emitida por um material após este ter absorvido uma radiação proveniente de uma fonte, como por exemplo, a de um laser. Neste trabalho utilizamos a espectroscopia de fotoluminescência para caracterizar os filmes de PFO, bem como investigar os processos ópticos na interface $\mathrm{PFO} / \mathrm{TiO}_{2}$.

A configuração experimental está ilustrada na Figura 3.6. Como mostra a figura, utilizamos um laser de He-Cd de onda contínua (cw) operando em $325 \mathrm{~nm}$ com potência de $10 \mathrm{~mW}$, lentes convergentes (L's) para focar a radiação laser incidente $\left(\mathrm{L}_{1}\right)$, para focar a fotoluminescência da amostra no detector $\left(\mathrm{L}_{2}\right.$ e $\left.\mathrm{L}_{3}\right)$ e um pequeno prisma $(\mathrm{P})$ para desviar a radiação para a amostra. Para controlar a incidência da radiação na amostra utilizamos um shutter (similar a um diafragma de máquina fotográfica).

As medidas foram realizadas com pressão atmosfera controlada, aproximadamente $5 \times 10^{-4}$ Torr, para isso, utilizamos um criostato no qual as amostras foram inseridas. O controle da pressão no criostato foi realizado utilizando uma bomba de vácuo Pfeiffer Balzers TCP121. Para realizarmos medidas em diferentes temperaturas utilizamos um circuito de gás hélio 
acoplado ao criostato que foi conectado ao controlador de temperatura da marca Neocera, modelo LTC-11.

Utilizamos um espectrômetro da marca Ocean Optics, modelo HR4000, para detectar o sinal de fotoluminescência da amostra. A fim de evitar os efeitos de espalhamento da radiação laser pelas janelas do criostato foi colocado um filtro em $325 \mathrm{~nm}$ localizado próximo ao espectrômetro. $\mathrm{O}$ espectrômetro foi conectado ao notebook e a aquisição dos dados foi realizada através do software Spectra Suíte.

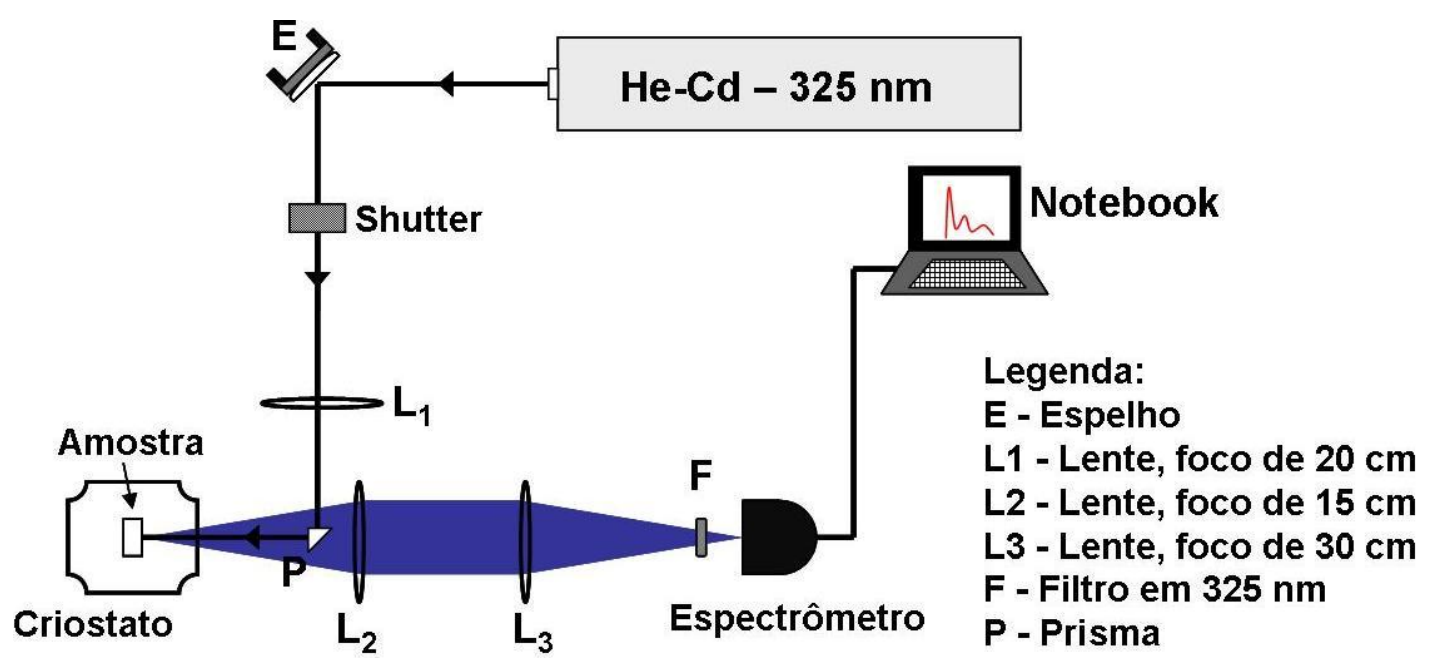

Figura 3.6: Ilustração da configuração experimental da espectroscopia de fotoluminescência de onda contínua.

\subsection{Microscopia Confocal de fluorescência de varredura a laser (LSCM)}

A principal característica da microscopia confocal de fluorescência de varredura a laser (laser scanning confocal microscope, LSCM) é que somente os feixes de fotoluminescência da amostra que estão em foco são detectados. Para isso utiliza-se um anteparo com um pequeno orifício, denominado de pinhole, localizado próximo ao detector. Os feixes de fotoluminescência fora de foco são bloqueados pelo pinhole, como ilustrado na Figura 3.7(b). Com isso é possível, não só obter imagens de alta resolução, como obter imagens em diferentes planos focais da amostra (HIBBS, 2004).

A Figura 3.7(a) mostra um diagrama esquemático dos principais componentes da microscopia confocal de luminescência de varredura a laser. Como mostra a figura, uma radiação proveniente de um laser é utilizada para excitar a amostra. O feixe de laser passa inicialmente pela abertura de um pinhole e é direcionado para a amostra por um espelho dicromático que também possui a função de diferenciar a radiação laser da fotoluminescência da amostra. A varredura do feixe de laser na amostra é feita por dois espelhos de varredura 
que podem rotacionar em torno de um eixo fixo, estes espelhos são localizados entre a amostra e a objetiva. Um dos espelhos varre em alta velocidade o eixo x e outro um pouco mais lento varre o eixo y.

A radiação de excitação é focada na amostra por uma lente objetiva localizada próxima a amostra. A luminescência da amostra retorna passando pela objetiva e é direcionada para o detector. O pinhole localizado próximo do detector seleciona somente os feixes de luminescência em foco para serem detectados, Figura 3.7(b). Controlando a distância da amostra em relação a objetiva é possível obter vários planos focais na amostra.

(a)

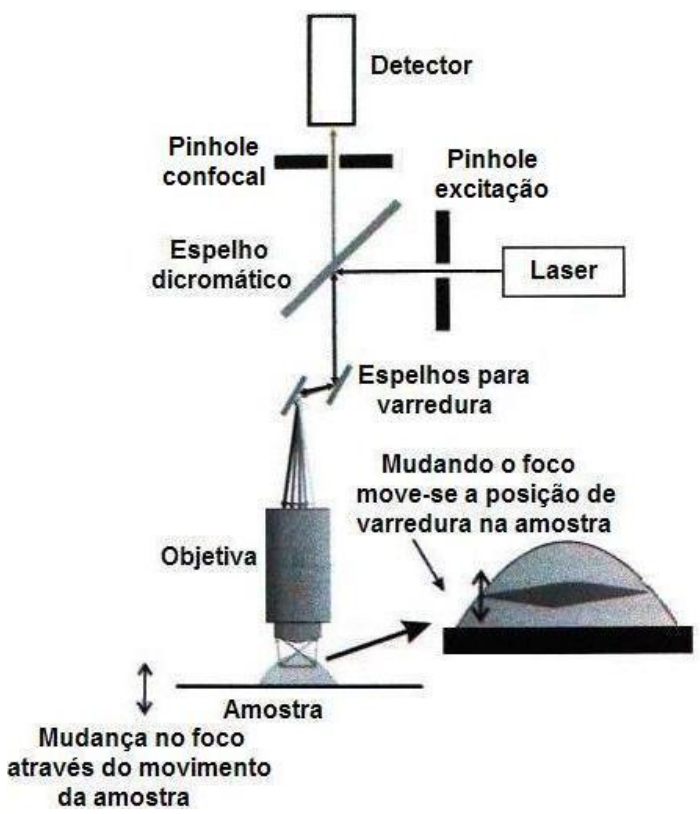

(b)

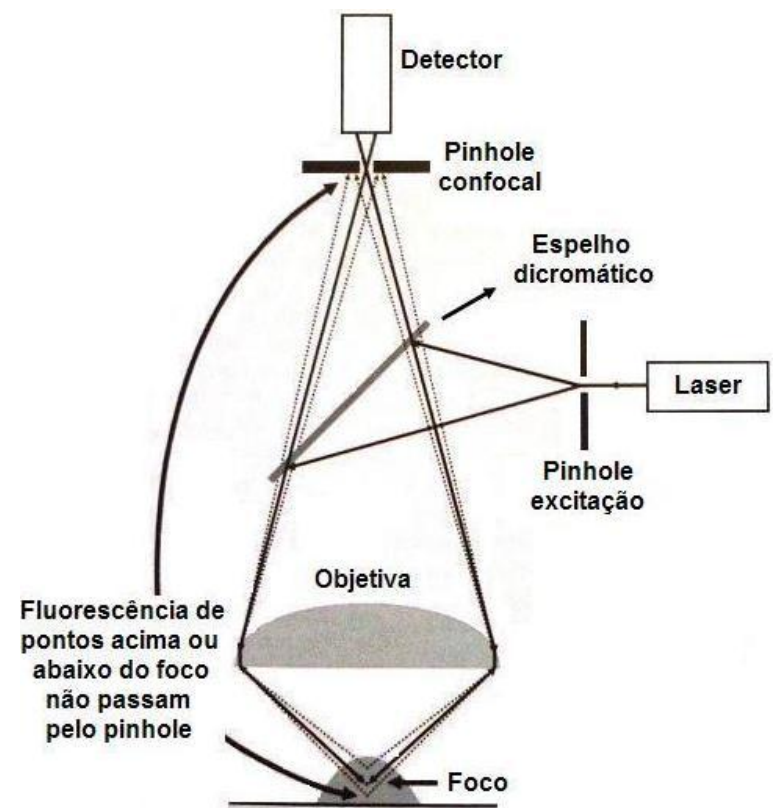

Figura 3.7: (a) Diagrama dos principais componentes ópticos da microscopia confocal de fluorescência de varredura a laser. (b) Ilustração do bloqueio das fluorescências fora de foco realizada pelo pinhole, nesta figura os espelhos de varredura foram omitidos para facilitar a visualização da imagem. Adaptado de (HIBBS, 2004).

Utilizamos neste trabalho o microscópio confocal de fluorescência de varredura a laser LSM 780 da marca Zeiss para obter imagens dos filmes de PFO, tanto sobre o quartzo, quanto sobre as nanopartículas de $\mathrm{TiO}_{2}$. Com isso foi possível investigar a qualidade dos filmes ultrafinos sobre o quartzo bem como as propriedades ópticas na interface $\mathrm{PFO} / \mathrm{TiO}_{2}$. Neste trabalho foi utilizado o laser de diodo operando em $405 \mathrm{~nm}$ no regime $\mathrm{cw}$ (potência de $6 \mathrm{~mW}$ ) e pulsado (repetição de $20 \mathrm{MHz}$ ) e lente objetiva de 63X com imersão em água. O software para aquisição e tratamento das imagens foi o Zen 2010 Light Edition.

Este microscópio também contém um sistema de redes de difração acoplado próximo a um arranjo de 34 detectores (fotomultiplicadoras refrigeradas de $\mathrm{InGaP}$ ) que permite a 
obtenção de imagens nas quais cada ponto ou pixel da imagem corresponde a um espectro dentro da região de 400 a $750 \mathrm{~nm}$. Esses espectros podem ser combinados (superpostas) formando uma única imagem com a qual é possível medir a fotoluminescência ao longo da área da amostra. Este modo de operação do microscópio é denominado de modo espectral e as imagens são denominadas de imagens espectrais.

Ao contrário das imagens espectrais também é possível obter imagens obtidas a partir do sinal de decaimento da fluorescência dos cromóforos em uma área da amostra, neste caso, a técnica é denominada de FLIM (do inglês Fluorescence lifetime imaging microscopy). A partir das imagens FLIM é possível medir o tempo de decaimento por pixel da área da amostra sondada. Dois sensores de diodos de avalanche (canal 1 e canal 2) foram utilizados com resposta temporal em torno de 70 ns. O canal 1 mede o decaimento da emissão para comprimentos de ondas maiores que $490 \mathrm{~nm}$ e o canal 2 para comprimentos de ondas menores que $490 \mathrm{~nm}$.

\section{7 Ângulo de Contato}

As medidas de ângulo de contato são utilizadas para caracterização da superfície de materiais. Com essa técnica é possível obter informações sobre a hidrofilicidade e da tensão superficial. Nessa técnica utiliza-se uma câmera para capturar a imagem de uma gota de um líquido conhecido sobre uma superfície. Mede-se o ângulo de contato formado entre uma gota de um líquido e a superfície, como mostra a ilustração da Figura 3.8. O ângulo de contato (a forma da gota) depende do material da gota, da superfície na qual ela está em contato e do ar em torno dela.

As tensões interfaciais na qual esse sistema está sujeito são descritas pela equação de Young (TADMOR, 2004),

$$
\gamma_{S L}+\gamma \cos \left(\theta_{0}\right)=\gamma_{S V}
$$

onde $\gamma_{S L}$ é a tensão interfacial entre o líquido e o sólido (o filme), $\gamma$ é a tensão interfacial entre o líquido e o ar (ou vapor), $\gamma_{S V}$ é a tensão interfacial entre o sólido e o ar (ou vapor) e $\theta_{0}$ é o ângulo de contato de equilíbrio que a gota faz com a superfície. No presente trabalho as medidas de ângulo de contato foram utilizadas para caracterizar as superfícies dos filmes de PFO com diferentes espessuras. 


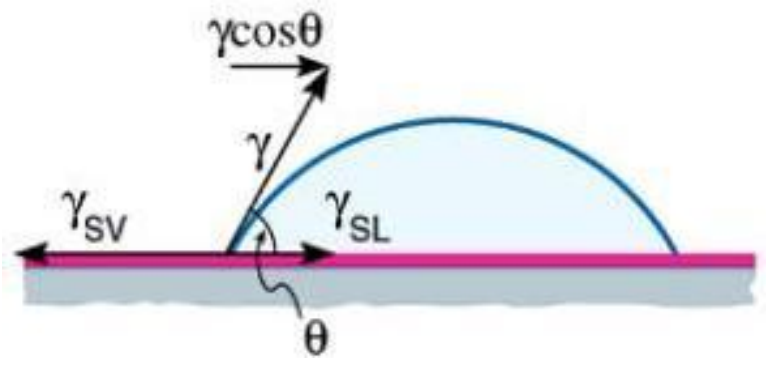

Figura 3.8: Ilustração bidimensional de uma gota sobre uma superfície e as tensões interfaciais em equilíbrio no eixo horizontal que resultam na equação de Young (TADMOR, 2004).

\subsection{Microscopia de Força Atômica}

A microscopia de força atômica (Atomic Force Microscope - AFM) é utilizada para estudar as propriedades superficiais (topográfica) de materiais sólidos, tais como, de filmes poliméricos. Além disso, é possível medir a espessura de filmes poliméricos avaliando a profundidade de um corte feito no filme. O corte no filme é obtido retirando uma pequena quantidade do material do substrato através de um risco que é feito no filme utilizando um material pontiagudo como, por exemplo, uma ponta de prova de AFM.

A técnica AFM baseia-se na varredura da superfície da amostra realizada por uma ponta de prova (com diâmetro em torno de $10 \mathrm{~nm}$ ). A varredura é monitorada por um sistema óptico como ilustrado na Figura 3.9. O feixe de laser é refletido pela parte traseira do "cantilever" e é direcionado para um fotodetector. Devido a diferentes forças de interação entre a ponta de prova e os átomos da superfície da amostra o "cantilever" pode sofrer desvios mudando o ângulo de reflexão do feixe de laser e, consequentemente, os pontos de incidência no fotodetector. Com isso é produzida uma imagem da topologia da superfície do material com a qual é possível obter informações da superfície.

No presente trabalho a técnica de AFM foi utilizada para caracterizar a superfície dos filmes de PFO. O parâmetro utilizado para avaliar a rugosidade foi o desvio padrão em relação a uma altura média $(\mathrm{Rq})$. Para medir as espessuras dos filmes foi utilizada uma ponta de prova de AFM para fazer o corte nos filmes. O software empregado nas análises das imagens foi o NanoScope Analysis. 


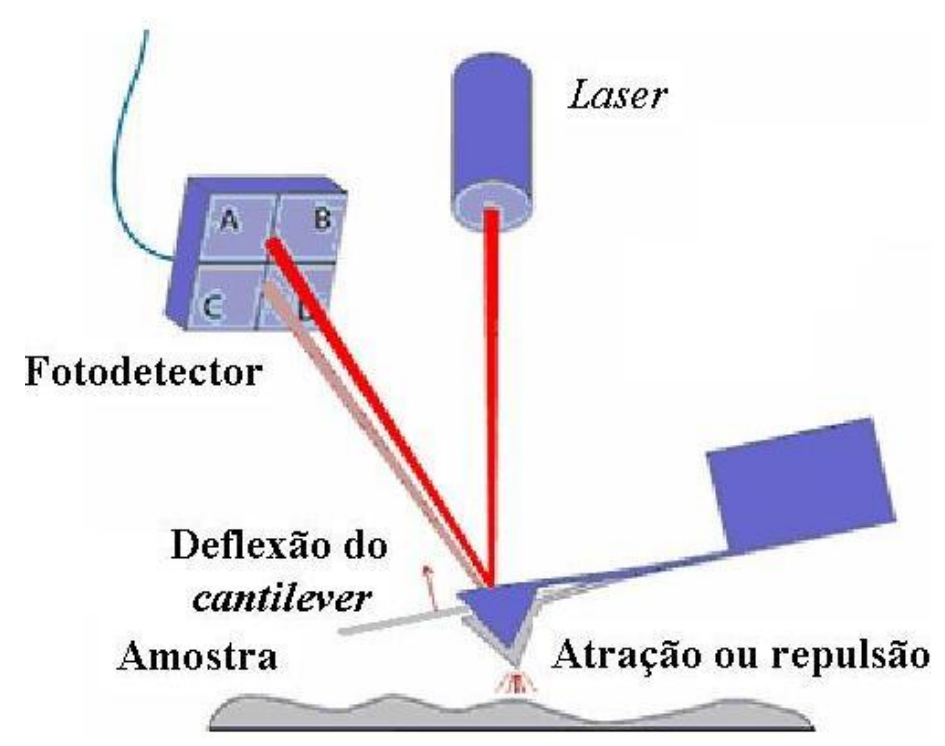

Figura 3.9: Ilustração do funcionamento básico da técnica AFM (BORGES, 2005). 


\section{Capítulo 4 - Resultados e Discussão}

\section{RESULTADOS E DISCUSSÃO}

\subsection{Caracterização espectroscópica de filmes de PFO amorfo}

Semicondutores orgânicos apresentam características únicas que incluem processabilidade em solução e sintonia da lacuna de energia ao variar sua estrutura química, que os torna atrativos para aplicação em dispositivos optoeletrônicos. Além disso, filmes de polifluorenos em especial apresentam emissão eficiente no azul e podem possuir diferentes estruturas moleculares tais como estrutura amorfa, estruturas cristalinas (cristal líquido) e a fase $\beta$. Esta última característica será discutida na próxima seção. A absorção e a emissão na região do ultravioleta próximo e no azul observada em filmes de PFO são justificadas pelo fato de que os anéis se encontram girados em forma de hélice ao longo da cadeia (SRIWICHITKAMOL, et al. 2006) e isso quebra a conjugação entre os monômeros. Estes filmes são denominados desordenados em relação as estruturas ordenadas (cristalinas e fase $\beta$ ). Sabe-se que filmes de PFO produzidos a partir de uma solução de PFO diluído em clorofórmio possui uma estrutura molecular totalmente amorfa denominada na literatura de vítrea (ARIU, et al. 2002; ARIU, et al. 2003). Esta primeira seção trata principalmente da caracterização espectroscópica de filmes de PFO amorfos preparados pela técnica spincoating utilizando o solvendo clorofórmio.

A Figura 4.1 mostra o espectro de absorção de um filme de PFO amorfo. As setas mostram as energias associadas a transições ópticas do polímero. A estrutura química de um monômero é também mostrada no detalhe da Fig.4.1. O filme de PFO absorve a radiação entre 2 e 6,50 eV, cinco picos são identificados neste espectro e estão localizados em 3,18 eV, 4,24 eV, 5,74 eV e 6,30 eV.

$\mathrm{O}$ pico em 3,18 eV é identificado como sendo resultado da transição entre os estados eletrônicos não localizados fundamental $\pi\left(S_{0}\right)$ e o primeiro estado excitado $\pi^{*}\left(\mathrm{~S}_{1}\right)$. O éxciton gerado nesta transição corresponde a um estado fracamente ligado e pode ser tratado como sendo um éxciton de Wannier-Mott unidimensional (KIROVA, et al. 1999; BARFORD, 2005).

Já o pico de menor intensidade em 4,24 eV é proveniente de uma transição eletrônica envolvendo estados localizados e não localizados. O segundo pico mais intenso, em 5,74 eV é devido a transições entre os estados eletrônicos localizados. E por fim o pico em 6,23 eV é resultado da transição entre o estado fundamental $S_{0}$ e o segundo estado excitado eletrônico não localizado (KIROVA, 1999). 


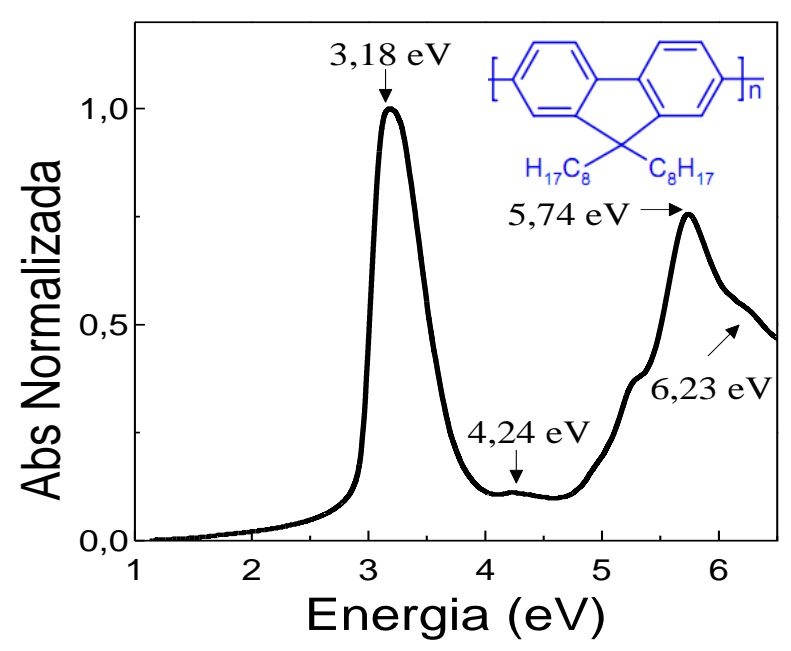

Figura 4.1: (a) Espectro de absorção de um filme de PFO amorfo (espessura de $41 \mathrm{~nm}$ ) e no canto superior direito a estrutura química de um mero do PFO.

Estamos interessados nas propriedades ópticas do PFO resultante das transições entre os estados eletrônicos não localizados $\left(S_{0}-S_{1}\right)$, portanto, para as próximas análises serão consideradas somente a região do espectro eletromagnético próximo ao visível. Além disso, os espectros serão apresentados em termos do comprimento de onda e, ocasionalmente, em termos da energia.

A Figura 4.2 mostra os espectros de absorção e de fotoluminescência (PL) de um filme de PFO com espessura de $41 \mathrm{~nm}$ medidos a temperatura ambiente. A banda de absorção entre estados conjugados entre $300 \mathrm{~nm}$ a $425 \mathrm{~nm}$ é larga e não estruturada, com máximo em 390 nm. Para polímeros conjugados, a banda larga de absorção a 297 K é resultado da superposição de estados vibracionais devido ao acoplamento elétron-fônon forte nesses materiais e pela desordem energética promovida pelas interações intermoleculares e pelos diversos segmentos conjugados com diferentes tamanhos que participam da absorção (YU et al., 1995).

O espectro de luminescência (PL) a $297 \mathrm{~K}$ apresenta estruturas vibracionais com três picos bem resolvidos (círculos abertos). Como será discutido em detalhes mais adiante, o pico mais intenso em $421 \mathrm{~nm}$ é atribuído à transição puramente eletrônica (ou de fônon zero) entre o estado excitado $S_{1}{ }^{*}$ de mais baixa energia e o estado fundamental $S_{0}(0-0)$, enquanto que os outros dois picos em $447 \mathrm{~nm}$ e em $481 \mathrm{~nm}$ correspondem a transições do mesmo estado excitado para níveis vibracionais envolvendo a energia de um fônon (0-1) e de dois fônons (02). A largura da emissão de zero fônon é de praticamente $20 \mathrm{~nm}(80 \mathrm{meV})$ e é a contribuição de um alargamento homogêneo térmico a $297 \mathrm{~K}$ e de um alargamento devido a perturbações produzidos pelas interações entre cadeias. 
A Figura 4.2 apresenta também um ajuste (linha vermelha) do espectro de emissão que é descrito pela superposição das três contribuições vibracionais (picos hachurados em magenta) e outra emissão larga de baixa energia centrada em $507 \mathrm{~nm}$ (banda hachurada em verde). Ainda existem muitas discussões e controvérsias na literatura a respeito da origem desta emissão que é típica de polifluorenos e é normalmente chamada de "banda verde" (SIMS, et al. 2004; ROMANER, et al. 2003; LIST, et al. 2002).

É interessante notar que a contribuição somente das estruturas vibracionais (linha magenta) para o espectro total possui forma e largura de linha semelhante ao apresentado pelo espectro de absorção. Isto indica que todos os estados acessados pela excitação na absorção óptica são praticamente os mesmos que participam da emissão, ou seja, o PFO estudado aqui possui uma distribuição estreita de estados conjugados. Isto é uma característica única deste material, pois o tamanho de conjugação médio é pequeno formado por poucos meros devido à rotação dos anéis aromáticos na forma de hélice ao longo da cadeia à temperatura ambiente.

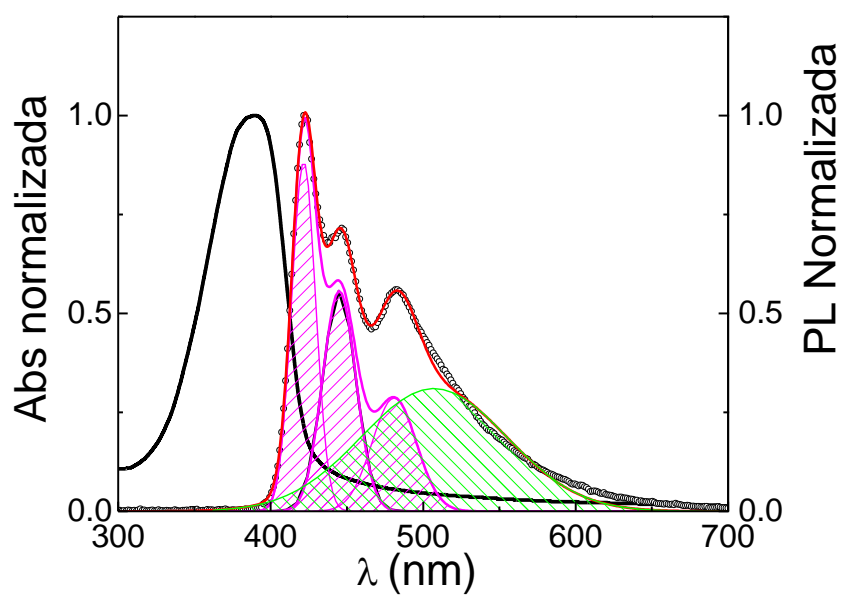

Figura 4.2: Espectro de absorção e fotoluminescência do filme de PFO (41 nm) medidos a temperatura ambiente. Na medida de fotoluminescência a amostra foi excitada em $325 \mathrm{~nm}$ utilizando laser de $\mathrm{He}-\mathrm{Cd}$.

Também na Figura 4.2 é observado um deslocamento de $31 \mathrm{~nm}(230 \mathrm{meV})$ do pico da transição 0-0, para regiões de menor energia, em relação ao máximo de absorção em $390 \mathrm{~nm}$. Isso é resultado da combinação da variação energética devido à conformação de menor energia assumida pelo estado excitado e da migração do éxciton que leva ao decaimento radiativo em sítios de menor energia. A relaxação conformacional da cadeia gera um pequeno deslocamento da emissão conhecido também como deslocamento Stokes. Este processo intramolecular não deve ser confundido com a conversão interna que corresponde à relaxação energética rápida que ocorre entre estados vibracionais com uma taxa da ordem de $10^{12} \mathrm{~s}^{-1}$. Já 
a migração do éxciton é um processo intermolecular que resulta da transferência de energia entre os segmentos conjugados. O éxciton migra, por meio de saltos aleatórios, de segmentos de menor tamanho de conjugação de alta densidade para segmentos de maior comprimento de conjugação de baixa densidade. Este processo é conhecido como difusão espectral. Assim, o deslocamento observado de $31 \mathrm{~nm}$ entre o máximo da banda de absorção e a linha de zero fônon da emissão é produzido principalmente pela difusão espectral.

A fim de investigar a dinâmica do estado excitado no filme de PFO amorfo, foram realizadas medidas de fotoluminescência para algumas temperaturas selecionadas entre 5 e 297 K. Estes resultados são apresentados na Figura 4.3. Nota-se que há um aumento da intensidade espectral conforme a temperatura é reduzida. Por exemplo, a $5 \mathrm{~K}$ a intensidade do pico da transição 0-0 é aproximadamente três vezes maior do que a mesma emissão em temperatura ambiente. A largura a meia altura $(\Gamma)$ da transição 0-0 diminui com a redução da temperatura e os picos passam a ser mais resolvidos. Além disso, há um deslocamento espectral de $7 \mathrm{~nm}$ para o vermelho da temperatura ambiente para $5 \mathrm{~K}$. A $5 \mathrm{~K}$ quatro picos estão localizados em 426 nm, 454 nm, 487 nm e 517 nm e correspondem à transições de fônon zero (0-0) e de fônons de ordem superior (0-1), (0-2) e (0-3), respectivamente. Por fim, observa-se uma mudança no acoplamente elétron-fônon dado pelo parâmetro de Huang-Rhys $(S)$ que pode ser avaliado, em primeira aproximação, pela razão $I_{0-1} / I_{0-0}$ entre as intensidades dos picos (0-1) e (0-0).

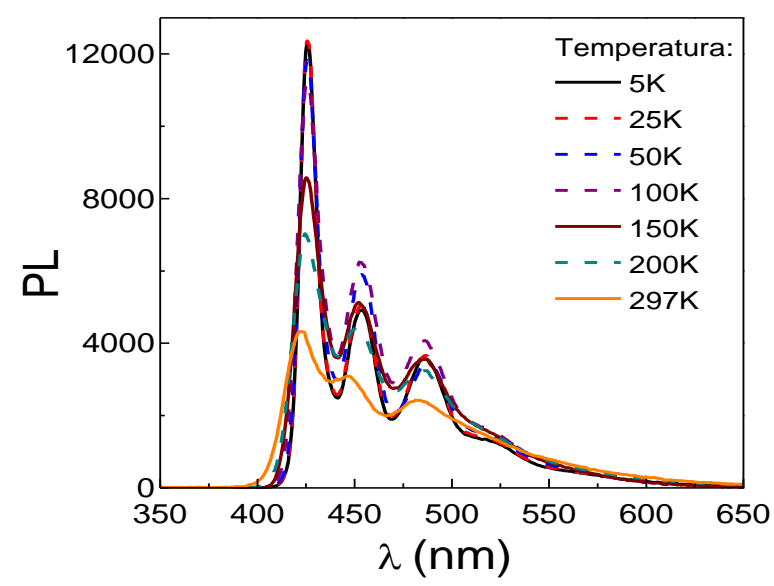

Figura 4.3: Espectro de fotoluminescência do filme de PFO (41 $\mathrm{nm})$ medidos em diferentes temperaturas. Excitação em 325 nm utilizando laser de He-Cd.

As mudanças espectrais com a temperatura da PL do PFO amorfo descritas acima são melhores visualizados na Figura 4.4 através da (a) da intensidade da PL normalizada com a intensidade quando $T \approx 0 \mathrm{~K}\left(I_{0}\right)$, (b) da largura a meia altura da transição $(0-0)$ em elétron- 
volts, (c) da posição energética do pico da transição 0-0 e (d) do parâmetro $S$. A largura a meia altura foi obtida através de um ajuste gaussiano da transição 0-0. As curvas contínuas vermelhas referem-se ao ajuste por meio das funções mostradas no detalhe de cada figura.
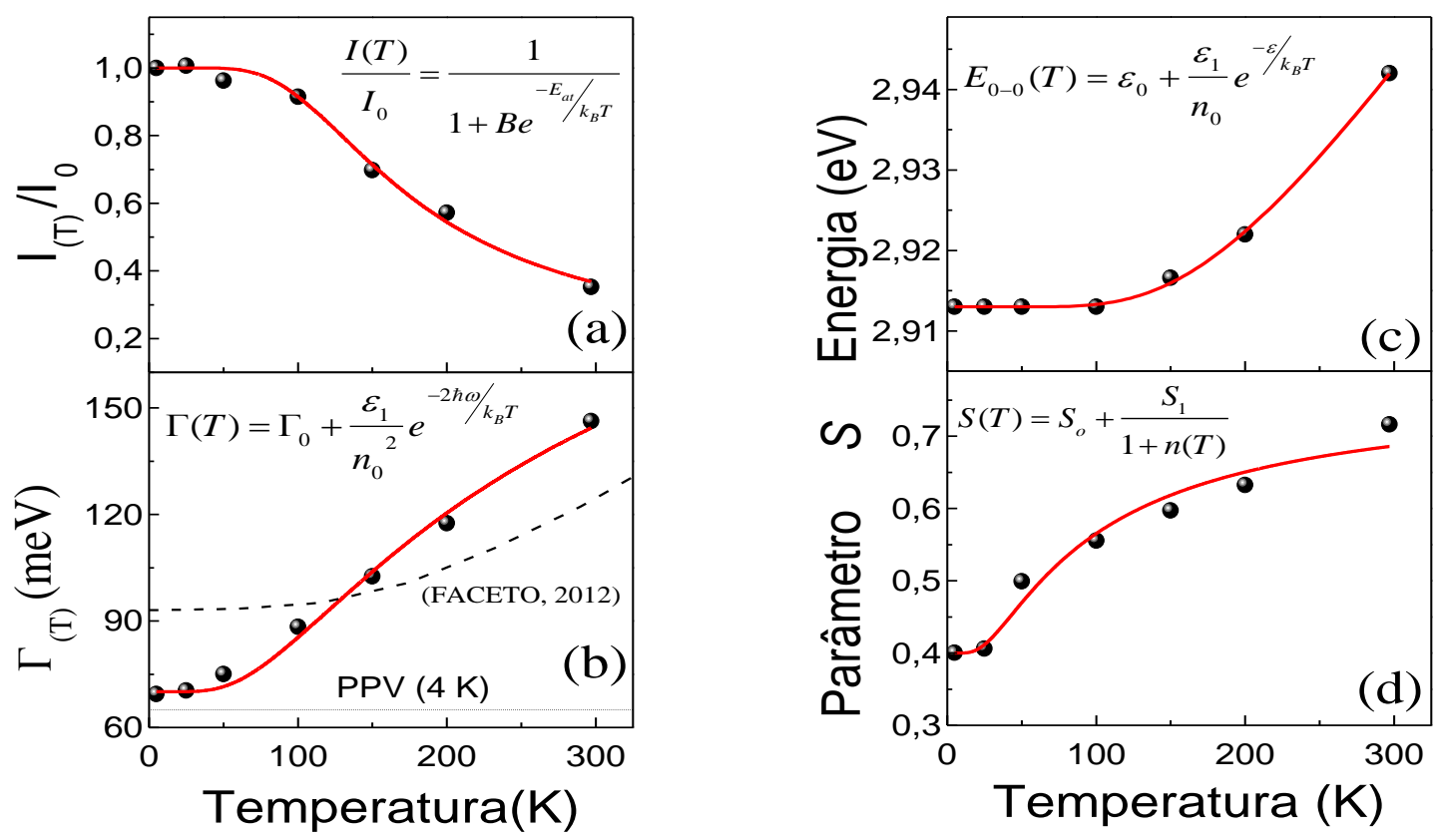

Figura 4.4: (a) Intensidade normalizada, (b) largura a meia altura da transição 0-0, (c) posição energética do pico da transição 0-0 e (d) fator $S$. Em (a), (b), (c) e (d) a linha vermelha é o ajuste dos dados experimentais com a equação em destaque na figura.

A intensidade da transição 0-0 aumenta continuamente com o decréscimo da temperatura até atingir um patamar para temperaturas menores que $80 \mathrm{~K}$ conforme é apresentado na Figura 4.4(a). Este comportamento segue uma curva tipo de Arrhenius, uma vez que a intensidade de emissão é proporcional à eficiência quântica $\eta$ que é uma função da temperatura dada por,

$$
\eta(T)=\frac{k_{r}}{k_{r}+k_{n r}}=\frac{1}{1+k_{n r} / k_{r}},
$$

onde $k_{r}$ é a taxa radiativa e $k_{n r}(T)=k_{o} e^{-E_{a t} / k_{B} T}$ é a taxa de algum processo não radiativo que é ativado com a temperatura a partir da temperatura $E_{a t} / k_{B}$, sendo $k_{B}$ a constante de Boltzmann, $E_{a t}$ é a energia de ativação e $k_{o}$ a taxa não radiativa a $0 \mathrm{~K}$. Processos não radiativos em materiais poliméricos são basicamente defeitos na cadeia, tais como o radical carbonila que é gerado através de fotooxidação (GOBATO et al., 2002) e/ou impurezas. Estes centros desativam o éxciton em suas mediações através da captura (transferências de carga) do elétron 
ou buraco por serem eletropositivos ou eletronegativos, respectivamente. No entanto, presença de um centro supressor dentro do raio de migração do éxciton aumenta em muito a probabilidade desse processo de desativação da emissão.

Comportamento semelhante ao da Figura 4.4(a) foi observado por Ariu (et al., 2002) para a eficiência quântica de fluorescência de filmes de PFO amorfo. Segundo estes autores isso ocorre porque em baixas temperaturas o volume de interação do éxciton na amostra é reduzido, ou seja, é pouco provável que o éxciton fotogerado possa interagir com defeitos ou armadilhas não radioativas (canais não radiativos), tais como, segmentos de polímeros oxidados, "trapped charges" e etc. Atribuímos que esta mesma redução da interação do éxciton com canais não radiativos é a responsável pelo aumento da intensidade da transição 00 quando a temperatura diminui.

Estudos recentes da migração do éxciton em sistemas desordenados como polímeros emissores de luz por meio de simulação Monte Carlo e da resolução da equação mestre (FACETO, 2012) mostra que o seu raio de difusão diminui duas vezes com o decréscimo da temperatura de $297 \mathrm{~K}$ para $5 \mathrm{~K}$. Isto significa que o volume de difusão é 8 vezes menor a $0 \mathrm{~K}$ do que a temperatura ambiente e, assim, diminui a probabilidade do éxciton ser extinto por um centro não radiativo. $\mathrm{O}$ melhor ajuste da intensidade da PL em função da temperatura através da equação em detalhe na figura ocorre para energia de ativação $E_{a t}$ igual a $(38 \pm 3)$ meV e a constante $B=k_{o} / k_{r}=(8 \pm 1)$. Como é esperado, $k_{o}$ é aproximadamente 8 vezes maior que a taxa radiativa, o que confere uma alta eficiência de aniquilamento para os defeitos que estão atuando no PFO. Em outras palavras, nas condições de produção de filmes ultrafinos adotadas no presente trabalho a eficiência quântica $\eta$ estimada para o PFO é da ordem de $10 \%$ a temperaturas de $297 \mathrm{~K}$. Eficiência quântica de aproximadamente $50 \%$ à temperatura ambiente foi obtida por Ariu (et al. 2002) para filmes com espessuras da ordem de micrometros. Nossos dados mostram que esta eficiência diminui 3 vezes com o aumento da temperatura de $5 \mathrm{~K}$ até a temperatura ambiente, isso é resultado da ativação térmica da migração. A migração é mais eficiente quando o éxciton ocupa estados de mais alta densidade (FACETO, 2012). Esta ativação, portanto, se refere ao fato do éxciton se manter mais tempo nessa região de alta densidade de estados pela ativação dada pelo fator $e^{-E_{a t} / k_{B} T}$. Assim, a ativação térmica passa a competir com os processos de relaxação interna mediada por fônons e com a transferência de energia, isto é, com a difusão espectral. Portanto, $E_{a t}$ deve ser a barreira energética que separa o estado eletrônico do éxciton a baixas temperaturas e estados 
energéticos virtuais de fônon de maior energia, para os quais a densidade de energia total é maior e a taxa de transferência de energia passa a ter valores competitivos com a relaxação interna para baixo e excitação térmica para cima.

Fônons com energia de $38 \mathrm{meV}\left(\lambda^{-1} \sim 300 \mathrm{~cm}^{-1}\right.$ ou $\left.\Theta=442 \mathrm{~K}\right)$ correspondem a modos transversais que envolvem variações do ângulo da ligação por dobra ou pela variação do ângulo entre anéis (torsão). É sabido pela experiência que a temperatura necessária para que a excitação térmica seja detectada é $T_{\mathrm{c}} \sim \Theta / 3$, onde $\Theta$ é a temperatura característica associada a um fônon (VETTEGREN, et al. 2009). Assim, $T_{\mathrm{c}} \sim 147 \mathrm{~K}$, o que está próxima de $100 \mathrm{~K}$ para qual a intensidade da PL começa a diminuir através da ativação da migração que leva aos centros não radiativos. Assim, a ativação térmica em sistemas desordenados é necessária para que o éxciton difunda durante o seu tempo de vida. Este processo de re-excitação térmica (para energias mais altas) é mediada por fônons transversais de baixa energia. Em primeira instância, portanto, a migração do éxciton precisa ser ativada termicamente para que ele alcance os estados defeitos.

A Figura 4.5 ilustra bem de forma esquemática esses conceitos. No final da difusão espectral as taxas de transferência de energia caem devido à baixa densidade de estados (DOS). A baixas temperaturas (T 0), porém, o éxciton alcança estados emissivos isolados (emissão 3) que representam um mínimo local (de maior energia), e não um mínimo absoluto, da distribuição de estados (DOS). A temperaturas intermediárias $\left(0<\mathrm{T}<\mathrm{T}_{\mathrm{C}}\right)$, o éxciton pode ser re-excitado termicamente e se transferir para outro mínimo local (emissão 2), mas a energia térmica não é suficiente para ativar a migração. Dizemos que a migração é frustrada a baixas temperaturas (FACETO, 2012; HOFFMANN et al., 2010). Para $\mathrm{T}>\mathrm{T}_{\mathrm{C}}$, o éxciton pode obter energia suficiente para alcançar estados excitados que estão acoplados por processos de transferência de energia. Nessa situação a migração é ativada e o éxciton pode alcançar estados de menor energia (tamanho de conjugação alto) que representam um mínimo absoluto da DOS para uma dada temperatura em que o éxciton se encontra e então emitir (emissão 1). Desta forma o éxciton acessa estados menos afetados pela desordem (maior conjugação e menor energia). 


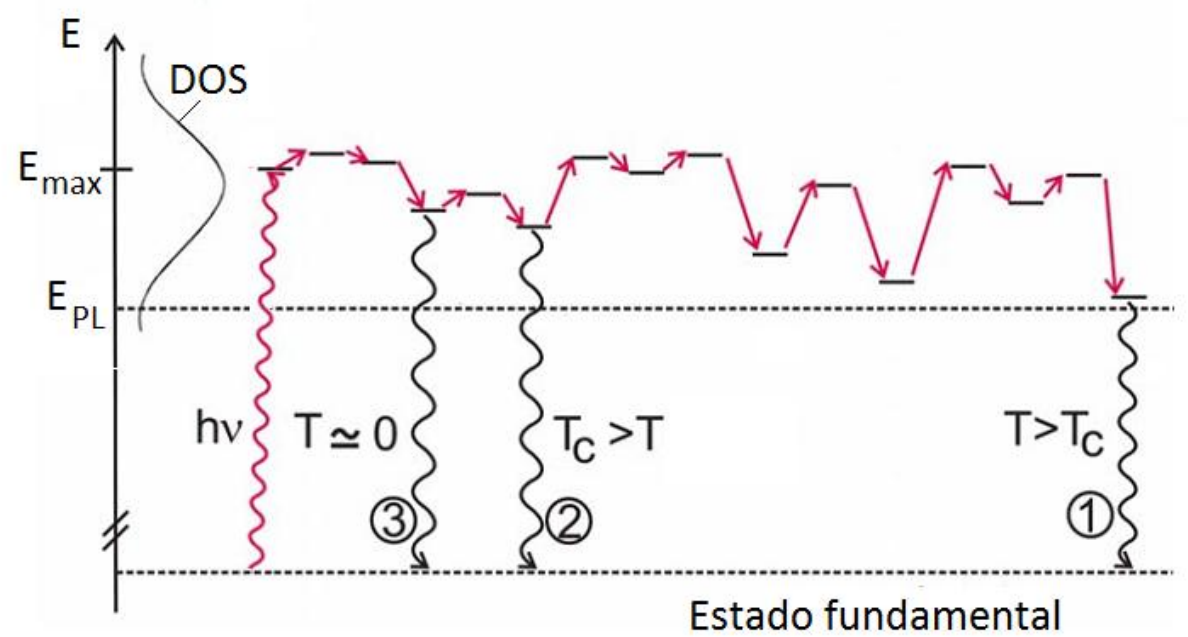

Figura 4.5: Ilustração da difusão espectral em diferentes temperaturas. DOS é a densidade de estados, $\mathrm{E}_{\max }$ a energia máxima da DOS e $\mathrm{E}_{\mathrm{PL}}$ a energia final de emissão. Adaptado de (HOFFMANN et al., 2010).

Este resultado é de fundamental importância para aplicações deste material como emissor de luz, ou seja, materiais poliméricos amorfos devem ser livres de defeitos ou impurezas para serem usados como material emissor eficiente a temperatura ambiente. Como será discutido na seção 4.2, se existir um defeito por volume de migração (um segmento com defeito em $4,2 \times 10^{3}$ moléculas, veja seção 4.2), então a concentração de segmentos conjugados com defeitos (incluindo impurezas) é da ordem de $0,005 \%$ na matriz polimérica.

Fica claro, portanto, que o estado final emissivo alcançado pelo éxciton depende da migração. A intensidade da luminescência traz informações sobre os processos não radiativos que atuam ao longo de toda a difusão espectral e que concorrem com o processo radiativo final do éxciton. Já a posição e a largura do espectro de emissão contêm informações únicas dos níveis de energia finais alcançados após a migração e também da ocupação dos mesmos no momento do processo radiativo. Assim, a largura (Figura 4.4(b)) e posição (Figura 4.4(c)) da linha de emissão do PFO amorfo é uma medida direta do grau de desordem desse material, seja ela estrutural extrínseca ou de origem térmica intrínseca (quebra de conjugação, por exemplo).

Portanto, a largura da emissão reflete, primeiramente, efeitos da desordem energética dos poucos estados emissivos na cauda de baixa energia da DOS alcançados pelo éxciton após o término da difusão espectral. Esta largura independe da temperatura e é dada pela constante $\Gamma_{\mathrm{o}}$. Simulações de Monte Carlo e resolução da equação mestre realizados por Faceto (2012) em sistemas poliméricos desordenados mostram que a forma de linha final é do tipo 


\section{Capítulo 4 - Resultados e Discussão}

Gaussiana com largura da ordem de $90 \mathrm{meV}$ (linha tracejada na Figura 4.4(b)) próximas à 0 K. O segundo efeito é dada pela desordem térmica. A temperatura introduz efeitos de ocupação de estados vibracionais de alta energia dado pelo termo de Boltzmann $e^{-E / k_{B} T}$ e de ativação de vibrações térmicas moleculares, que por sua vez promove a quebra do tamanho de conjugação, principalmente, por meio de torções da cadeia. $\mathrm{O}$ alargamento dado pela ocupação térmica de estados de maior energia pelo éxciton é da ordem de $k_{\mathrm{B}} T=26 \mathrm{meV}$ à temperatura ambiente. Assim, o alargamento produzido pela ocupação térmica é desprezível a baixas temperaturas quando comparado com $\Gamma_{\mathrm{o}}$. A curva tracejada na Figura 4.4(b) foi calculada por Faceto (2012) considerando apenas o efeito da ocupação térmica e não é suficiente para explicar a variação da largura de linha entre 5 e 297 K. Portanto, a desordem introduzida pelas mudanças energéticas através da quebra de conjugação através das vibrações do esqueleto polimérico ativadas pela temperatura deve ser responsável por tal efeito.

Considerando a energia de um estado excitônico em um segmento polimérico de tamanho de conjugação $n$ descrita pela equação $E=\varepsilon_{0}+\varepsilon_{1} / n$, uma variação $\Delta$ n a uma dada temperatura $T$ introduz uma variação $\Delta E$ na sua energia dada em módulo por $|\Delta E|=\left[\varepsilon_{1} / n^{2}(T)\right] \Delta n=\Gamma_{1}(T) \Delta n$. Considerando o menor $\Delta \mathrm{n}=1$, a desordem energética introduz um alargamento homogêneo $\Gamma_{1}(T)$ proporcional ao inverso do quadrado do tamanho de conjugação e ao coeficiente $\varepsilon_{l}=1,7 \mathrm{eV}$ (SRIWICHITKAMOL et al., 2006). Assim, podemos assumir a ativação do processo vibracional (torções) que quebra a conjugação da cadeia através da expressão,

$$
n(T)=n_{0} e^{\hbar \omega / k_{B} T},
$$

onde $n_{o}$ é o tamanho de conjugação médio e $\hbar \omega$ é a energia para ativar o processo vibracional. Então, a largura de linha total é dada por,

$$
\Gamma(T)=\Gamma_{0}+\Gamma_{1}=\Gamma_{0}+\frac{\varepsilon_{1}}{n_{0}{ }^{2}} e^{-2 \hbar \omega / k_{B} T} .
$$

Esta expressão ajusta perfeitamente a dependência da largura de linha na faixa de temperatura entre 5 e 297 K. Para o PFO, a desordem estrutural contribui com um alargamento energético de $\Gamma_{\mathrm{o}}=71,5 \mathrm{meV}$ e um tamanho de conjugação efetivo dos segmentos conjugados $n_{0}=(4 \pm 1)$ muito pequeno, que é o esperado para o material amorfo devido às torções entre monômeros intrínsecas da cadeia. A energia de ativação de fônons transversais, 
necessária para uma quebra ainda maior da conjugação, é de $\hbar \omega=(10,8 \pm 0,5) m e V(\Theta \sim 125$ $\mathrm{K})$. Esta energia de $\approx 90 \mathrm{~cm}^{-1}$ corresponde a uma energia térmica mínima necessária para produzir mudanças conformacionais na cadeia polimérica. Pode-se notar o efeito da quebra de conjugação pode ser detectada para $\Theta / 3 \sim 42$ K (Figura 4.4(b)).

O deslocamento do pico da transição 0-0 com a temperatura apresenta o comportamento mostrado na Figura 4.4(c). Há um deslocamento de aproximadamente 29 meV para o vermelho quando a temperatura é reduzida de $297 \mathrm{~K}$ para $5 \mathrm{~K}$. Como no alargamento homogêneo apresentado acima, este deslocamento é atribuído a mudanças conformacionais ao longo da cadeia polimérica que promovem o aumento no comprimento da conjugação do polímero quando a temperatura diminui. Levando em conta as considerações apresentadas acima, a dependência da energia da transição 0-0 deve ser dada por $E(\mathrm{~T})=\varepsilon_{0}+\varepsilon_{1} / n(\mathrm{~T})$ ou seja,

$$
E_{0-0}(T)=\varepsilon_{0}+\frac{\varepsilon_{1}}{n_{0}} e^{-\hbar \omega / k_{B} T} .
$$

Para ajustar os dados experimentais utilizamos $\varepsilon_{0}=2,91 \mathrm{eV}$ que corresponde a energia da transição puramente eletrônica quando a temperatura tende a zero e novamente $\varepsilon_{1}=1,7 \mathrm{eV}$ obtido a partir da literatura como descrito na seção introdução teórica. Segundo o ajuste, a energia responsável pelas mudanças conformacionais é $\hbar \omega=(59 \pm 2) \mathrm{meV}$, esta energia está dentro do valor da barreira de rotação, igual a $74 \mathrm{meV}$, calculado para uma molécula de bifluoreno (SRIWICHITKAMOL et al., 2006). A temperatura associada a essa energia é de $\Theta \sim 690 \mathrm{~K}$ e $\Theta / 3 \sim 230 \mathrm{~K}$. Também, do ajuste temos que $n_{0}=(5,7 \pm 0,4)$.

A Figura 4.4(d) apresenta o comportamento do fator $S$ em função da temperatura. O fator $S$ é um parâmetro proporcional ao deslocamento relativo entre os mínimos das superfícies de energia potencial dos estados excitado e fundamental, caracterizando, portanto, a eficácia do acoplamento elétron-fônon (BORGES, 2001). Para moléculas pequenas, a promoção de um elétron do HOMO para o LUMO tem um grande efeito na ligação local e, consequentemente, na conformação molecular. Portanto, se espera um parâmetro Huang-Rhys grande em moléculas pequenas. Assim, o fator $S$ depende diretamente do tamanho dos segmentos conjugados e aumenta com o decréscimo de $n$. Na Figura 4.4(d), o aumento de $S$ com o aumento da temperatura é uma consequência da diminuição do tamanho de conjugação efetivo imposto pela desordem térmica aos segmentos conjugados do PFO. Uma relação empírica entre o fator Huang-Rhys $S$ e o tamanho de conjugação $n$ é conhecida na literatura (BORGES, 2001; HAGLER, et al. 1991; HEUN, et al. 1993). Estes autores sugerem a 
seguinte dependência para sistemas moleculares com grande tamanho de conjugação $(n>>1)$

$$
S(T)=S_{o}+\frac{S_{1}}{1+n(T)}
$$

onde $S_{\mathrm{o}}$ é o fator Huang-Rhys para $T=0 \mathrm{~K}, S_{1}$ é um parâmetro a ser determinado e $n(T)$ é dado pela eq. 6. A equação acima descreve bem a dependência de $S$ com a temperatura para o PPV (BORGES, 2001) com tamanho de conjugação $n_{0}=7$. Para o caso do PFO, a linha contínua vermelha descreve bem o comportamento de $S$ com a temperatura fixando $S_{0}=0,4$ e $n_{0}=5,7$. Os parâmetros ajustados foram $S_{1}=(2,6 \pm 0,3)$ e $\hbar \omega=(8 \pm 1) \mathrm{meV}$, que diferem bastante daqueles encontrados para o PPV (BORGES, 2001). Em temperatura próximas de $0 \mathrm{~K}$, valores de $S$ entre 0 e 0,5 indicam que o fator de Franck-Condon $\left(F_{(0, m)}\right)$ possui um valor máximo quando o estado vibracional for zero $(m=0)$, ou seja, a transição mais intensa é a puramente eletrônica. A $5 \mathrm{~K}$ o parâmetro de Hung-Rhys medido para o PFO é $S=0,4$, confirmando que a transição mais intensa (em $426 \mathrm{~nm}$ ) é puramente eletrônica.

A Figura 4.6 mostra a intensidade normalizada da PL do PFO amorfo medida a $5 \mathrm{~K} \mathrm{em}$ função da ordem do modo vibracional $(m=0,1,2,3,4 \ldots)$ envolvido na transição óptica. Como a intensidade do pico da PL $\left(P L_{O m}\right)$ é proporcional ao fator de Franck-Condon, os dados experimentais da Figura 4.6 podem ser ajustados utilizando a equação em destaque na Figura 4.6. Nessa equação o termo $A$ é uma constante de proporcionalidade que é adimensional. Do ajuste dos dados com essa equação temos que $A=(1,6 \pm 0,2)$ e $S=(0,5 \pm 0,2)$. Esse valor de $S$ obtido do ajuste, dentro do erro, se assemelha ao valor de 0,4 apresentado anteriormente.

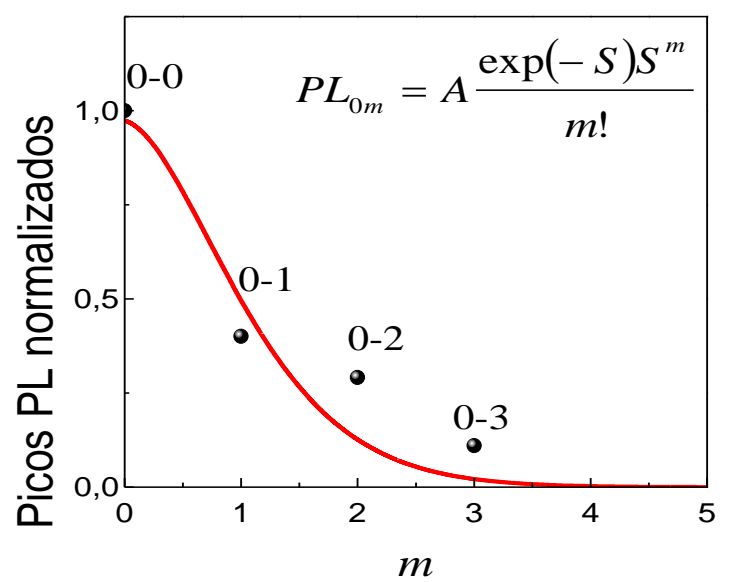

Figura 4.6: Intensidade normalizada dos picos da PL a $5 \mathrm{~K}$ em função dos modos vibracionais $m$. A linha vermelha é o ajuste dos dados utilizando apresentada no canto superior da figura.

A partir da PL medida a $5 \mathrm{~K}$ estimou-se os modos vibracionais e a energia de fônon. Esses resultados estão apresentados na Figura 4.7(a) que mostra o logaritmo da intensidade da 
PL a 5 K em função da energia da PL do filme de PFO, a escala logarítmica foi utilizada para evidenciar a estrutura vibracional da PL e a energia no eixo das abscissas para melhor identificar as transições. A diferença de energia entre a transição 0-0 (426 nm) e a 0-1 (454 $\mathrm{nm})$ é de $1452 \mathrm{~cm}^{-1}(0,18 \mathrm{eV})$, este valor corresponde a energia de fônon óptico. Já a diferença da energia entre a transição 0-2 (487 nm) e a 0-0 é de $2903 \mathrm{~cm}^{-1}(0,36 \mathrm{eV})$, ou seja, duas vezes a energia do fônon $\left(1452 \mathrm{~cm}^{-1}\right)$. Por fim, a diferença de energia entre transição 0-3 (517 nm) e a 0-0 é de 0,51 eV que é aproximadamente igual a três vezes a energia de fônon. Essa separação energética de $1452 \mathrm{~cm}^{-1}$ entre estas estruturas vibracionais corresponde a fônons localizados (não resolvidos) de maior acoplamento elétron-fônon que são associados ao estiramento de $\mathrm{C}$-C mais dobras (bending) do $\mathrm{CH}$ que ocorre no plano dos anéis aromáticos (MAIA, 2011).

Os resultados obtidos da caracterização espectroscópica do filme de PFO amorfo são resumidos na ilustração da Figura 4.7(b), que mostra a coordenada de configurações com o estado eletrônico fundamental singleto $\left(S_{0}\right)$, o primeiro estado eletrônico excitado $\left(S_{1}\right)$, as transições eletrônicas envolvidas na PL e a energia de fônon.

(a)

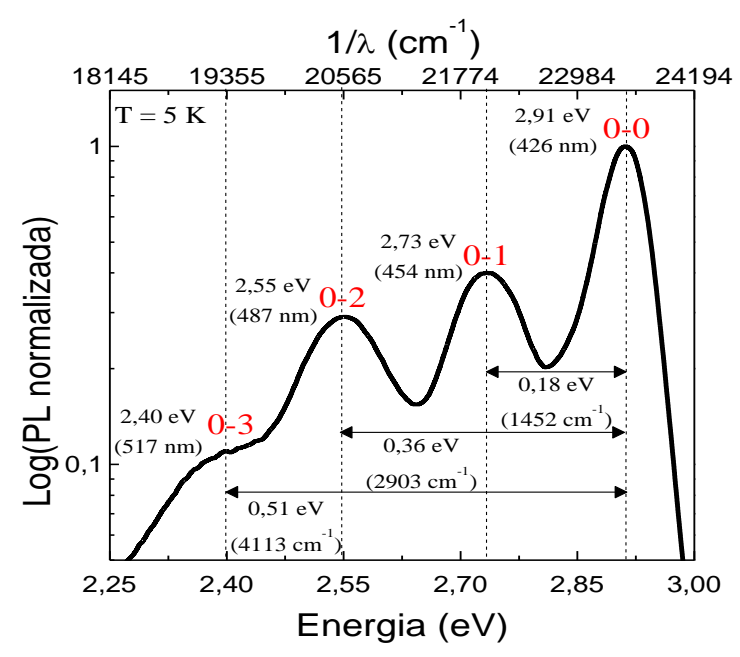

(b)

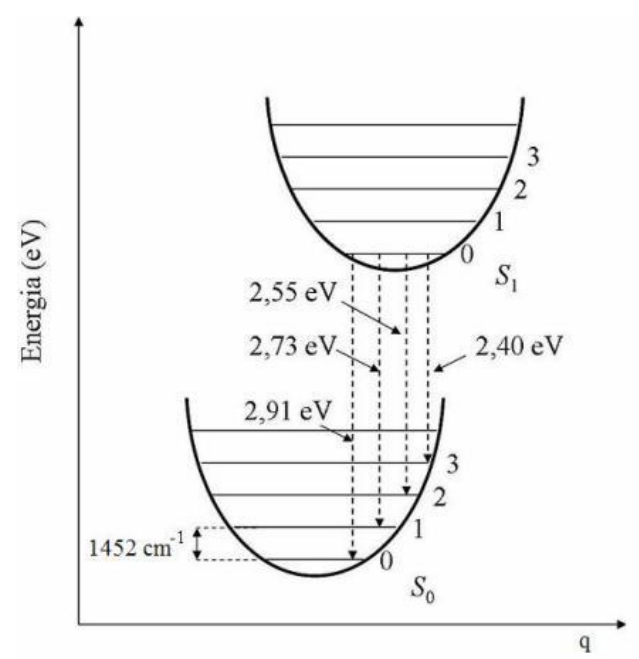

Figura 4.7: (a) PL do filme de PFO amorfo com a intensidade da PL na escala logarítmica em função da energia da emissão. Medida realizada a $5 \mathrm{~K}$, excitação em $325 \mathrm{~nm}$ utilizando laser de He-Cd. (b) Ilustração do diagrama de energia das transições eletrônicas envolvidas na PL ao longo da coordenada de configurações (q).

\subsection{Caracterização espectroscópica de filmes de PFO com fase $\beta$}

Em polifluorenos há dois tipos de organizações moleculares, uma intramolecular (não cristalino) e outra intermolecular (fase nemática e semicristalina). A fase nemática (cristal líquido) é produzida nos filmes amorfos através de tratamento térmico acima do ponto de 


\section{Capítulo 4 - Resultados e Discussão}

fusão (433 K) e bem abaixo da temperatura de decomposição térmica (CHEN et al., 2005). Já a estrutura cristalina é denominada de fase $\alpha$, possui uma estrutura ortorrômbica e se forma próximo a uma temperatura de cristalização igual a $403 \mathrm{~K}$ (CHEN et al., 2005).

O ordenamento intramolecular é resultado da organização dos monômeros ao longo da cadeia molecular, neste caso um monômero está rotacionado em $180^{\circ}$ em relação aos dois monômeros vizinhos (ver ilustração na Figura 4.8), estas regiões são conhecidas por fase $\beta$ (GRELL et al., 1999). Normalmente a fase $\beta$ é induzida em filmes de PFO amorfo através de um tratamento a vapor de tolueno ou por ciclos de esfriamento/aquecimento lentos entre temperaturas criogênicas e temperatura ambiente (ARIU et al., 2003; KAWAMURA et al., 2011; CHEN et al., 2005; GRELL et al.,1999). No entanto, sabe-se que a fase $\beta$ é uma fase metaestável, a partir de $353 \mathrm{~K}$ esta fase começa a se dissipar e em torno de $373 \mathrm{~K}$ a fase $\beta$ deixa de existir e não é recuperada após o resfriamento até a temperatura ambiente (CHEN et. al., 2005).

Estudos espectroscópicos mostram que em filmes de PFO contendo camadas de fase $\beta$ há a formação de uma banda em baixas energias e extremamente estreita, o que sugere que o alinhamento dos anéis se processa ao longo de toda a cadeia ou leva a formar segmentos conjugados grandes (alto grau de conjugação). Porém, ainda não se sabe se esta subestrutura ordenada leva a formação de uma superestrutura entre moléculas com a formação de domínios.

Em filmes de PFO contendo a fase $\beta$, o espectro de absorção é caracterizado por uma banda larga centrada em aproximadamente $390 \mathrm{~nm}$ que é atribuída à fase amorfa e uma banda estreita com pico em aproximadamente $435 \mathrm{~nm}$ que é atribuída a camadas de fase $\beta$. Esta absorção em regiões de maior comprimento de onda ocorre porque a fase $\beta$ possui maior comprimento de conjugação do que a fase amorfa e, portanto, menor gap de energia (ARIU et al., 2003).

Temos observado que ao se utilizar o PFO em solvente tolueno uma fração de camadas de fase $\beta$ já é induzida nos filmes spin-coating de PFO. Também há evidências da formação de fase $\beta$ em filmes de PFO produzidos utilizando o solvente ciclopentanona (KHAN et al., 2003). A Figura 4.8(a) mostra o espectro de absorção (linha contínua preta $A_{\beta}$ ) de filme de PFO de espessura de $41 \mathrm{~nm}$ produzidos utilizando o solvente tolueno na concentração 0,6 g/L. Como esperado pode ser observado nessa figura, o espectro de absorção possui uma banda larga de absorção centrada em torno de $390 \mathrm{~nm}$ associada à região amorfa e uma banda estreita centrada em aproximadamente $435 \mathrm{~nm}$ que é atribuída à fase $\beta$. 
Para confirmar se o pico em $435 \mathrm{~nm}$ é realmente da fase $\beta$, a Figura. 4.7(a) também mostra o espectro de absorção do mesmo filme de PFO, produzido com solução de tolueno, após um tratamento térmico à vácuo realizado a $403 \mathrm{~K}$ por $1 \mathrm{~h}$ (linha pontilhada vermelha $\mathrm{A}$ ). Este filme foi resfriado lentamente, no vácuo, até a temperatura ambiente. O tempo de resfriamento de aproximadamente $12 \mathrm{~h}$. Com isso, nota-se que a banda de absorção associada à fase $\beta$ em $435 \mathrm{~nm}$ desaparece, o que confirma a presença desta fase nos filmes spin-coating de PFO preparados com solução de tolueno no presente trabalho.

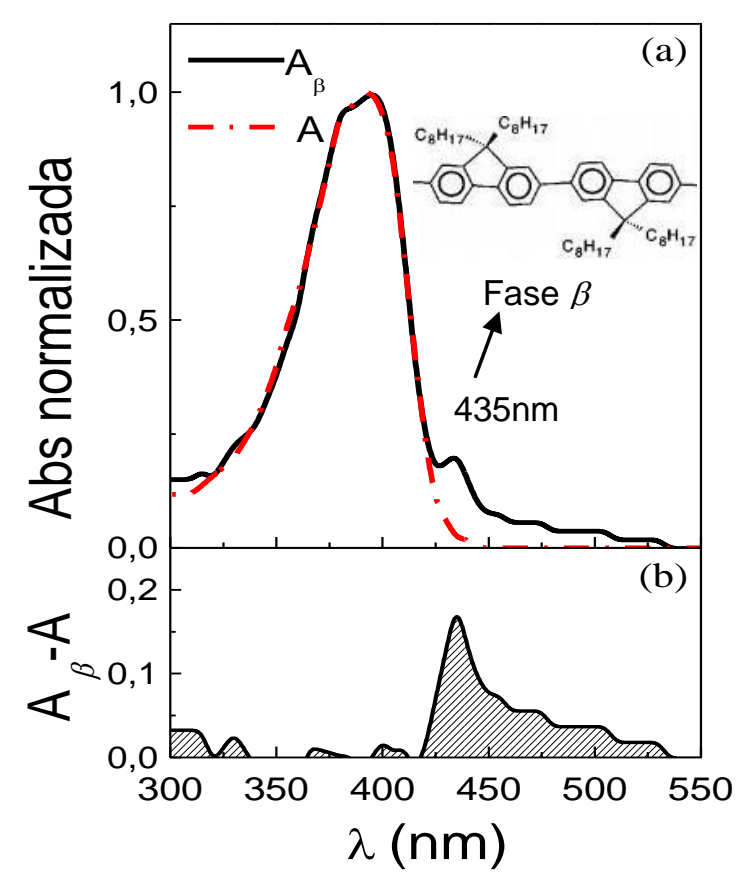

Figura 4.8: (a) Espectros de absorção normalizados do filme de PFO contendo a fase $\beta$ (linha preta contínua $\mathrm{A}_{\beta}$ ) e do mesmo filme após tratamento térmico (linha vermelha pontilhada $\mathrm{A}$ ). (b) Diferença entre os espectros de absorção $\mathrm{A}_{\beta}$ e A da Figura 4.8(a).

Para estimar a fração de fase $\beta$ presente no filme adotamos o procedimento utilizado por Ariu (et al., 2003). Esse procedimento consiste em comparar a área do espectro de absorção de um filme contendo apenas a fase amorfa (A) com outro que possui a fase $\beta$ embebida na fase amorfa $\left(\mathrm{A}_{\beta}\right)$. Para isso, deve-se considerar que as moléculas de PFO da região amorfa e as moléculas da fase $\beta$ possuem forças de oscilador similares. $\mathrm{O}$ espectro de absorção somente das camadas de fase $\beta$ foi obtido fazendo a diferença entre os espectros de absorção mostrados na Figura 4.8(a), ou seja, $\mathrm{A}_{\beta}-\mathrm{A}$. Este espectro está apresentado na Figura 4.8(b). Tomando a razão das áreas da absorção entre o filme contendo somente a fase $\beta$ e o filme contendo a fase $\beta\left(\mathrm{A}_{\beta}\right)$, temos que a porcentagem de camada de fase $\beta$ presente no filme 
é de aproximadamente $8,6 \%$.

A vantagem em utilizar o PFO diluído em tolueno para fazer o filme é que a fase $\beta$ é induzida nestes filmes sem a necessidade de tratamento a vapor de tolueno. Por outro lado, quando se utiliza este último procedimento, é possível controlar a quantidade de fase $\beta$ através do tempo de exposição do filme ao vapor de tolueno. A princípio, o controle da fração de fase $\beta$ não é possível de ser realizado nos filmes produzidos diretamente por spin-coating a partir do PFO diluído em tolueno. Assim, por questão de simplicidade, nesta seção referências aos filmes de PFO contendo a fase $\beta$ devem ser entendidas como aqueles produzidos a partir de uma solução de PFO em tolueno.

Em relação às modificações estruturais discutidas acima, medidas de luminescência fornecem informações complementares às medidas de absorção apresentadas acima. A Figura 4.9 compara espectros de PL e de absorção (linhas contínuas vermelha e preta, respectivamente) à temperatura ambiente do filme de PFO contendo a fase $\beta$. Os mesmos espectros da fase amorfa (linhas pontilhadas) foram colocados para efeito de comparação. É interessante notar que picos bem resolvidos aparecem localizados em 439 nm, $467 \mathrm{~nm}$ e 496 nm para a amostra contendo a fase $\beta$. Além disso, nessa mesma amostra há uma emissão pouco intensa em torno de $424 \mathrm{~nm}$.

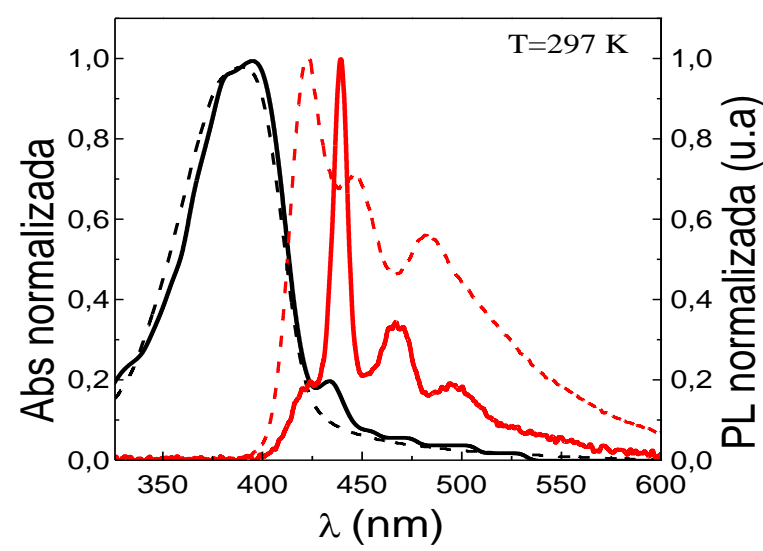

Figura 4.9: Espectro de absorção e fotoluminescência do filme de PFO contendo a fase $\beta$ medidos a temperatura ambiente. Na medida de fotoluminescência a amostra foi excitada em $325 \mathrm{~nm}$ utilizando laser de He-Cd.

Para melhor identificar as transições envolvidas na PL, a Figura 4.10(a) compara a fotoluminescência do filme contendo a fase $\beta$ com a de um filme totalmente amorfo medidos a 5 K. Como vimos na seção anterior, as linhas de emissão se estreitam consideravelmente a temperaturas criogênicas de He-líquido, produzindo mudanças consideráveis na PL para as 
duas amostras quando a temperatura é reduzida. A figura mostra também ajustes gaussianos de forma de linha da amostra contendo fase $\beta$ de seis picos visando melhor a identificação dos mesmos. Três conjuntos distintos de emissões podem ser identificas a partir deste ajuste.

$\mathrm{O}$ primeiro conjunto é associado às transições largas e de baixa intensidade (gaussianas hachuradas em azul) que têm contribuições mais importantes nas linhas de fônon zero (0-0) e de fônon de ordem um (0-1) localizadas em $426 \mathrm{~nm}$ e $457 \mathrm{~nm}$, respectivamente. Estes comprimentos de onda correspondem a aqueles do PFO amorfo (linha preta na Figura 4.10(a)), ficando evidente que estas emissões no filme contendo fase $\beta$ são provenientes da região amorfa do material.

O segundo conjunto de mais baixa energia é associado a transições estreitas e de alta intensidade (gaussianas hachuradas em magenta) que correspondem a uma linha de zero fônon (0-0) localizada em $443 \mathrm{~nm}$ e de duas linhas próximas em $471 \mathrm{~nm}$ e $477 \mathrm{~nm}$ e bem resolvidas associadas a fônons de ordem um (0-1) de energias distintas. As energias de fônons foram calculadas através do ajuste e a partir da distância energética entre a transição (0-1) e a transição (0-0). Estas energias se correlacionam a 2 modos vibracionais longitudinais posicionados em $1371 \mathrm{~cm}^{-1}$, que se atribuem a estiramentos C-C e em $1613 \mathrm{~cm}^{-1}$ associado a estiramento simétrico da dupla ligação $\mathrm{C}=\mathrm{C}$ (MAIA, 2011). Este conjunto de emissões muito estreitas é característico de filmes que contém a fase $\beta$ ordenada (ARIU et al, 2003). Portanto, no sistema estudado no presente trabalho nos espectros de luminescência de filmes contendo a fase $\beta$ é possível identificar emissões originadas tanto na região amorfa e quanto em moléculas pertencentes à fase $\beta$. Mesmo que a fração da fase $\beta$ seja de $8,6 \%$, é interessante notar que a área da linha de zero fônon da fase $\beta$ é duas vezes maior que a área calculada para a emissão correspondente oriunda da região amorfa. Isso ocorre porque as moléculas da fase $\beta$ possuem maior comprimento de conjugação e, consequentemente, menor lacuna de energia HOMO-LUMO em relação às moléculas da região amorfa. Portanto, o éxciton excitado na região amorfa possui uma alta probabilidade de encontrar moléculas da região contendo fase $\beta$ dentro do seu raio de migração e de, então, ser capturado por elas. A Figura 4.10(b) ilustra esse processo de migração e captura entre moléculas da região amorfa e moléculas da fase $\beta$ no PFO. Ainda no segundo conjunto de emissão, nota-se que o pico da transição 0-0 (443 nm) está deslocado de $8 \mathrm{~nm}$ (50 meV) em relação ao máximo de absorção da fase $\beta(435 \mathrm{~nm})$. Este deslocamento é muito pequeno quando comparado com o da fase amorfa (230 meV), indicando que a difusão espectral promovida pela migração do éxciton é extremamente limitada entre as moléculas da fase $\beta$. Como veremos abaixo, isso se deve à formação de 
domínios com estados de baixa energia, o que limita em muito a migração do éxciton e, portanto, a difusão espectral.

Considerando que o PFO amorfo possui dobras e defeitos que geram segmentos de tamanho médio de 10 monômeros ao longo da cadeia e que cada monômero ocupa um volume de $0,5 \mathrm{nmx} 0.2 \mathrm{nmx} 0.2 \mathrm{~nm}\left(2 \times 10^{-2} \mathrm{~nm}^{3}\right)$, então o volume ocupado por cada segmento de 10 monomeros é de $0,2 \mathrm{~nm}^{3}$. Por outro lado, os volumes transferência de energia e de migração para o éxciton são de $4,2 \mathrm{~nm}^{3}$ e $4,2 \times 10^{3} \mathrm{~nm}^{3}$, respectivamente, se considerarmos raios típicos de transferência de Förster $R_{0}=1 \mathrm{~nm}$ e de migração $R_{m}=10 \mathrm{~nm}$, respectivamente. Assim, o volume de transferência contém em média 21 segmentos médios e o volume de migração $2,1 \times 10^{4}$ segmentos (5 segmentos/ $\mathrm{nm}^{3}$ ). Portanto, podemos concluir que existem aproximadamente 2 segmentos contendo anéis alinhados (fase $\beta$ ) dentro do volume de Förster e 2000 dentro do volume de migração nos filmes contendo 8,6 \% de moléculas da fase $\beta$. Este resultado leva a uma inconsistência, pois com a densidade de duas moléculas da fase $\beta$ por volume de Förster $\left(\sim 0.5 \mathrm{~mol}\right.$ da fase $\left.\beta / \mathrm{nm}^{3}\right)$, não poderíamos observar emissão provinda da fase amorfa, já que todos os éxcitons migrariam para estados moleculares de mais baixa energia da fase $\beta$. Para uma taxa de transferência de energia típica da ordem de $10^{12} \mathrm{~s}^{-1}$, espera-se que o éxciton visite em média 1000 moléculas dentro do volume de migração durante o seu tempo de vida ( nsegundo). Assim, estimamos que apenas 4 moléculas da fase $\beta$ (e não 2000) por volume de migração $\left(\sim 5 \times 10^{-4} \mathrm{~mol}\right.$ da fase $\left.\beta / \mathrm{nm}^{3}\right)$ já seria suficiente para aumentar consideravelmente a probabilidade do éxciton encontrar uma dessas moléculas nesse volume. Este resultado sugere que as moléculas da fase $\beta$ não se encontram isoladas e dispersas nas regiões amorfas, mas formam domínios ordenados contendo em média 500 moléculas da fase $\beta$ (4 domínios por volume de migração). Pode-se estimar um tamanho médio de $30 \mathrm{~nm}$ para cada domínio da fase $\beta$, se assumirmos uma densidade de aproximadamente 5 segmentos $/ \mathrm{nm}^{3}$ e domínios com geometria esférica. Materiais poliméricos possuem em geral uma estrutura amorfo-cristalina, ou seja, o volume do material consiste de cristalitos embebidos em uma estrutura amorfa. O tamanho característico destes cristalitos fica na faixa de nanômetros (10-100 nm) (VETTEGREN et al., 2009). 
(a)

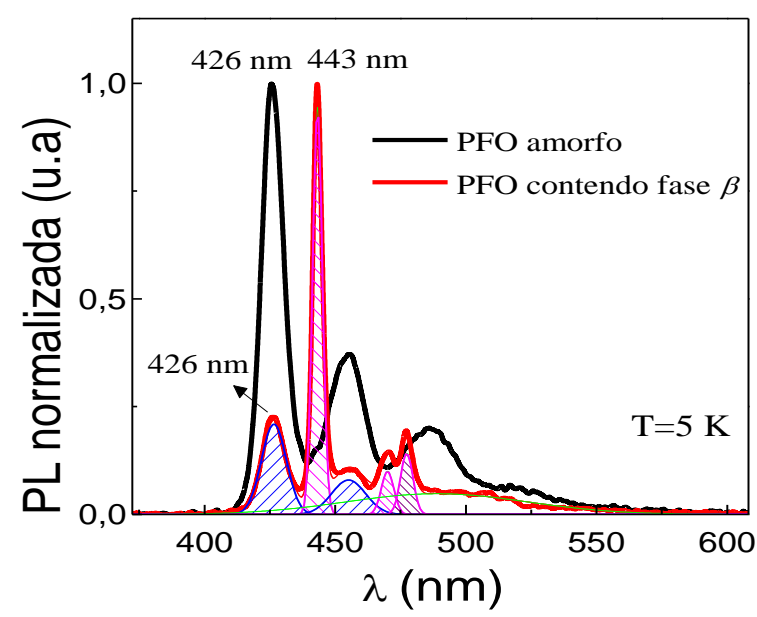

(b)

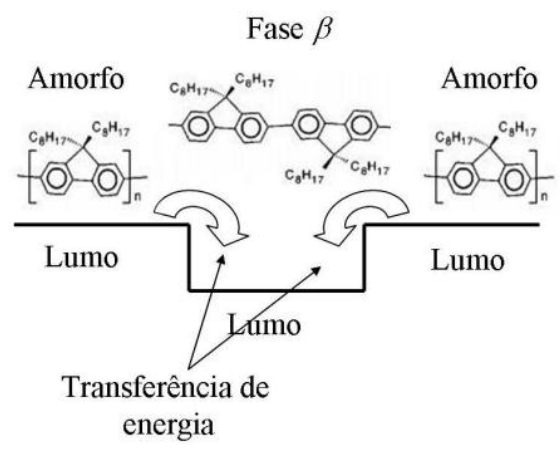

Figura 4.10: (a) PL normalizada do filme de PFO amorfo e contendo fase $\beta$. (b) ilustração dos LUMO's (Lowest Unoccupied Molecular Orbital) da região amorfa e da fase $\beta$ mostrando a transferência de energia entre essas regiões. Excitação em $325 \mathrm{~nm}$ utilizando laser de $\mathrm{He}-\mathrm{Cd}$.

O terceiro conjunto de emissões não resolvidas e de baixa intensidade está localizado na faixa espectral de baixas energias e é associado a transições envolvendo fônons de ordem maior ou igual a dois e a banda relacionada a defeitos como foi discutido acima. Esta região espectral foi ajustada por uma gaussiana larga somente para efeito de visualização (gaussiana em verde).

\subsection{Filmes de PFO ultrafinos}

No presente trabalho, filmes poliméricos ultrafinos foram definidos como aqueles que têm espessura igual ou menor que o raio típico de migração do éxciton $(10 \mathrm{~nm})$. Estes filmes poliméricos encontram aplicação em estruturas quânticas de multicamadas, como poços quânticos simples e múltiplos (SHI et al., 2007), super-redes (HONG et al. 1996), espaçadores e camadas de transferência de energia e carga (BORGES et al., 2005; FAVARIM, 2006). Porém, a maioria destes filmes foram feitos por evaporação de pequenas moléculas ou pela deposição de filmes auto-montados (LbL) sobre substratos específicos e pouco se foi feito na caracterização de filmes ultrafinos poliméricos preparados por spin-coating até o momento. Nesta seção será apresentado o estudo de propriedades como estabilidade (resistência mecânica), estrutura e uniformidade com a espessura dos mesmos.

Os filmes de PFO depositado sobre o substrato de quartzo foram obtidos utilizando a técnica de spin-coating. Os parâmetros de spin-coating foram mantidos constantes para todos os filmes (3000 rpm por $60 \mathrm{~s}$ ). A espessura foi controlada através da concentração da solução de PFO diluído em clorofórmio com concentrações que variaram em mais de uma ordem de 
magnitude no intervalo de $0,30 \mathrm{~g} / \mathrm{L}$ a $5,00 \mathrm{~g} / \mathrm{L}$. A Figura 4.11 mostra o espectro de absorbância em escala semi-logarítmica em função da concentração de PFO na região no UVvisível dos filmes produzidos a partir das soluções descritas acima.

Como mostrado na Figura 4.11, há um comportamento crescente da absorbância monitorada em $390 \mathrm{~nm}$ em função da concentração da solução polimérica. De acordo com a lei de Beer-Lambert, o aumento linear de 0.025 para 0.42 da absorbância (variação de fator 21) com a concentração indica que há uma variação considerável da espessura do material polimérico que é depositado sobre o quartzo. Se considerarmos o valor do coeficiente de absorção típico para polifluorenos de $10^{5} \mathrm{~cm}^{-1}$ (QUILES et al., 2005; ARIU et. al, 2002), estas espessuras devem estar variando no intervalo de 2,5 a $42 \mathrm{~nm}$. A escala logarítmica evidencia que o espectrômetro utilizado possui sensibilidade suficiente para detectar variações de absorbância em filmes com espessuras menores que $10 \mathrm{~nm}$. É interessante notar, a forma de linha da absorbância varia substancialmente com o decréscimo da espessura dos filmes, principalmente no que se refere a largura e a cauda de baixa energia entre 425 a $500 \mathrm{~nm}$. Estas modificações espectrais serão estudadas com mais detalhes a seguir.

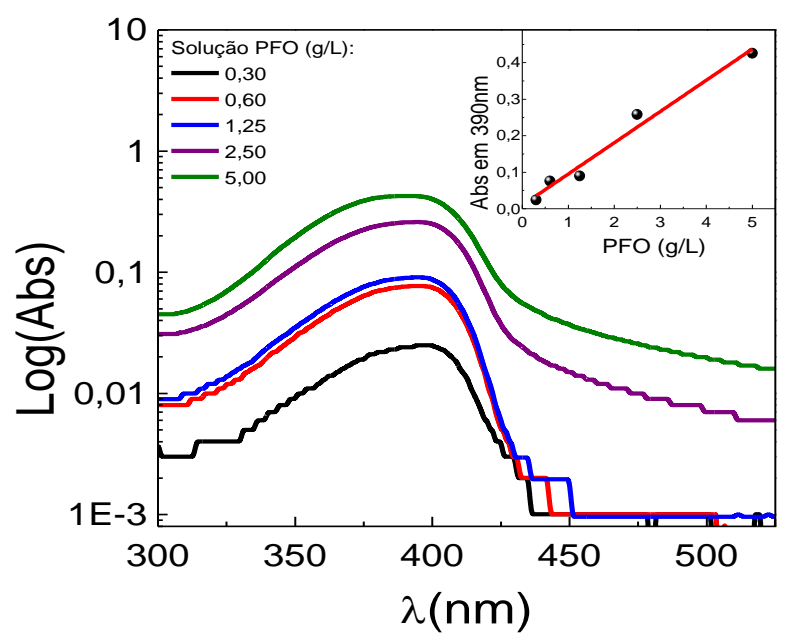

Figura 4.11: Espectro de absorção dos filmes de PFO na região do visível e monitoramento em 390 nm do crescimento linear da absorção em função da concentração da solução de PFO utilizada para produzir os filmes. Medidas realizadas a temperatura ambiente.

As espessuras dos filmes preparados a partir das soluções com concentrações de 5,00 $\mathrm{g} / \mathrm{L}, 2,50 \mathrm{~g} / \mathrm{L}$ e $1,25 \mathrm{~g} / \mathrm{L}$ foram medidas utilizando a microscopia de força atômica (AFM), os valores obtidos são: $(41 \pm 3) \mathrm{nm},(17 \pm 1) \mathrm{nm}$ e $(5,9 \pm 0,7) \mathrm{nm}$, respectivamente. A medida da espessura utilizando a AFM é realizada a partir da diferença de altura entre uma região da amostra que contém o filme polimérico e uma região que contém somente o quartzo. A região que contém somente o quartzo é obtida através da retirada de uma pequena região do filme 
polimérico por meio de um risco que é feito no filme utilizando um material pontiagudo. Nestas medidas foi utilizada uma ponta de AFM com diâmetro em torno de $10 \mathrm{~nm}$. Os filmes de PFO produzidos a partir das soluções poliméricas com concentrações inferiores a $1,25 \mathrm{~g} / \mathrm{L}$ são completamente transparentes o que dificulta a visualização do risco para que seja feita a medida da espessura por AFM. Por esse motivo não foi possível medir a espessura destes filmes utilizando esta técnica. Porém, as espessuras medidas por AFM dos filmes indicam que os filmes produzidos a partir das soluções com as concentrações $0,6 \mathrm{~g} / \mathrm{L}$ e $0,3 \mathrm{~g} / \mathrm{L}$ possuem espessuras menores do que 5,9 nm (filme produzido com solução de 1,25 g/L).

A Figura 4.12 mostra a absorbância dos filmes de PFO (obtido a partir da Figura 4.11) em função da espessura medida por AFM. Como esperado, a absorbância aumenta linearmente conforme o aumento da espessura do filme. Através do ajuste dos dados experimentais com a equação da Lei de Beer-Lambert, o coeficiente de absorção obtido é $\alpha_{m}=(1,1 \pm 0,1) 10^{5} \mathrm{~cm}^{-1}$. Este valor é da mesma ordem de grandeza do coeficiente de absorção em $390 \mathrm{~nm}$ encontrada na literatura para o filme de PFO, em torno de $2,2 \times 10^{5} \mathrm{~cm}^{-1}$ (ARIU et al., 2002).

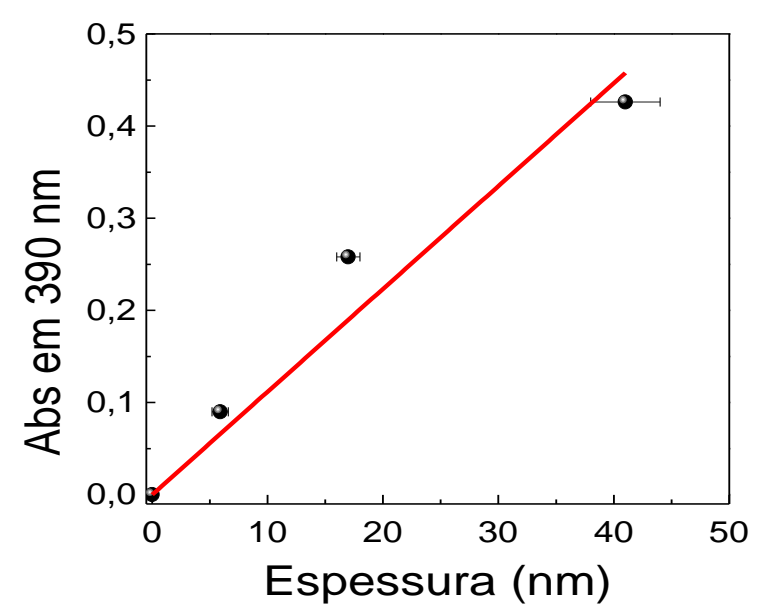

Figura 4.12: Absorbância em função da espessura medida por AFM das amostras $41 \mathrm{~nm}, 17 \mathrm{~nm}$ e 5,9 $\mathrm{nm}$. A linha vermelha é o ajuste utilizando a equação da Lei de Beer-Lambert.

A técnica de ângulo de contato é sensível o suficiente para inferir sobre as propriedades estruturais como rugosidade e recobrimento de filmes ultrafinos. As medidas de ângulo de contato dos filmes de PFO amorfo sobre o quartzo em função da concentração utilizada para produzir os filmes são apresentadas na Figura 4.13. O ângulo de contato é maior que $100^{\circ}$ para filmes de PFO com espessura maior que 5,9 nm (solução de 1,25 g/L), ou seja, o filme de PFO é hidrofóbico (ângulo de contato maior que $90^{\circ}$ ), o que é uma propriedade da maioria dos polímeros (Figura 4.13(a)). No entanto, o ângulo de contato que permanece 
constante decresce abruptamente para filmes com espessuras menores que $5,9 \mathrm{~nm}$ e os filmes de PFO passam a ter um caráter mais hidrofílico. Podemos dizer deste experimento que a interação sólido/líquido está sendo profundamente alterada se a estrutura do filme é mantida para as espessuras estudadas no presente trabalho.

(a)

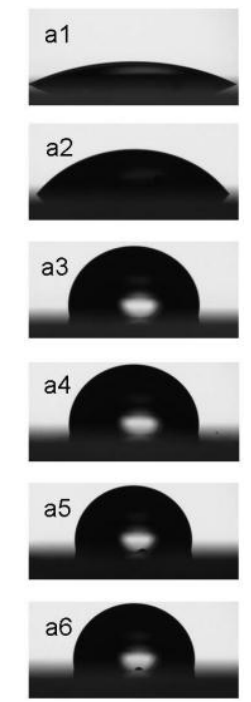

(b)

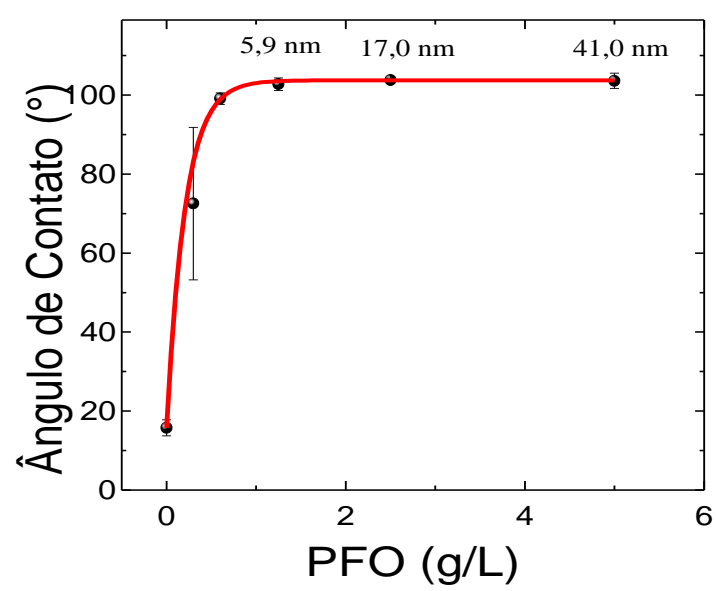

Figura 4.13: Ângulo de contato de filmes de PFO (amorfo) depositados sobre o quartzo com diferentes espessuras. (a) Imagem da gota de água sobre: $\left(a_{1}\right)$ quartzo, $\left(a_{2}\right)$ filme PFO (solução 0,3 $\mathrm{g} / \mathrm{L}),\left(\mathrm{a}_{3}\right)$ filme PFO $(0,6 \mathrm{~g} / \mathrm{L}),\left(\mathrm{a}_{4}\right)$ filme PFO $(1,25 \mathrm{~g} / \mathrm{L}),\left(\mathrm{a}_{5}\right)$ filme PFO $(2,50 \mathrm{~g} / \mathrm{L})$ e $\left(\mathrm{a}_{5}\right)$ filme PFO $(5,00 \mathrm{~g} / \mathrm{L})$. (b) Comportamento do ângulo de contato em função das concentrações das soluções poliméricas utilizadas para produzir os filmes. A linha vermelha é somente um guia para os olhos.

Medidas de microscopia confocal de varredura foram realizadas para verificar se as mudanças do ângulo de contato estão relacionadas com a qualidade dos filmes sobre o quartzo (recobrimento do substrato). Imagens no modo espectral de microscopia confocal de uma área de $150 \times 150 \mu \mathrm{m}$ estão apresentadas na Figura 4.14 para uma resolução em pixel de 1024x 1024. Cada ponto sondado nessas imagens durante a varredura do laser de $405 \mathrm{~nm}$ corresponde a um espectro avaliado em uma região com resolução óptica de aproximadamente $250 \mathrm{~nm}$ (objetiva 63x, água, abertura numérica $\mathrm{N}=1,4$ ). As imagens foram feitas em regiões sobre o substrato que continham defeitos produzidos pela manipulação para permitir a focalização e garantir o mesmo caminho óptico, condição necessária para se fazer comparações de intensidade. Essa figura também mostra o perfil de intensidade ao longo de uma linha (cor branca na imagem) ao longo do filme, a distribuição de intensidades (frequência absoluta pela intensidade) sobre a área sondada, assim como espectros de PL avaliado sobre três pontos ao longo da diagonal da imagem. O perfil e a distribuição de intensidade das imagens foram obtidos utilizando o software Zen 2010 Light Edition. 
Capítulo 4 - Resultados e Discussão
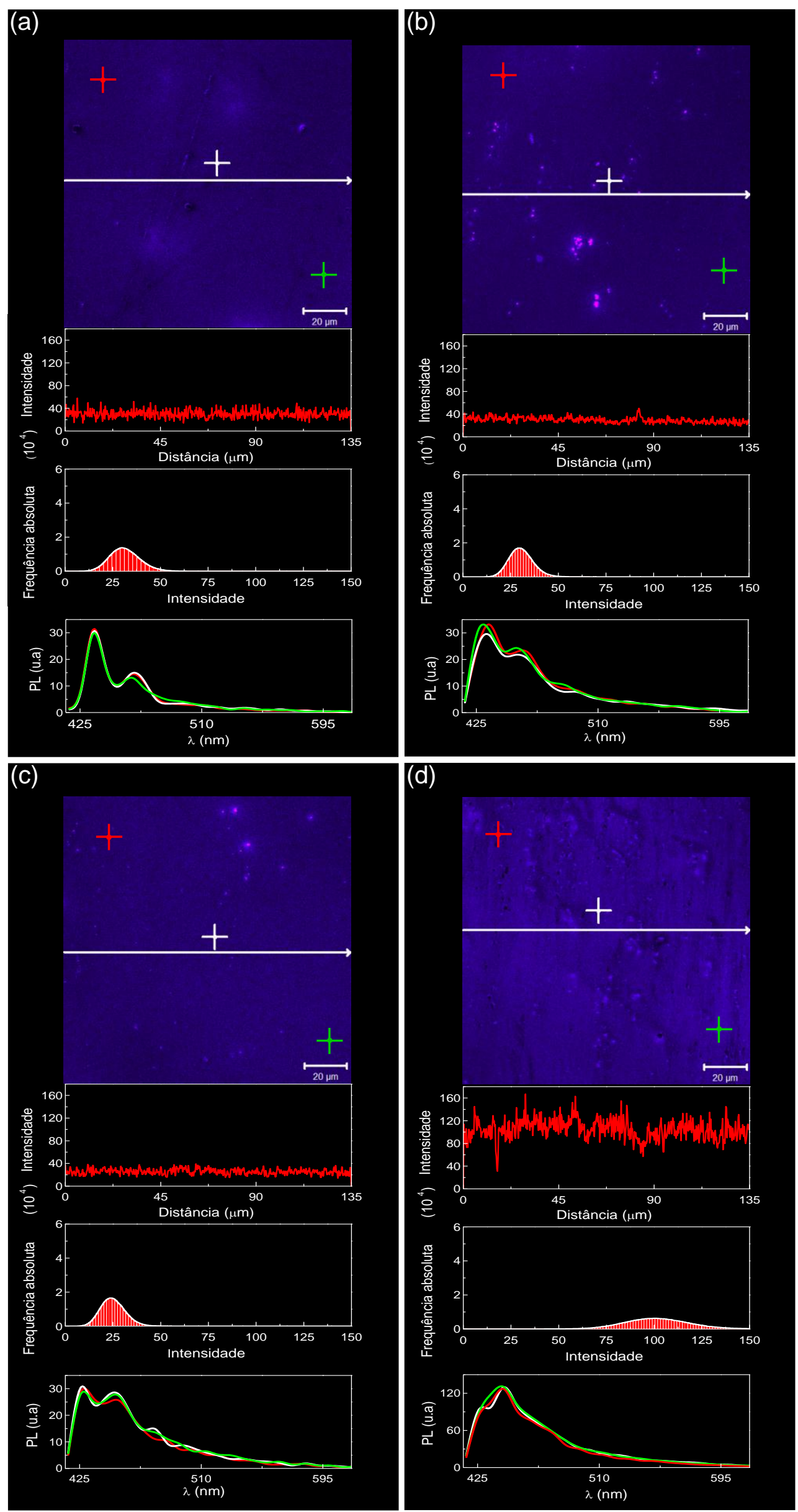


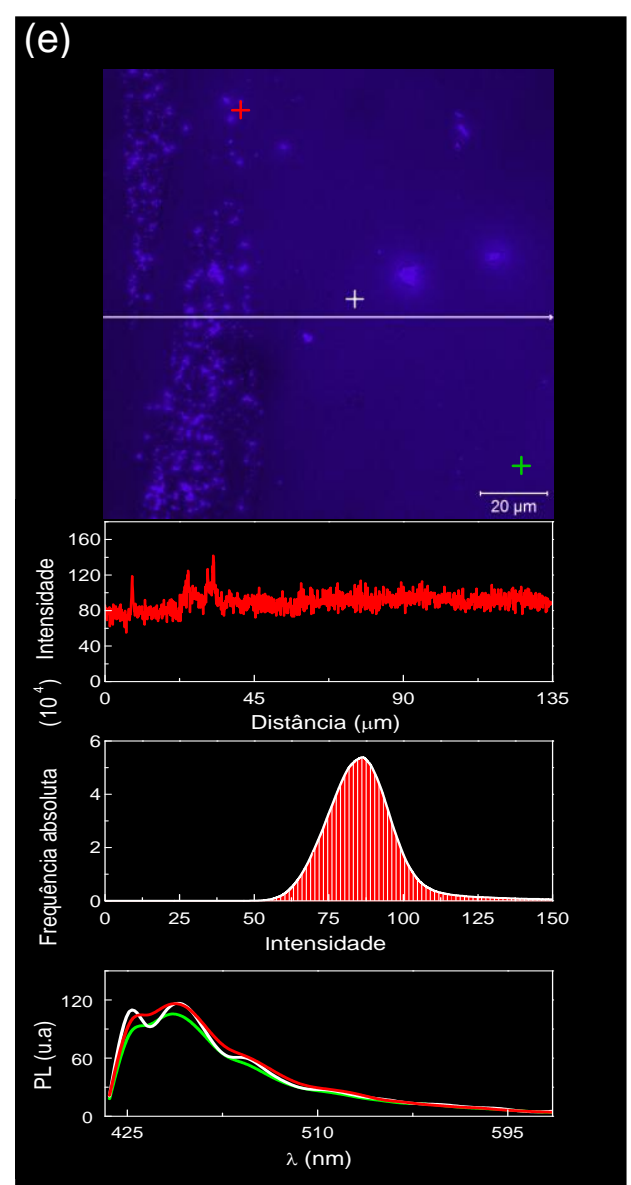

Figura 4.14: Imagens de microscopia confocal no modo espectral de filmes de PFO sobre o quartzo produzido a partir das seguintes concentrações poliméricas: (a) 0,30 g/L, (b) 0,60 g/L, (c) 1,25 g/L (5,9 $\mathrm{nm}$ de espessura), (d) 2,50 g/L (17 nm de espessura) e (e) (41 nm de espessura). Excitação em $405 \mathrm{~nm}$. Cada figura mostra também o perfil de intensidade ao longo de uma linha (cor branca na imagem) ao longo do filme, a distribuição de intensidades (frequência absoluta pela intensidade) sobre da área sondada, assim como espectros de PL avaliado sobre três pontos ao longo da diagonal da imagem.

Primeiramente, é importante obter informações sobre a homogeneidade dos filmes. Pode-se ver que regiões distintas de cada amostra, a PL do filme de PFO possui praticamente as mesmas características espectrais de intensidade e de forma de linha, demonstrando que os filmes são homogêneos em toda a área sondada. Observa-se que a intensidade aumenta com o aumento da espessura conforme esperado. Esse aumento se reflete na distribuição da frequência absoluta da intensidade. Nota-se que há um deslocamento da distribuição para maiores intensidades à medida que a espessura do filme aumenta. É interessante notar ainda que os filmes mais finos possuem distribuições de intensidades mais estreitas o que garante a homogeneidade dentro da resolução óptica de $250 \mathrm{~nm}$ ao longo de uma grande área. Porém, o resultado mais importante é a cobertura do substrato de quartzo pelos filmes spin-coating ultrafinos de PFO é total tanto quanto a integridade física dos filmes. Defeitos como ilhas e fissuras não foram detectadas em imagens de maior resolução $(20 \times 20 \mu \mathrm{m}$, não mostrado) de 
microscopia confocal e os filmes encontram-se com boa aderência sobre a superfície do quartzo. Assim, podemos concluir que as mudanças do ângulo de contato observadas na Fig.4.13(b) não estão associadas com aspectos relacionados a defeitos na cobertura ou falta de homogeneidade dos filmes em uma escala microscópica.

Espera-se que defeitos ou resíduos superficiais afetem drasticamente a tensão superficial e também a formação de filmes. Os resultados das medidas de microscopia confocal não são suficientes para inferir sobre estruturas nanoscópicas da ordem ou menores que as espessuras de 5,9 $\mathrm{nm}$ dos filmes de PFO que podem estar afetando suas propriedades, como a tensão superficial, que foram detectadas pelas medidas de ângulo de contato.

Medidas de microscopia de força atômica (AFM) podem dar informação destas estruturas na escala nanométrica. A Figura 4.15(de a-e) mostra imagens de AFM no modo de contato dos filmes spin-coating de PFO sobre quartzo para as mesmas espessuras (concentrações de PFO) utilizadas nas medidas de ângulo de contato acima. Além disso, a Figura 4.15(f) mostra a variação da rugosidade média quadrática $(\mathrm{Rq})$ com a concentração de PFO (espessura) dos mesmos filmes e para a superfície do substrato de quartzo (concentração zero, não mostrado). É interessante notar que a rugosidade do quartzo é maior e que a rugosidade dos filmes de PFO cai aproximadamente 6 vezes com o aumento da espessura, sugerindo que a estrutura altamente rugosa da superfície de quartzo está sendo coberta pelos filmes de PFO com espessuras maiores que $5 \mathrm{~nm}$. Porém, estas imagens de contraste de fase destas superfícies mostram que a superfície do quartzo está coberta mesmo para espessuras do filme de PFO de $\sim 3 \mathrm{~nm}(0.3 \mathrm{~g} / \mathrm{l})$. Medidas ópticas da orientação das cadeias em filmes finos spin-coating de polímeros luminescentes solúveis (MCBRANCH et al., 1995) sugerem que moléculas estão em média deitadas ao longo do plano do filme e não possuem dependência radial ou ordem azimutal. Isto sugere que, nos filmes de PFO com espessura menores que 5 $\mathrm{nm}$, as cadeias poliméricas encontram-se alinhadas com a superfície do quartzo preenchendo os espaços entre as rugosidades deste substrato. Assim, precisamos de 10 a 12 camadas moleculares $(5 \mathrm{~nm})$ para cobrir as rugosidades do quartzo considerando as dimensões dos segmentos conjugados assumidas na seção anterior de $5 \mathrm{nmx} 0,2 \mathrm{nmx} 0,2 \mathrm{~nm}$ e espaçamentos entre moléculas de 0,2 $\mathrm{nm}$ dados por efeitos estéricos. Além disso, filmes poliméricos preparados por spin-coating têm a tendência de aumentar a rugosidade Rq com o aumento da espessura (LOBO, 2003), o que não é observado para os filmes de PFO preparados no presente trabalho. Isto indica que os filmes sobre substrato quartzo estudados acima são de alta qualidade estrutural, o que resulta na baixa rugosidade Rq. Assim, a Figura 4.15(f) mostra claramente a redução da rugosidade Rq que muda de valores próximos a aqueles da superfície 
do quartzo $(2,8 \mathrm{~nm})$ para valores assintóticos $(0,3 \mathrm{~nm})$ para filmes de PFO de maior espessura.

Pode-se concluir dos resultados de AFM que as nanorugosidades da superfície do quartzo podem estar afetando a tensão superficial (ângulo de contato) na interface filme(PFO)/líquido $\left(\mathrm{H}_{2} \mathrm{O}\right)$ para espessuras de $\mathrm{PFO}$ menores que $5 \mathrm{~nm}$.
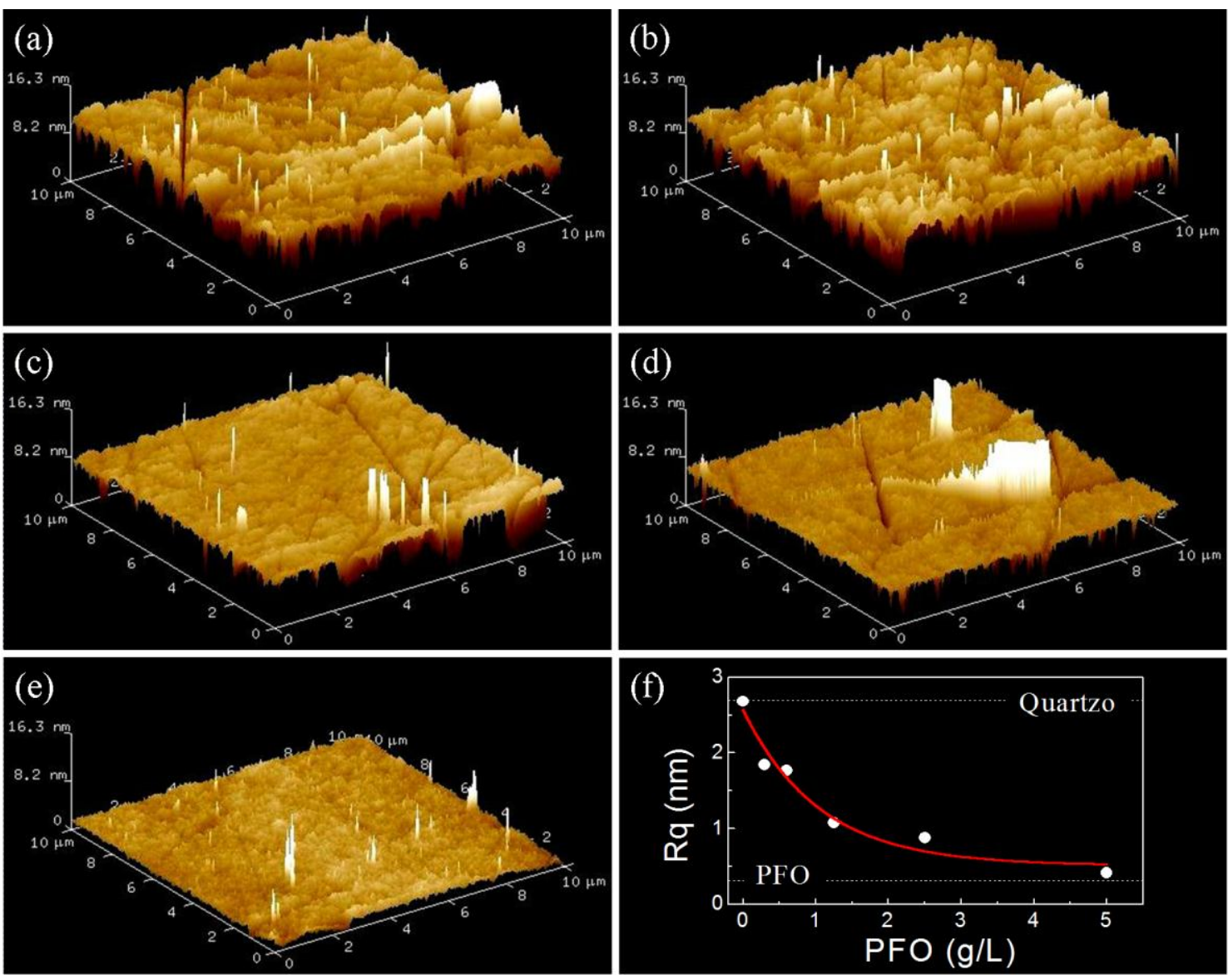

Figura 4.15: Imagens de microscopia de força atômica (AFM) no modo de contato de filmes de PFO sobre o quartzo produzido a partir das seguintes concentrações poliméricas: (a) $0,30 \mathrm{~g} / \mathrm{L}$, (b) $0,60 \mathrm{~g} / \mathrm{L}$, (c) 1,25 g/L (5,9 nm de espessura), (d) 2,50 g/L (17 nm de espessura) e (e) 5,00 g/L (41 nm de espessura). (f) Variação da rugosidade RMS (Rq) com a concentração de PFO (espessura) dos mesmos filmes e para a superfície do substrato de quartzo (concentração zero, não mostrado).

A interface entre o filme polimérico e o substrato parece influenciar não só a tensão superficial, mas produz também modificações significativas das propriedades estruturais do PFO que refletem diretamente nas suas propriedades ópticas, como será discutido a seguir.

Estas mudanças podem ser visualizadas na Figura 4.16(a), que compara espectros normalizados de emissão de cada um dos filmes contendo diferentes espessuras (concentrações) estudadas acima. A escala semi-log no eixo das ordenadas e energética no eixo das abscissas foram utilizadas para melhor visualização. Estes espectros foram obtidos de um único ponto das imagens de microscopia confocal e, por isso, corresponde a um sinal provindo de uma área com resolução de aproximadamente $250 \mathrm{~nm}$. Isto significa que estamos 
sondando um conjunto (ensemble) muito pequeno de aproximadamente $1 \times 10^{6}$ segmentos de PFO contendo em média dez monômeros em um filme de $5 \mathrm{~nm}$ de espessura. Este número de moléculas é muito menor que aqueles acessados $\left(\sim 10^{14}\right.$ segmentos de PFO) por espectroscopia de luminescência usando óptica convencional com resolução de $0,5 \mathrm{~mm}$. Desta forma, o espectro de microscopia confocal corresponde a uma média de um conjunto muito menor de moléculas e, por isso, é muito mais sensível a variações locais sofridas pelas moléculas de PFO. Em contrapartida, a fluência $\Phi$ (número de fótons por unidade de área e tempo) deve ser alta para garantir sensibilidade suficiente para a detecção do sinal de luminescência. A fluência utilizada no presente estudo foi a mínima permitida para o equipamento (6 $\mathrm{mW}$ para o laser de $405 \mathrm{~nm}$ focado em uma área de $\left.\pi \times(125 \mathrm{~nm})^{2}\right)$ é de aproximadamente $2,5 \times 10^{25}$ fótons $/ \mathrm{cm}^{2} \mathrm{~s}$. Este valor é uma ordem de grandeza maior do que a fluência $\Phi_{0}=1 / \tau \sigma=2,5 \times 10^{24}$ fótons $/ \mathrm{cm}^{2} \mathrm{~s}$ necessária para re-excitar um segmento conjugado de PFO excitado de seção de choque $\sigma=4 \times 10^{-16} \mathrm{~cm}^{2}(=0,2 \mathrm{nmx} 0,2 \mathrm{~nm})$ exatamente após o seu decaimento em $\tau=1 \mathrm{~ns}$. Isto significa que os $10^{6}$ segmentos conjugados que se encontram dentro do volume confocal encontravam-se sempre excitados durante o tempo de permanência do laser $(12,6 \mu \mathrm{seg})$ em um dado ponto da imagem. Nesse caso, as moléculas de PFO sofrem em média $10^{4}$ processos de decaimento radiativo/excitação durante o tempo de permanência do laser em cada ponto da imagem. Esta condição aumenta em muito a probabilidade de fotodegradação destas moléculas, principalmente em filmes extremamente finos. Porém, cuidados foram tomados na otimização da velocidade de varredura confocal para não danificar estes filmes. Como estamos interessados nas mudanças da forma de linha sob as mesmas condições de excitação e não da intensidade de emissão, possível fotodegradação destes filmes extremamente finos não foram significativas para alterar as conclusões tiradas a seguir.

Como pode ser observado na Figura 4.16(a), a forma e a posição espectral mudam significativamente com a espessura (concentração) dos filmes. Estas mudanças podem ser acompanhadas através da energia da transição 0-0, do parâmetro $S$ e da energia de fônon nos gráficos apresentados nas Figuras 4.16(b), (c) e (d), respectivamente, em função da concentração da solução de PFO utilizada para depositar os filmes. Há uma redução da energia da transição 0-0 conforme a espessura do filme diminui. Por exemplo, no filme mais espesso (41 nm produzido com a solução de $5 \mathrm{~g} / \mathrm{L}$ ) a energia dessa transição é de 2,90 eV, esse valor está próximo do encontrado na literatura para transição 0-0 (2,92 eV) de filmes amorfos (ARIU et al., 2003). Já no filme de menor espessura (produzido com a solução de 0,3 
g/L) a energia dessa transição é de $2,85 \mathrm{eV}$ e tende para a transição $0-0(2,82 \mathrm{eV})$ de filmes que contém camadas de fase $\beta$ (ARIU et al., 2003). Além disso, o espectro de PL desse filme se estreita consideravelmente em comparação com os outros da mesma série. Já o parâmetro $S$, que é obtido pela razão entre as intensidades da transição 0-0 (transição de menor energia nestes filmes de PFO) e transição 0-1, dá uma indicação do grau de desordem sistema polimérico (BORGES, 2001). Os resultados da Figura 4.16(c) mostram que o parâmetro $S$ tende a diminuir conforme a espessura do filme é reduzida. Este comportamento indica que há uma diminuição da desordem do sistema em filmes menos espessos preparados com clorofórmio. Os resultados acima sugerem que a diminuição gradual da espessura promove uma transição de filmes amorfos espessos para filmes menos espessos (espessura menor que $5,9 \mathrm{~nm}$ ) contendo frações de cadeias na fase $\beta$.

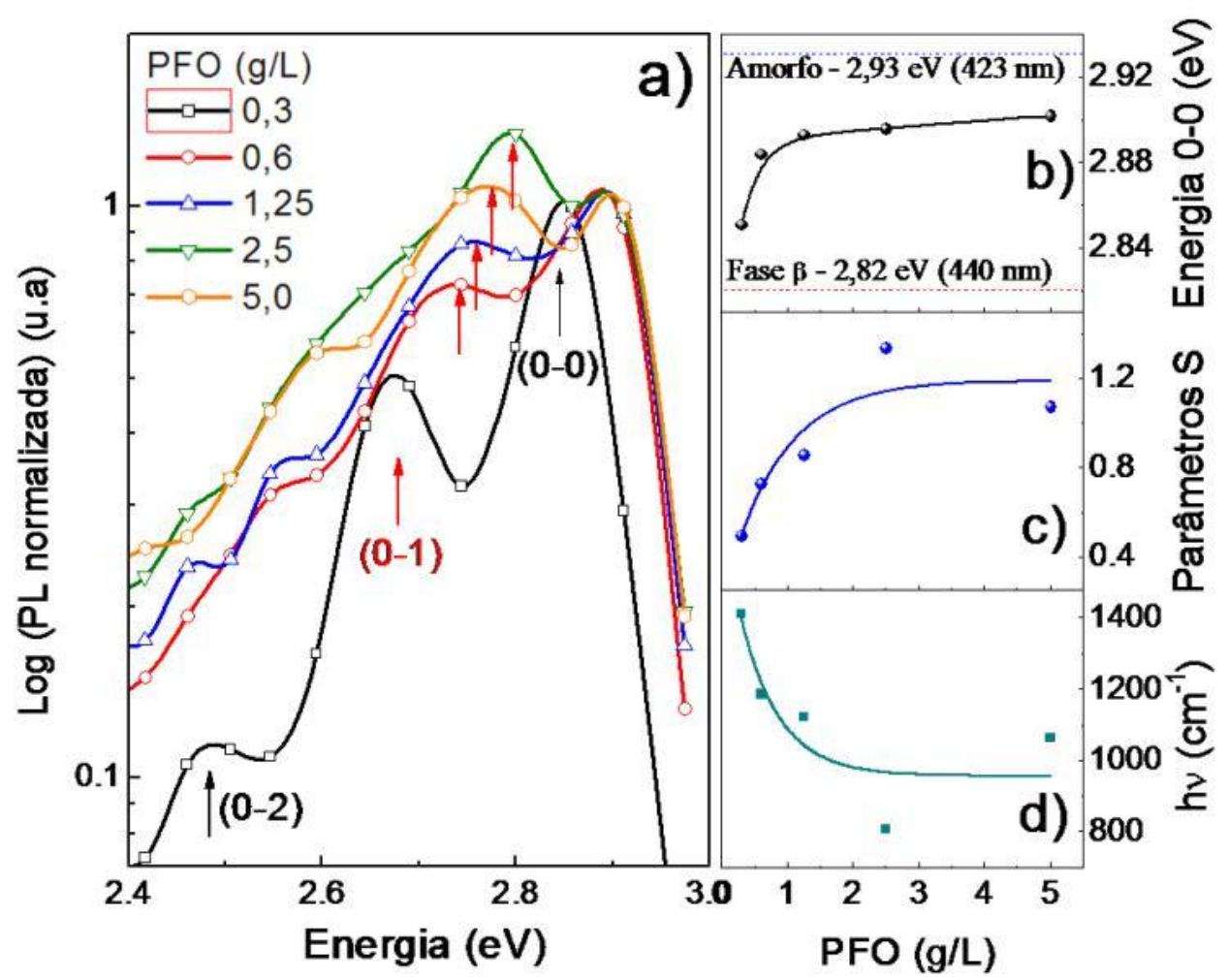

Figura 4.16: (a) Comparação entre espectros normalizados de emissão de cada um dos filmes contendo diferentes espessuras (concentrações) estudadas acima medidos por microscopia confocal. A escala semi-log no eixo das ordenadas e energética no eixo das abscissas foram utilizados para melhor visualização. As medidas realizadas a temperatura ambiente. As mudanças nestes espectros podem ser visualizadas através (b) da energia da transição 0-0, (c) do parâmetro S e (d) da energia de fônon em função da concentração da solução de PFO utilizada para depositar os filmes.

Na Figura 4.16(d) os pontos apresentam como a energia de fônon altera com a espessura (concentração do PFO). A energia de fônon foi avaliada pela distância entre o máximo da transição (0-0) e a transição (0-1) e correspondem à média das energias dos modos vibracionais longitudinais não resolvidos à temperatura ambiente posicionados em $1286 \mathrm{~cm}^{-1}$ 
e em $1612 \mathrm{~cm}^{-1}$.

Como discutido na seção anterior, o aparecimento da fase $\beta$ está associada a uma sequência alinhada bem definida de unidades repetitivas de PFO ao longo da cadeia (e que leva a um aumento de conjugação) e este ordenamento é induzido nos filmes por vários processos distintos, tais como, tratamento a vapor de tolueno, ciclos de aquecimento e resfriamento e também em forma de gel em soluções altamente concentradas em solventes pobres (GRELL et al., 1999). Sabe-se também que esta fase é estável até $353 \mathrm{~K}\left(80^{\circ} \mathrm{C}\right)$ e não se estabiliza quando o PFO se encontra completamente disperso em matriz polimérica vítrea de poli-estireno (PS e 1\% PFO). Além disso, a posição do pico de absorção na cauda de baixa energia associado à fase $\beta$ depende de cada método (GRELL et al., 1999).

Ainda não estão claros os mecanismos que levam a formação da fase $\beta$. Alguns experimentos demonstram que o ordenamento das unidades monoméricas não tem origem na interação entre cadeias (GRELL et al., 1999). Os tratamentos que levam à formação da fase $\beta$ fazem com que os filmes de PFO estejam sujeitos com alguma forma de tensão seja ela de origem mecânica ou termodinâmica. No processo cíclico de resfriamento/aquecimento lento, os diferentes coeficientes de expansão entre filme e substrato geram necessariamente uma tensão mecânica no filme polimérico que pode ser uma compressão ou um estiramento. $\mathrm{O}$ coeficiente de expansão térmica linear de materiais poliméricos $\alpha_{p}\left(40-200 \times 10^{-6} \mathrm{~m} / \mathrm{Km}\right)$ chega a ser duas ordens de grandeza maior que o do quartzo $\alpha_{q}\left(0,5 \times 10^{-6} \mathrm{~m} / \mathrm{Km}\right)$ (CALLISTER, 2008). Em materiais poliméricos desordenados, uma tensão mecânica $\sigma_{p}$ externa resultará na elongação $\Delta \mathrm{l}$ de um segmento da cadeia somente através do contato efetivo ou aderência efetivo na interface entre os dois materiais, ou seja, o filme não pode deslizar sobre o substrato durante o estiramento mecânico. Assim, uma variação de temperatura $\Delta \mathrm{T}$ produzirá um alongamento efetiva no filme de comprimento 1 de

$$
\varepsilon=\frac{\Delta l_{p}-\Delta l_{q}}{l}=\left(\alpha_{p}-\alpha_{q}\right) \Delta T
$$

Para um filme ultrafino produzido sobre a temperatura ambiente (297 K) sem tensão e resfriado a $5 \mathrm{~K}$, o seu alongamento $\varepsilon$ será de aproximadamente $\alpha_{\mathrm{p}} \Delta T \mathrm{x} 100=3 \%$, considerando $\alpha_{\mathrm{p}}=1 \times 10^{-4} \mathrm{~m} / \mathrm{Km} \gg \alpha_{\mathrm{q}}$. Este alongamento está no limite da faixa de alongamento de ruptura da maioria dos polímeros, que varia de 1,2-1200\% (CALLISTER, 2008; MATWEB). Um polímero conjugado possui $\varepsilon$ típico da ordem de 100-500\% (MAIA, 2006; CAZATI, 2003), portanto, um alongamento de $3 \%$ ainda se encontra abaixo do alongamento de ruptura, condição que gera microfissuras no material. Num filme fino com alta aderência ao substrato 
(sem deslizamento), este alongamento se converte em uma tensão $\sigma$ por estiramento dos segmentos conjugados, ou seja, as cadeias próximas à interface estarão alongadas conforme é mostrado esquematicamente na Figura 4.17(a). No regime linear em que vale a lei de Hooke, esta tensão é proporcional ao alongamento efetivo $\varepsilon$ na forma $\sigma=Y \varepsilon$, onde $Y$ é o módulo de tensão ou módulo de Young e tem valores variando de 1-10 GPa para a maioria dos materiais poliméricos (MATWEB). Assim, a tensão no filme amorfo de PFO a baixa temperatura (5 K) será de aproximadamente $90 \mathrm{MPa}$, assumindo um $Y=3 \mathrm{GPa}$. Esta tensão é maior que o limite de ruptura para diferentes polímeros (20-110 Mpa). Porém, esta tensão pode ser relaxada ao longo das camadas mais distantes da interface como sugere a Figura 4.17(b) de forma esquemática, de forma a reduzir a energia elástica total.

(a)

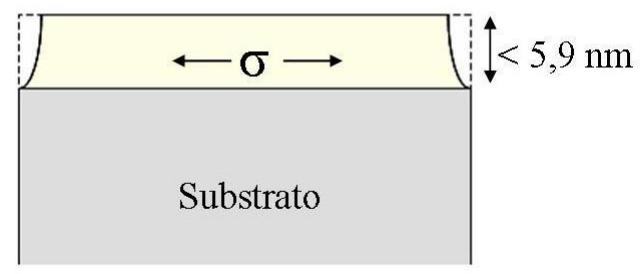

Filmes ultra finos (b)

$$
\sigma^{\prime}<\sigma
$$

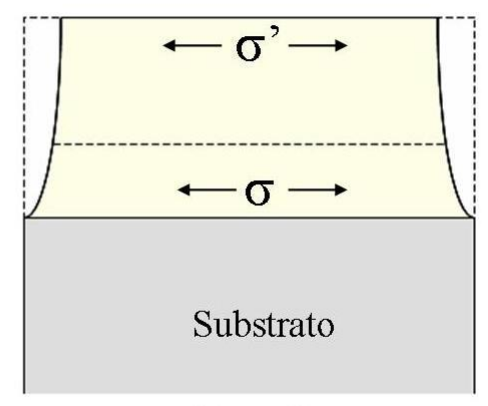

Filmes finos

Figura 4.17: Ilustração da influência da tensão na formação de filmes ultrafinos (a) e de filme finos (b).

Outra maneira do PFO reduzir esta forte tensão mecânica seria assumir uma conformação mais estendida para a cadeia (GRELL et al., 1999). De fato, a presença de um pico de absorção adicional e estreito em baixas energias $(435 \mathrm{~nm})$ sugere que este estado está associado a segmentos conjugados muito longos formados por unidades repetitivas totalmente coplanares. Pode-se dizer que o PFO possui duas estruturas moleculares básicas, uma primária que é formada por segmentos conjugados separados por quebra de conjugação e outra secundária que é dada pela orientação dos meros do longo dos segmentos conjugados. Esta estrutura secundária coplanar adotada pela cadeia na fase $\beta$ é mais alongada do que aquela torcida em forma de hélice em que anéis consecutivos assumem um ângulo de equilíbrio de aproximadamente $38^{\circ}$ (SRIWICHITKAMOL et al., 2006). A estrutura alongada reduziria o alto valor da tensão mecânica a temperaturas criogênicas.

Os resultados a seguir referem-se a filmes de PFO contendo fase $\beta$ induzida pela tensão mecânica por estiramento causada pela diferença entre os coeficientes de expansão 
linear do PFO e do substrato de quartzo durante o processo cíclico de resfriamento/aquecimento. A Figura 4.18 mostra espectros de emissão de um filme de PFO ultrafino (0,6 g/L em clorofórmio) durante o último ciclo de 4 ciclos de resfriamento (a) de $297 \mathrm{~K}$ a $5 \mathrm{~K}$ e aquecimento lento (b) ( 1 K/min). É interessante notar que nesse ciclo, a amostra apresenta características espectrais de um filme de PFO amorfo ao ser resfriada até 5 K (Figura 4.18(a)). Após alguns minutos nessa temperatura, emissões estreitas típicas da fase $\beta$ aparecem concomitantemente com aquelas do PFO amorfo conforme mostrado na Figura 4.10(a) da seção anterior. A fase $\beta$ se preserva com o aumento lento da temperatura que apenas alarga e altera as intensidades relativas dessas emissões. A presença da emissão das duas fases no espectro de emissão indica que a densidade de domínios da fase $\beta$ presentes no volume de migração é insuficiente para que todos os éxcitons excitados na região amorfa migrem para o domínio da fase $\beta$.

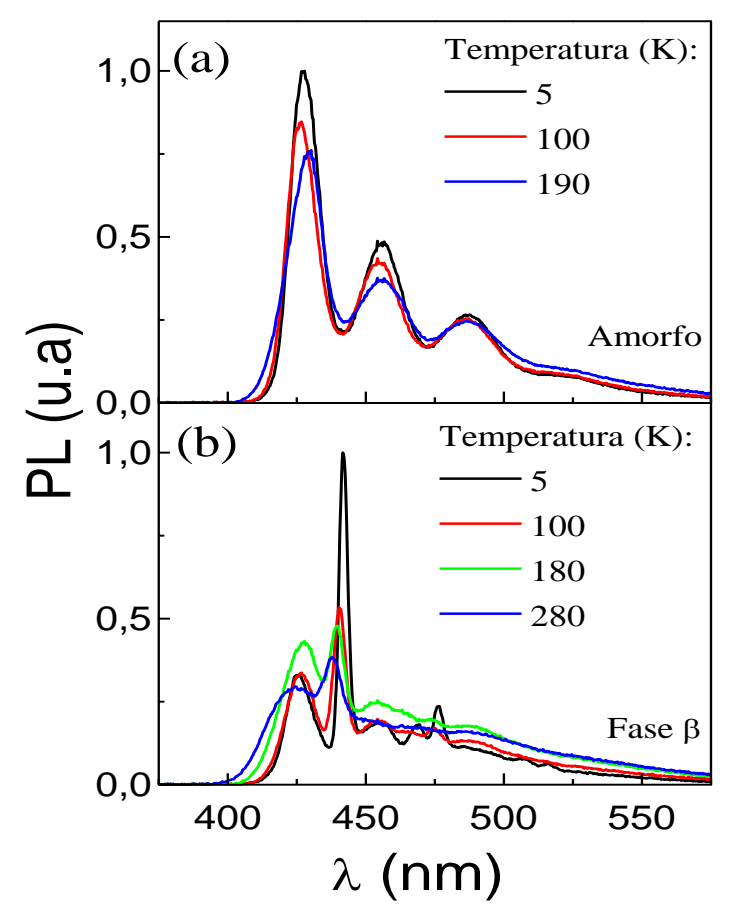

Figura 4.18: Espectros de emissão de um filme de PFO ultrafino $(0,6 \mathrm{~g} / \mathrm{L}$ em clorofórmio $)$ durante o último ciclo de 4 ciclos de resfriamento (a) de $297 \mathrm{~K}$ a $5 \mathrm{~K}$ e aquecimento lento (b) $(\sim 1 \mathrm{~K} / \mathrm{min})$.

Podemos controlar a geração e a densidade de domínios da fase $\beta$ fazendo o tratamento dos filmes ultrafinos em atmosfera contendo vapor de tolueno e monitorar a produção de fase $\beta$ através de medidas de absorbância. É sabido que o tratamento com vapor de solventes apolares pobres promove a solvatação das cadeias e o inchaço dos filmes, o que 
gera, consequentemente, uma tensão mecânica nos mesmos (GRELL et al., 1999). Esta tensão pode induzir o alinhamento das unidades monoméricas de modo a reduzir a energia elástica do filme. Conforme o procedimento descrito na seção 3.3, os filmes foram colocados no espectrômetro UV-Vis em uma câmera lacrada e com janelas por onde foi passado um fluxo contínuo nitrogênio gasoso contendo vapor de tolueno. Esse experimento foi realizado para dois filmes spin-coating: um com espessura menor que $10 \mathrm{~nm}$ (preparado com solução de PFO em clorofórmio 0,3 g/L) e outro com espessura de aproximadamente $41 \mathrm{~nm}$ (preparado com solução de PFO em clorofórmio 5,0 g/L). Como foi mostrado na Figura 4.16, o filme de espessura menor apresenta características espectrais da fase $\beta$ apesar de ser preparado com solução de clorofórmio, procedimento que gera filmes mais espessos estritamente amorfos.

A Figura 4.19 mostra a evolução temporal dos espectros de absorbância para os dois filmes descritos acima medidos em intervalos de tempo entre 0 e 20 minutos. Para a amostra mais espessa ( $5 \mathrm{~g} / \mathrm{L})$, a formação da fase $\beta$ é confirmada pelo aparecimento gradual da banda estreita na região de baixa energia em torno de $430 \mathrm{~nm}$ (Figura 4.19(b)). Esta banda não se desloca durante todo o processo, o que caracteriza a formação instantânea de segmentos de PFO altamente conjugados, ou seja, uma sequência bem definida de unidades repetitivas alinhadas que leva a uma conformação de segmentos da cadeia totalmente estendidos. Esse resultado sugere que o tamanho médio de segmentos da estrutura primária na cadeia do PFO produzidos pela desordem deve ser maior que 10 repetições de unidades monoméricas, o que é suficiente para produzir uma banda de absorção estreita relativa à fase $\beta$. Como vimos anteriormente, uma interação de longo alcance entre cadeias pode induzir a formação de domínios de dimensões nanométricas com as características da fase $\beta$. Portanto, o aumento da intensidade dessa banda é um indicativo de que a concentração da fase $\beta$ aumenta e satura após 10 min. Já a intensidade da banda conjugada larga em $390 \mathrm{~nm}$ relativa à fase amorfa apresenta uma pequena diminuição e um pequeno deslocamento para baixas energias nesse intervalo de tempo. A fração das áreas da banda da fase $\beta$ relativa à área da fase amorfa é de 9,3\% que é menor do que aquela encontrada para o mesmo filme preparado por spin-coating utilizando tolueno como solvente (ver seção 4.2). No entanto, as propriedades de emissão dos filmes submetidos ao vapor de tolueno são totalmente diferentes, como veremos a seguir.

Quando o mesmo processo é aplicado à amostra ultrafina (0,3 g/L), a banda adicional relativa a fase $\beta$ aparece pouco resolvida em $420 \mathrm{~nm}$ no flanco da banda relativa a fase amorfa que, por sua vez, cai em intensidade. Um ponto isosbéstico em $409 \mathrm{~nm}$ separa bem as variações opostas de intensidades das bandas das fases $\beta$ e amorfa. Este posicionamento da 
banda da fase $\beta$ para energias mais altas pode estar associado a uma desordem da estrutura primária imposta pela interface, que diminui o tamanho médio dos segmentos de PFO. O filme ultrafino atua como sonda da interface que sente as suas imperfeições através das alterações da estrutura. Como consequência, o tratamento a vapor de tolueno produz o alinhamento das unidades monoméricas nesses segmentos, o que gera tamanhos de conjugação efetivos menores. É interessante frisar que estes filmes de PFO ultrafinos já possuíam certo grau de ordenamento das unidades monoméricas (veja Figura 4.16(a)) mesmo sendo preparados através de solução de clorofórmio.

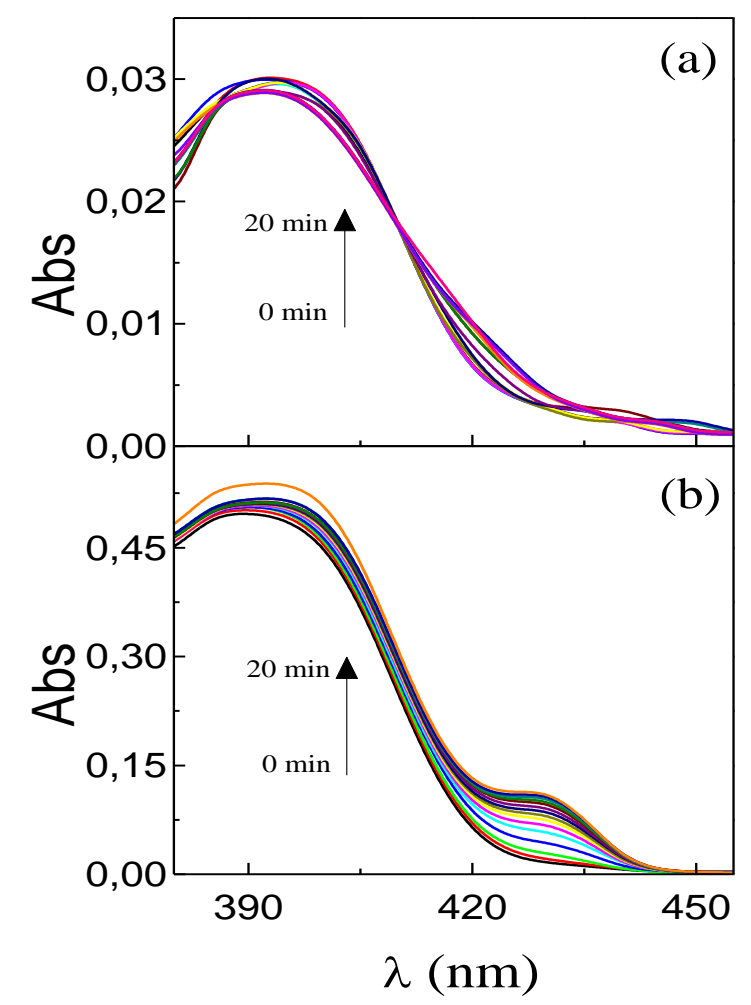

Figura 4.19: Evolução temporal dos espectros de absorbância medidas em intervalos de tempo entre 0 e 20 minutos para (a) um filme com espessura menor que $10 \mathrm{~nm}$ (preparado com solução de PFO em clorofórmio $0,3 \mathrm{~g} / \mathrm{L}$ ) e (b) outro com espessura de aproximadamente $41 \mathrm{~nm}$ (preparado com solução de PFO em clorofórmio 5,0 g/L).

A Figura 4.20 compara os espectros de luminescência medidos a (a) $5 \mathrm{~K}$ em um espectrômetro convencional através de excitação em 325 nm e (b) a 297 K em um microscópio confocal utilizando luz de excitação de $405 \mathrm{~nm}$ para os mesmos filmes spincoating preparados com clorofórmio (não tratados ou n/T) mostrados na Figura 4.16 e que sofreram posteriormente tratamento $(\mathrm{c} / \mathrm{T})$ com vapor de tolueno por 20 minutos. A $5 \mathrm{~K}$, o filme não tratado de $41 \mathrm{~nm}$ (preparado com solução de PFO em clorofórmio 5,0 g/l) apresenta-se no estado amorfo. Porém, ele apresenta estruturas vibracionais largas (espectro 
preto), mas com linhas de fônon zero e de fônon de ordem 1 resolvidas associadas a estiramento $\mathrm{C}-\mathrm{C}$ mais dobras $\mathrm{CH}(\mathrm{C}-\mathrm{O}$ e $\mathrm{C}=\mathrm{O})$ com energia em torno de $1200-1600 \mathrm{~cm}^{-1}$ (barras horizontais) como discutido na seção 4.1. Uma estimativa do acoplamento elétronfônon ou parâmetro $S$ leva ao valor de 0,68. Já a amostra não tratada com espessura menor que $10 \mathrm{~nm}$ (solução de PFO em clorofórmio 0,3 g/l) apresenta estruturas vibracionais mais estreitas e com a mesma separação energética. Porém, o acoplamento elétron-fônon é pequeno (parâmetro $S=0,28$ ) e o espectro está deslocado para o vermelho (setas verticais). O deslocamento energético e o pequeno valor de $S$ são indicativos da presença da fase $\beta$ ordenada e de mais baixa energia (espectro vermelho).

A mesma estrutura espectral se estreita e se desloca ainda mais para o vermelho com o tratamento em vapor de tolueno (espectro verde) que está associado a um melhor ordenamento planar dos anéis ao longo dos segmentos conjugados. As linhas espectrais de emissão para essa amostra estão mais resolvidas como mostra o ajuste gaussiano realizado para as linhas de fônon zero e para as linhas de fônon de primeira ordem entre 1200-1600 cm

${ }^{1}$. Uma estimativa do acoplamento elétron-fônon ou fator $S$ leva ao valor de 0,16 .
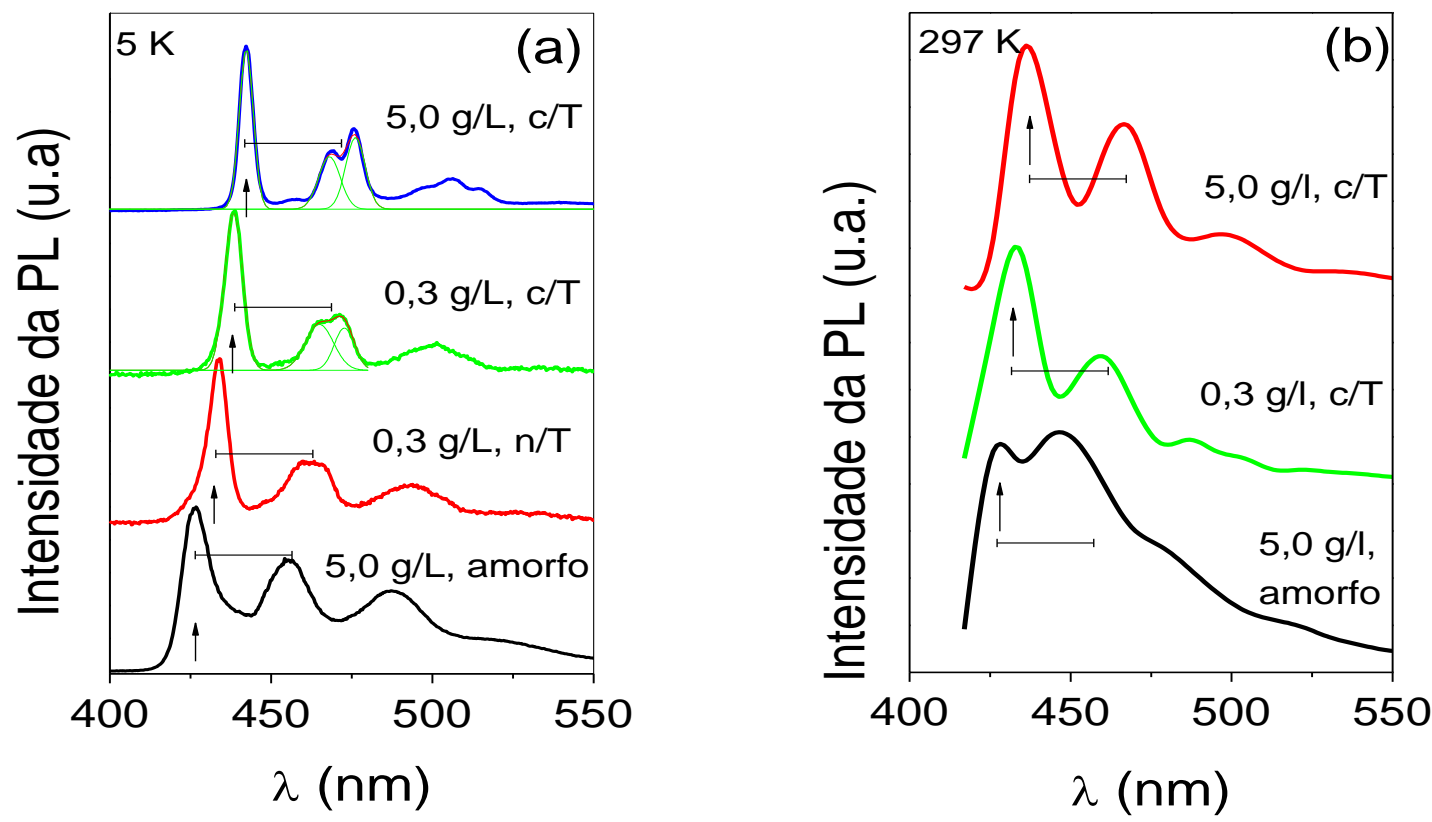

Figura 4.20: Espectros de luminescência medidos a (a) $5 \mathrm{~K}$ em um espectrômetro convencional através de excitação em $325 \mathrm{~nm}$ e (b) a $297 \mathrm{~K}$ em um microscópio confocal utilizando luz de excitação de $405 \mathrm{~nm}$ para os filmes spin-coating preparados com clorofórmio (não tratados ou $\mathrm{n} / \mathrm{T}$ ) mostrados na Figura 4.16 e que sofreram posteriormente tratamento com vapor de tolueno $(\mathrm{c} / \mathrm{T})$ por 20 minutos. As barras horizontais posicionam as transições envolvendo fônons longitudinais com energias entre 1200$1600 \mathrm{~cm}^{-1}$. As setas verticais posicionam as transições sem acoplamento com fônon. As linhas verdes são ajustes gaussianos destas transições. 
É muito interessante notar que, em contraste com outros sistemas poliméricos amorfos, as linhas de emissão dos filmes de PFO ultrafinos estão surpreendentemente estreitas $(4,3 \mathrm{~nm}$ ou $25 \mathrm{meV})$. Estas propriedades espectrais melhoram ainda mais quando o filme de $41 \mathrm{~nm}$ é tratado com tolueno (Figura 4.20(a) linha azul). As linhas espectrais se deslocam ainda mais para o vermelho e se estreitam vertiginosamente quando se compara com a emissão da mesma amostra antes do tratamento com vapor de tolueno (espectro preto). Os ajustes com gaussianas dão evidência aquelas estruturas vibracionais posicionadas em $1286 \mathrm{~cm}^{-1} 1371 \mathrm{~cm}^{-1}$ e em $1612 \mathrm{~cm}^{-1}$. Os acoplamentos elétron-fônon para estas transições são 0,12 e 0,29 , respectivamente. Outro aspecto importante é que as emissões para esta amostra não apresentam traços transições associadas à fase amorfa (espectro preto deslocado para altas energias). A coexistência das duas fases pode ser observada nas amostras spin-coating de PFO preparadas com solução de tolueno (Figura 4.10 da seção 4.2) e se deve à baixo número de domínios da fase $\beta$ dentro do raio de migração do éxciton. Deve-se esperar uma densidade muito maior desta fase nas amostras tratadas com vapor de tolueno do que aquela estimada de dois a quatro domínios para as amostras preparadas por spin-coating com solução de tolueno. Trabalhos anteriores conseguem a saturação do processo de formação da fase $\beta$ para tratamentos longos em vapor de tolueno. No entanto, tempos inferiores a 10 min são suficientes para se obter esta saturação nos filmes ultrafinos tratados nas condições do presente trabalho.

Os espectros de emissão detectados por microscopia confocal dos mesmos filmes à temperatura ambiente mostrados na Figura 4.20(b) sofrem fortes mudanças espectrais devido a desordem térmica imposta sobre as cadeias poliméricas conforme foi visto na seção anterior. A variação mais surpreendente está na redução da energia de fônon (barras horizontais) e no aumento acoplamento elétron-fônon. A desordem térmica altera a estrutura primária através da redução do tamanho de conjugação efetivo $n$, o que leva necessariamente a um aumento da largura espectral $\left(|\Delta E|=\left[\varepsilon_{1} / n^{2}(T)\right] \Delta n\right)$, a um deslocamento da energia de emissão para altas energias $\left(E_{g}=\varepsilon_{0}+\varepsilon_{1} / n\right.$ ) e a um aumento do acoplamento elétron-fônon $S$ (BORGES, 2001; FACETO, 2007). No entanto, o parâmetro $S$ é surpreendentemente pequeno para a amostra ultrafina com ou sem tratamento no vapor de tolueno. Vimos pelos espectros de absorbância (Figura 4.11) que a interface impõe uma desordem na estrutura primária da cadeia do PFO de modo a reduzir o tamanho de conjugação efetivo $n$ desse polímero. Este efeito é também confirmado nos espectros de emissão da Figura 4.20(a) medidos a $5 \mathrm{~K}$, já que a emissão dos filmes ultrafinos $(0,3 \mathrm{~g} / \mathrm{l})$ tratados com vapor de tolueno possui um deslocamento para $\mathrm{o}$ 
vermelho menor que aquele observado para o filme mais espesso de $41 \mathrm{~nm}$. Nós sugerimos que o pequeno valor do acoplamento elétron-fônon para os filmes ultrafinos se deve à imobilização da cadeia polimérica imposta pela interface de quartzo. Esta rigidez da cadeia impede as mudanças de conformação molecular da molécula excitada. Por exemplo, as deformações elásticas longitudinais ao longo do eixo principal da cadeia envolvem duas componentes: as mudanças no ângulo da ligação e a deformação das ligações $\mathrm{C}-\mathrm{C}$ ou $\mathrm{C}=\mathrm{C}$ dessas moléculas. Já as vibrações ortogonais a este eixo são chamadas de vibrações transversais que podem ser representadas por dois modos: o torcional (hélice) e a dobra (deformação). Repulsões estéricas ou tensões na interface podem estar atuando de modo a impedir que a cadeia adote uma dada configuração quando esta se encontra no estado excitado. Muitos dessas deformações como a torção dos monômeros, podem estar rígidas pela presença da interface. Por outro lado, quanto mais distante a região do filme polimérico está do substrato menor é a tensão e impedimentos estéricos. Baseado nisso, a formação de filmes proposto para explicar os resultados observados nesse trabalho está ilustrado na Figura 4.17.

\subsection{Caracterização da camada de $\mathrm{TiO}_{2}$}

Nanopartículas de $\mathrm{TiO}_{2}$ foram depositadas sobre o substrato de quartzo por spincoating a partir de uma solução concentrada de $\mathrm{TiO}_{2}$ em álcool etílico descrita na seção 3.1. A Figura 4.21 mostra as imagens obtidas por microscopia eletrônica de varredura (MEV) da camada de nanopartículas de $\mathrm{TiO}_{2}$. Como pode ser observada nas imagens de $\mathrm{MEV}$, a camada de $\mathrm{TiO}_{2}$ obtida com esta pasta é homogênea e é constituída por aglomerados de nanopartículas que formam uma microestrutura porosa. As nanopartículas que formam a camada de $\mathrm{TiO}_{2}$ sofreram ativação superficial através de um tratamento térmico posterior a $723 \mathrm{~K}$ por 30 minutos em atmosfera ambiente. Este processo preserva a integridade das nanopartículas e mantém a fase anatase (IBALDO, 2010) indicada pelo fabricante que é altamente reativa. Assim, espera-se que a superfície do $\mathrm{TiO}_{2}$ fica isenta de cargas devido a neutralização de possíveis radicais carregados. 


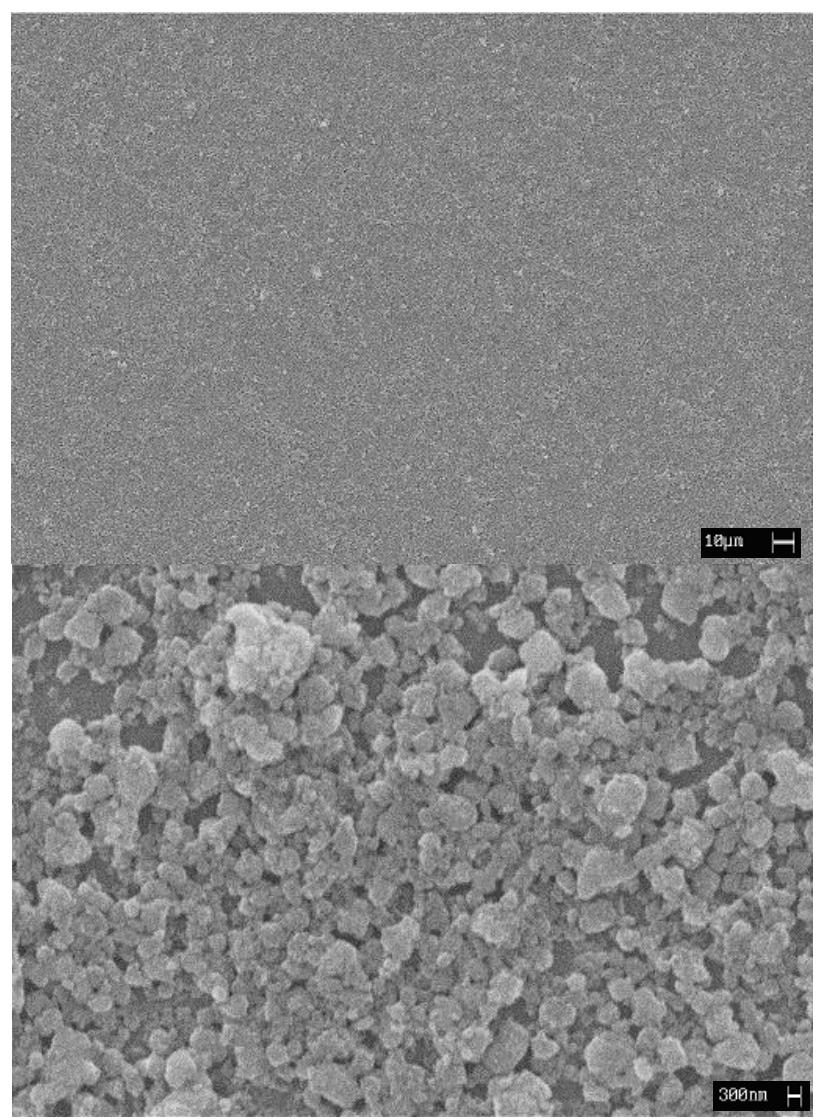

Figura 4.21: Imagens obtidas por MEV da camada de nanopartículas de $\mathrm{TiO}_{2}$ depositada a partir da pasta de $\mathrm{TiO}_{2}$ sobre substrato de quartzo.

A Figura 4.22 mostra a PL da camada de nanopartículas de $\mathrm{TiO}_{2}$ medidas a $297 \mathrm{~K}$ e a 5 K. Já a $5 \mathrm{~K}$, a $\mathrm{PL}$ do $\mathrm{TiO}_{2}$ é caracterizada por um máximo de emissão centrada em aproximadamente $544 \mathrm{~nm}$ e por um pico de emissão de maior energia em torno de $387 \mathrm{~nm}$. Por outro lado, as camadas de $\mathrm{TiO}_{2}$ praticamente não apresentam fotoluminescência a temperatura ambiente. Isso indica que possivelmente os estados excitados estão sendo desativados por mecanismos de decaimento não radiativo. 


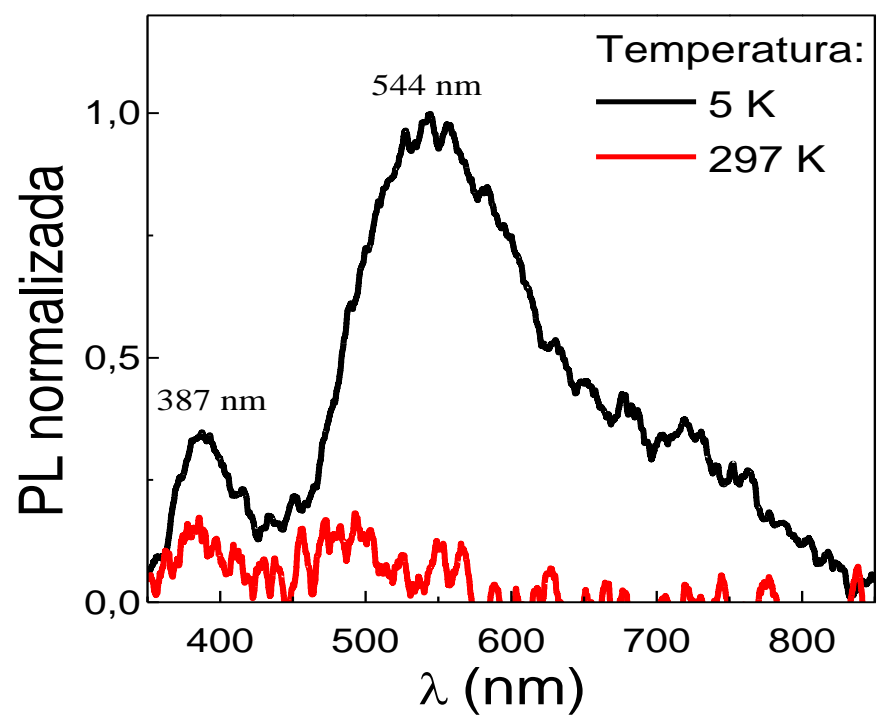

Figura 4.22: PL da camada de nanopartículas de $\mathrm{TiO}_{2}$ medidas a $297 \mathrm{~K}$ e $5 \mathrm{~K}$. Excitação em $325 \mathrm{~nm}$ utilizando um laser de He-Cd.

\subsection{Processos fotofísicos nas proximidades da interface $\mathrm{TiO}_{2} / \mathrm{PFO}$}

$\mathrm{Na}$ interface de materiais inorgânicos e orgânicos, os éxcitons fotogerados no material orgânicos podem se dissociar através da transferência de carga ou por transferência de energia. O mecanismo de dissociação do éxciton depende da combinação da banda energética dos materiais que compõe a interface. Por exemplo, em sistemas metal/semicondutores orgânicos a combinação das bandas energéticas é tal que há a transferência de energia ressonante entre estes materiais (BORGES, 2005). Uma evidência experimental de que pode haver transferência de energia entre dois materiais é através da análise do espectro de absorção do material aceitador e da PL do material doador. Se há sobreposição entre esses dois espectros, então pode haver a transferência de energia raditativa ou não radiativa (transferência de energia ressonante). A primeira envolve a emissão da radiação da molécula doadora e re-absorção da radiação pela molécula aceitadora, já, a segunda é mediada pela interação ressonante entre o dipolo de transição doador e o dipolo de transição do aceitador.

Já em interfaces de nanopartículas semicondutoras/semicondutores orgânicos há a transferência de elétrons do material inorgânico para as nanopartículas (HAINS et al., 2010). Neste caso, a transferência de carga ocorre pela sobreposição ou ressonância entre estados elétron excitado na banda $\pi^{*}$ (ou buraco na banda $\pi$ ) do doador (semicondutor orgânico) com um estado do aceitador (nanopartículas inorgânica).

No sistema estudado no presente trabalho, as bandas de condução do $\mathrm{TiO}_{2}$ e os orbitais 
$\pi^{*}$ do PFO se superpõem de tal maneira que propicia a transferência de elétron do PFO para o $\mathrm{TiO}_{2}$, Figura 4.23(a). Além disso, a garantia de que não há transferência de energia radiativa (re-absorção) e não radiativa (transferência de energia ressonante) entre o $\mathrm{PFO}$ e o $\mathrm{TiO}_{2}$ é observada na Figura 4.23(b) que mostra um espectro de absorção típico de nanopartículas de $\mathrm{TiO}_{2}$ juntamente com a PL do PFO. Como pode ser observado na figura, não há uma sobreposição entre o espectro de absorção do material aceitador $\left(\mathrm{TiO}_{2}\right)$ com a fotoluminescência do material doador (PFO). Portanto, a interface $\mathrm{TiO}_{2} / \mathrm{PFO}$ é ideal para a transferência de carga. Nesta seção são apresentados os resultados da investigação do processo de transferência de carga na interface $\mathrm{TiO}_{2} / \mathrm{PFO}$ utilizando técnicas de espectroscopia ópticas.

(a)

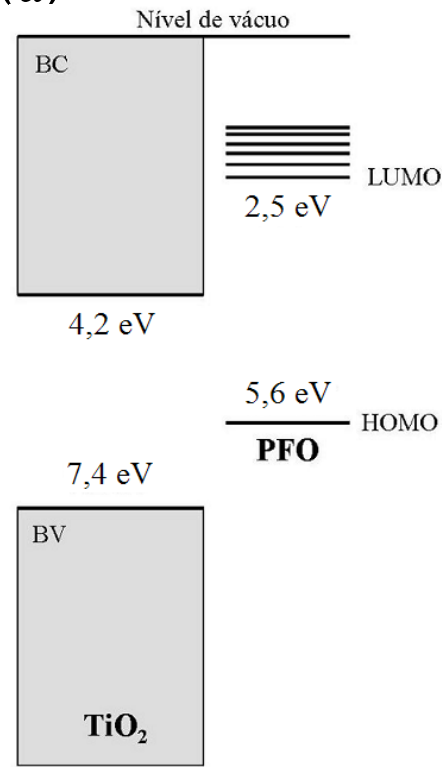

(b)

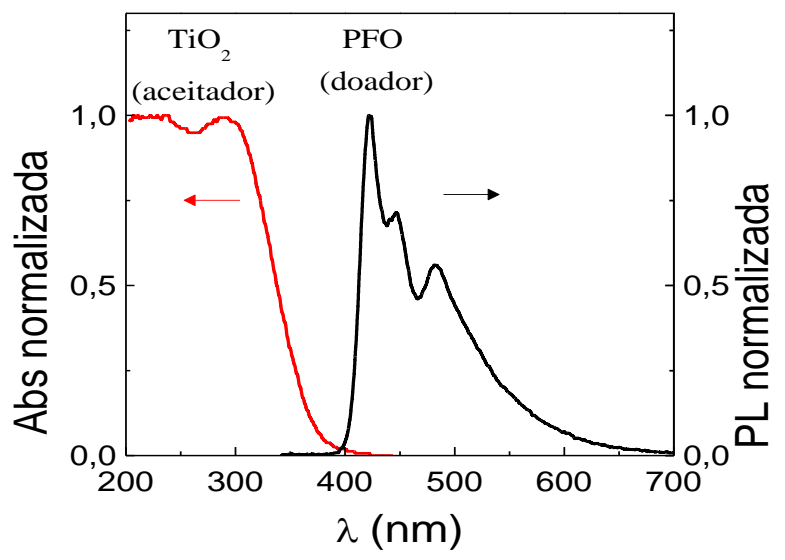

Figura 4.23: (a) Estrutura de banda energética do $\mathrm{TiO}_{2}$ (REEJA-JAYAN \& MANTHIRAM, 2010) e do PFO (LIAO et al., 2000). (b) Absorbância do $\mathrm{TiO}_{2}$, dados retirados de (CHEN \& MAO, 2007), e PL do filme do PFO ambos a temperatura ambiente. Na PL excitação em $325 \mathrm{~nm}$ utilizando laser de He-Cd.

A Figura 4.24(a) mostra a imagem de uma amostra investigada no presente trabalho. Metade da amostra contém uma camada de nanopartículas de $\mathrm{TiO}_{2}$ depositada sobre a superfície do substrato de quartzo. Um filme ultrafino de PFO foi depositado por spincoating, recobrindo homogeneamente as duas superfícies em consideração. A região em destaque evidencia a interface que separa o filme do PFO sobre quartzo e o mesmo filme sobre $\mathrm{TiO}_{2}$. O filme do PFO sobre o quartzo será utilizado como referência para comparação com a amostra contendo a interface $\mathrm{TiO}_{2} / \mathrm{PFO}$.

As Figuras 4.24(b) e (c) apresentam imagens de microscopia confocal de fluorescência de um filme de PFO de aproximadamente $6 \mathrm{~nm}$ na região da interface indicada na Figura 
4.24(a) com foco posicionado sobre as superfícies do quartzo e do $\mathrm{TiO}_{2}$, respectivamente. Nota-se que pouca variação da focalização entre as duas imagens é uma indicação de que a espessura do filme de $\mathrm{TiO}_{2}$ é da mesma ordem de magnitude ou menor que a resolução em z do microscópio (objetiva 63x/água, abertura numérica $\mathrm{N}=1,2$ ) de aproximadamente $300 \mathrm{~nm}$. Pode-se observar também que não há acúmulo de PFO na interface. No entanto, as imagens por luminescência utilizadas nesta seção foram coletadas em posições distantes da região da interface que separa os dois filmes.

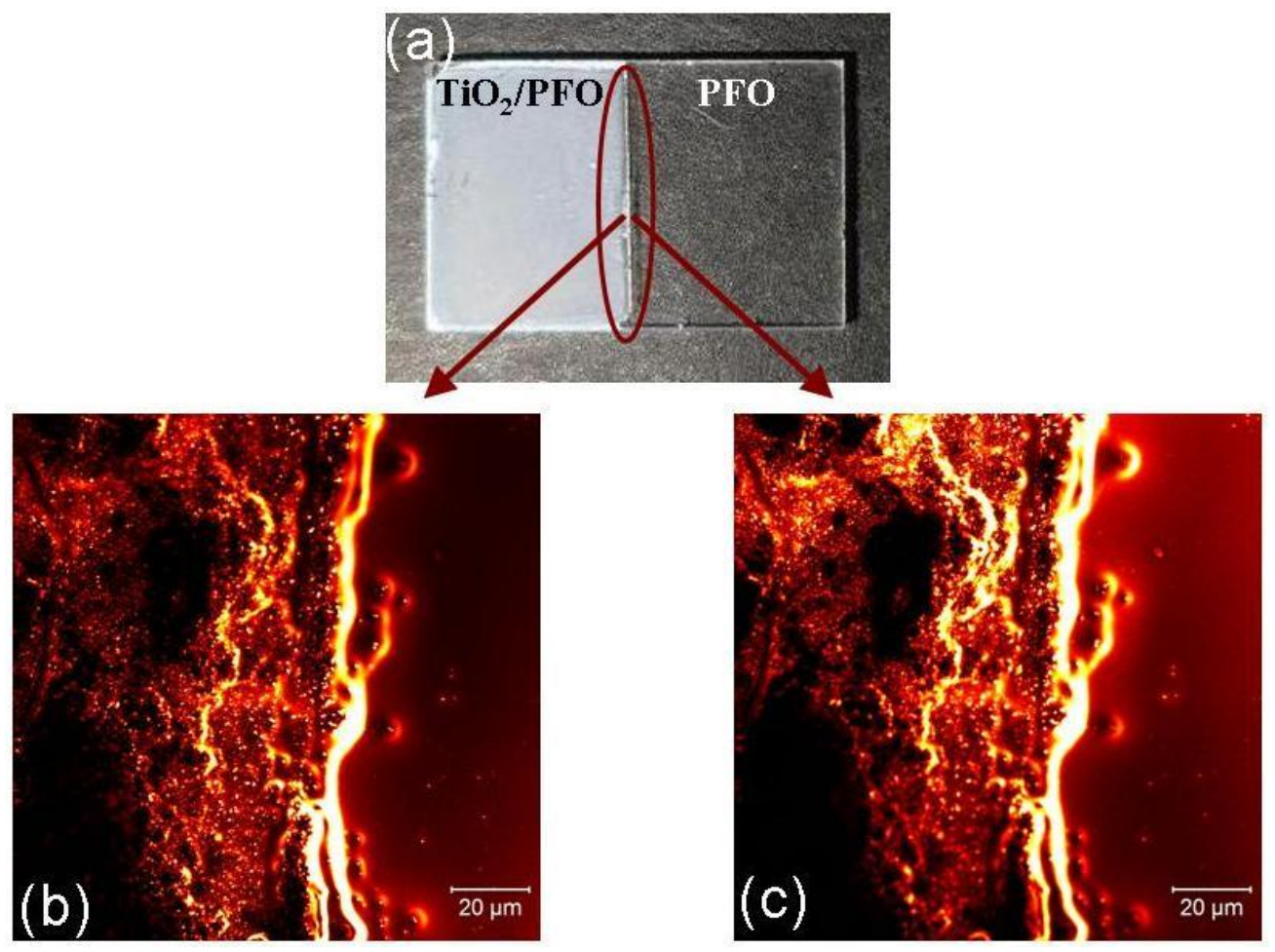

Figura 4.24: (a) Foto da amostra utilizada no presente trabalho. Imagens de microscopia confocal de fluorescência da região indica com foco em: (b) interface $\mathrm{TiO}_{2} / \mathrm{PFO}$ e (c) filme de PFO sobre o quartzo.

A caracterização dos processos ópticos próximos à interface $\mathrm{TiO}_{2} / \mathrm{PFO}$ foi realizada primeiramente através de medidas de microscopia confocal por varredura. A Figura 4.25 apresenta os resultados para filmes de PFO de diferentes espessuras preparados em solução de clorofórmio de concentrações a) 0,3; b) 0,6; c) 1,25 (5,9 nm de espessura); d) 2,5 (17 nm de espessura) e e) 5,0 g/L (41 nm de espessura), respectivamente. Em cada figura, as imagens (em cima) foram feitas no modo espectral dos filmes de PFO sobre as superfícies de $\mathrm{TiO}_{2}(\mathrm{em}$ cima à direita) e de quartzo (em cima à esquerda). O contraste de cada figura foi alterado para se ter melhor visualização. Esta modificação não altera as intensidades e espectros descritos a seguir. Além disso, a posição das imagens foram escolhidas em pontos contendo imperfeições ou defeitos que possibilitaram a focalização sobre os filmes extremamente finos. 
A Figura 4.25 apresenta ainda os perfis de intensidade em $434 \mathrm{~nm}$ tomados ao longo de uma linha de cor branca e a distribuição de intensidades avaliada em cada pixel sobre a área de cada imagem são mostrados abaixo das referidas figuras. Nesse caso, o tamanho da área é de 150x150 $\mu \mathrm{m}$ resolvida em 1024x1024 pixels.

Finalmente, os espectros de emissão estão mostrados na última linha da Figura 4.25 e foram avaliados nos pontos marcados com cruzes brancas e vermelhas sobre cada filme de PFO depositado sobre $\mathrm{TiO}_{2}$ e quartzo, respectivamente. Cada ponto sondado nessas imagens durante a varredura do laser de $405 \mathrm{~nm}$ corresponde a um espectro avaliado em uma região focal de diâmetro de aproximadamente $250 \mathrm{~nm}$ (objetiva 63x, água, abertura numérica $\mathrm{N}=1,2$ ). Vale ressaltar que as amostras foram excitadas numa região na qual o $\mathrm{TiO}_{2}$ não absorve $(405 \mathrm{~nm})$ e, portanto, a $\mathrm{PL}$ medida na amostra $\mathrm{TiO}_{2} / \mathrm{PFO}$ corresponde a fotoluminescência somente das moléculas de PFO que estão sobre as nanopartículas de $\mathrm{TiO}_{2}$.

Nota-se primeiramente que a intensidade da emissão cai consideravelmente quando o filme de PFO está depositado sobre o $\mathrm{TiO}_{2}$. Além disso, a intensidade para os filmes de PFO mais espessos depositados sobre o $\mathrm{TiO}_{2}$ são razoavelmente homogêneas, o que pode ser visto pelos perfis de intensidade. Para essas amostras, a largura da distribuição de intensidade são as mesmas para o PFO depositado sobre a superfície de quartzo tomada como referência (Io) e sobre o $\mathrm{TiO}_{2}(I)$, que é extremamente rugosa. Isto é uma indicação de que a cobertura do $\mathrm{TiO}_{2}$ está completa nos filmes espessos. É interessante observar que as intensidades da PL do PFO sobre o $\mathrm{TiO}_{2}$ são praticamente zero para as amostras preparadas com concentrações de PFO (a) 0,30 g/L, (b) 0,60 g/L, (c) 1,25 g/L (5,9 nm de espessura), ou seja, com espessuras menores que o raio médio migração típico de $10 \mathrm{~nm}$. Como mostra a Figura 4.26, a razão I/Io entre as intensidades médias avaliadas das distribuições das Figuras 4.25 sobre o $\mathrm{TiO}_{2}$ e sobre o quartzo aumenta conforme o esperado na forma sigmoidal e tem seu ponto de inflexão em $(13 \pm 3) \mathrm{nm}$ (linha vermelha). A razão I/Io não alcança os $100 \%$ (linha preta tracejada) para espessuras do PFO muito maiores que $13 \mathrm{~nm}$ e se deve a processos de espalhamento sobre a superfície do $\mathrm{TiO}_{2}$. Em resumo, esses dados permitem estimar o raio de migração do éxciton no PFO em torno de $13 \mathrm{~nm}$ e demonstra que o éxciton migra até a interface dentro do seu tempo de vida, onde é dissociado e seu elétron é transferido eficientemente para o $\mathrm{TiO}_{2}$. Existe, portanto, uma região escura ou sem emissão (em cinza) na camada de PFO (em lilás), próximas da interface com o $\mathrm{TiO}_{2}$, para espessuras menores que $13 \mathrm{~nm}$ conforme mostra a ilustração na Figura 4.26. 
Capítulo 4 - Resultados e Discussão

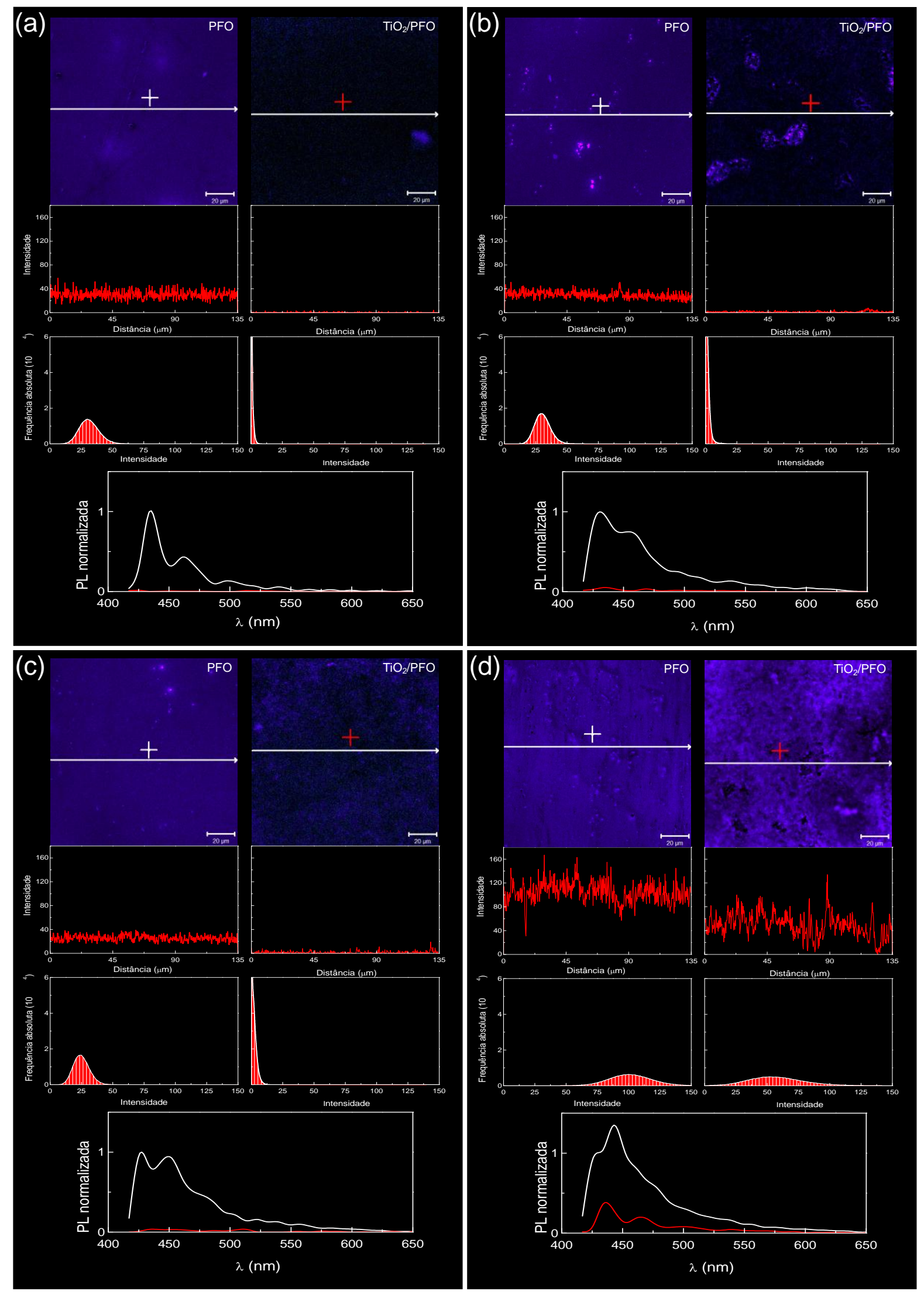




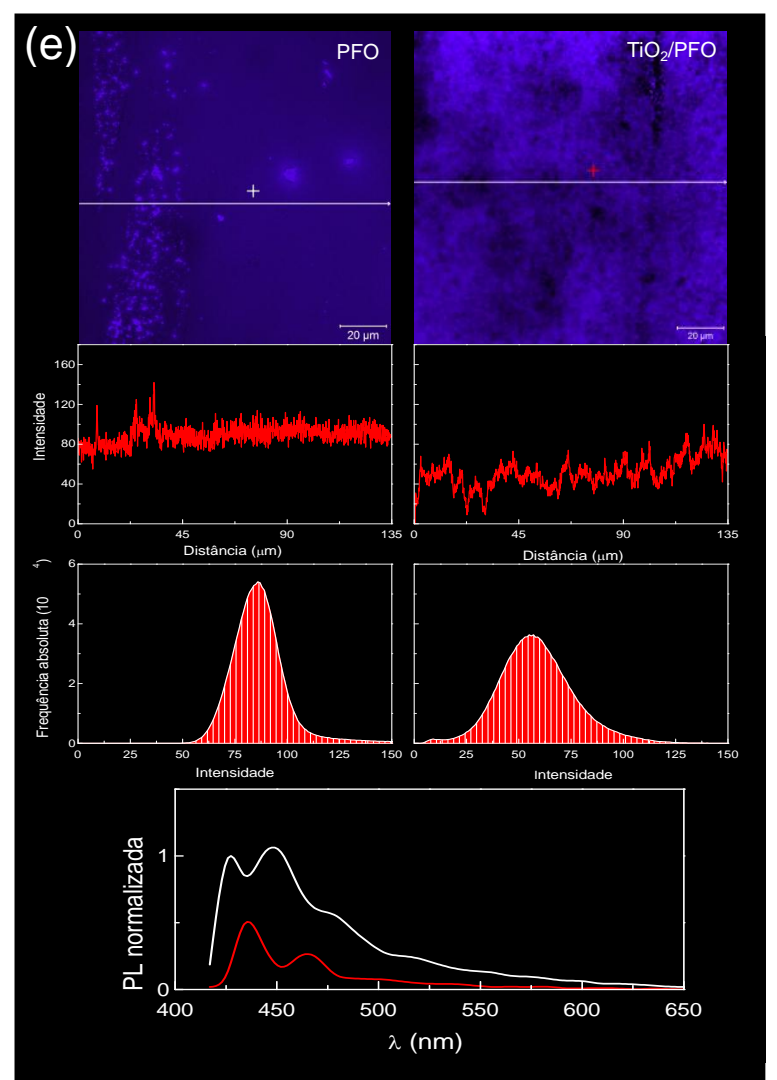

Figura 4.25: Resultados de microscopia confocal de fluorescência para filmes com diferentes espessuras: (a) $0,30 \mathrm{~g} / \mathrm{L}$, (b) $0,60 \mathrm{~g} / \mathrm{L}$, (c) $1,25 \mathrm{~g} / \mathrm{L}$ (5,9 nm de espessura), (d) 2,50 g/L (17 nm de espessura) e (e) (41 nm de espessura). Medidas realizadas a temperatura ambiente com excitação em $405 \mathrm{~nm}$. Cada figura mostra a imagem no modo espectral do filme de PFO sobre o quartzo (PFO) e sobre o $\mathrm{TiO}_{2}\left(\mathrm{TiO}_{2} / \mathrm{PFO}\right)$, o perfil de intensidade em $434 \mathrm{~nm}$ ao longo da linha de cor branca na imagem, a distribuição de intensidades (frequência absoluta pela intensidade) sobre a área sondada e o espectro de PL avaliado sobre os pontos marcados com cruzes bancas e vermelhas nas imagens espectrais.

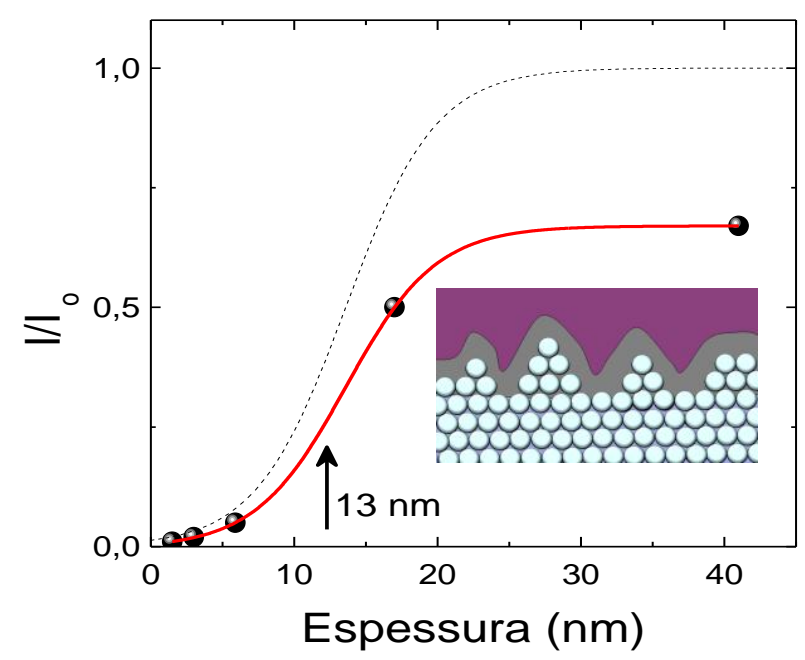

Figura 4.26: Razão I/Io entre as intensidades médias avaliadas das distribuições das Figuras 4.24 sobre o $\mathrm{TiO}_{2}$ e sobre o quartzo em função da espessura dos filmes de PFO (pontos pretos). A linha vermelha representa um ajuste sigmoidal dos dados experimentais e a linha preta tracejada representa o caso ideal em que a intensidade sobre o quartzo $I o$ é igual a intensidade medida sobre o $\mathrm{TiO}_{2} I$ para espessuras do filme de PFO muito maiores que $13 \mathrm{~nm}$. Medidas realizadas a temperatura ambiente. 


\section{Capítulo 4 - Resultados e Discussão}

Devido aos processos concorrentes não radiativos de transferência de carga, espera-se que o tempo de decaimento do estado excitado do polímero PFO seja menor do que o seu tempo vida em condições em que não há a transferência de carga. Medidas do decaimento da fluorescência com resolução temporal podem fornecer informações sobre a eficiência dos processos envolvidos na emissão. Para verificar isso, foram realizadas medidas de microscopia de fluorescência resolvida no tempo envolvendo a técnica de imagem do tempo de vida da fluorescência (FLIM), que estão mostradas na Figura 4.27. Na técnica FLIM, cada ponto de imagem ou pixel sobre a área de varredura está associado a uma medida de decaimento da fluorescência com o tempo. Já na imagem FLIM, cada ponto da imagem é associado a um tempo de decaimento avaliado pelo software. Assim, a imagem é obtida por contraste formado pela variação em tempo de decaimento ao longo da área de varredura. Para melhor visualização, essa figura compara apenas os dados das amostras mais fina $(0,3 \mathrm{~g} / \mathrm{L})$ e mais espessa ( $5 \mathrm{~g} / \mathrm{L}$ ). Além disso, por simplicidade, a imagem FLIM corresponde somente a amostra mais espessa. Essa imagem foi feita sobre uma região do $\mathrm{PFO/quartzo} \mathrm{próxima} \mathrm{à}$ interface $\mathrm{TiO}_{2} /$ Quartzo (Figura 4.27(a)) e sobre uma área do $\mathrm{TiO}_{2}$ (Figura 4.27(b)). Nesse caso, o tamanho da área é de $150 \times 150 \mu \mathrm{m}$ resolvida em $512 \times 512$ pixels. O contraste em escala de cor obtido na região da interface $\mathrm{TiO}_{2} / \mathrm{Quartzo}$ (Figura 4.27(a)) é nítido, portanto, se deve à variação do tempo de decaimento do PFO sobre o quartzo (tempo longos associados a cores deslocadas para o vermelho) e sobre o $\mathrm{TiO}_{2}$ (tempo curtos associados a cores deslocadas para o azul). Já a imagem FLIM sobre o $\mathrm{TiO}_{2}$ (Figura 4.27(b)) é homogênea sobre toda a área, o que é uma forte indicação de que o PFO está cobrindo a superfície do $\mathrm{TiO}_{2}$. 


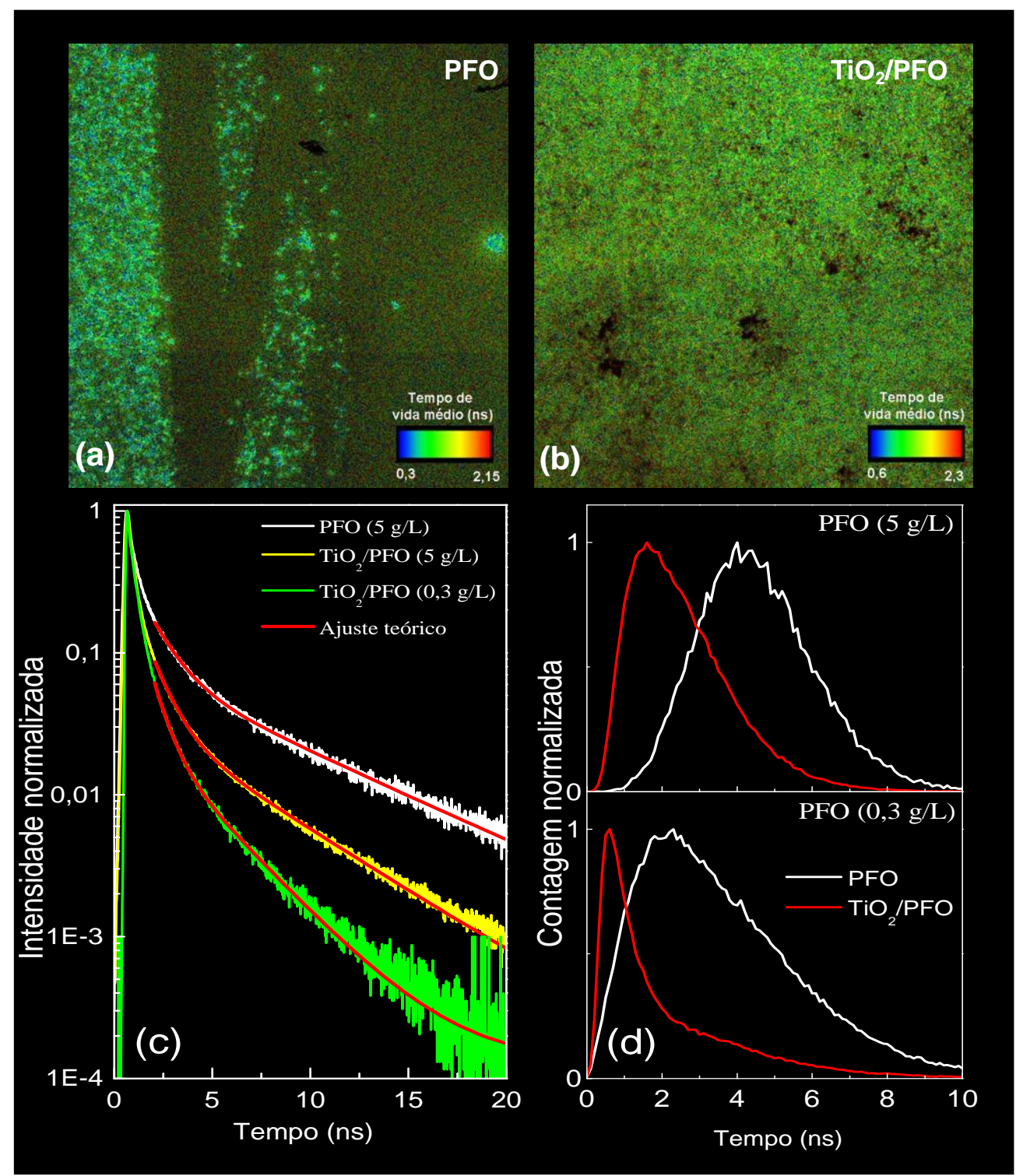

Figura 4.27: Imagens FLIM do filme de PFO preparado com clorofórmio (amostra espessa, $5 \mathrm{~g} / \mathrm{L}$ ) medida sobre uma região próxima à interface $\mathrm{TiO}_{2} /$ Quartzo (a) e sobre uma área do $\mathrm{TiO}_{2}$ (b). Comparação entre os decaimentos temporais da fluorescência (c) tomado sobre a superfície de quartzo para o filme de PFO espesso preparado com solução de clorofórmio a $5 \mathrm{~g} / \mathrm{L}$ (linha branca); para o mesmo filme sobre $\mathrm{TiO}_{2}$ (linha amarela), e para o filme de PFO mais fino sobre $\mathrm{TiO}_{2}$ preparado a 0.3 $\mathrm{g} / \mathrm{L}$ (linha verde). Comparação entre as contagens normalizadas do tempo de decaimento médio $\tau$ (d) calculadas para o filme de PFO espesso preparado $(5 \mathrm{~g} / \mathrm{L})$ e para o filme de PFO mais fino $(0.3 \mathrm{~g} / \mathrm{L})$.

A Figura 4.27(c) compara os decaimentos temporais da fluorescência tomado sobre a superfície de quartzo para o filme de PFO espesso preparado com solução de clorofórmio a 5 g/L e assumido aqui como referência (linha branca); para o mesmo filme sobre $\mathrm{TiO}_{2}$ (linha amarela), e para o filme de PFO mais fino sobre $\mathrm{TiO}_{2}$ preparado a $0,3 \mathrm{~g} / \mathrm{L}$ (linha verde). Estes decaimentos temporais foram obtidos por meio da soma de todos os decaimentos avaliados em cada ponto de imagem e representa, desta fora, o decaimento médio na área da imagem sondada. Além disso, os decaimentos temporais da fluorescência possuem duas contribuições 


\section{Capítulo 4 - Resultados e Discussão}

(linhas vermelhas) por dois decaimentos exponenciais distintos da forma

$$
\frac{I(t)}{I(0)}=A_{1} e^{-t / \tau_{1}}+A_{2} e^{-t / \tau_{2}}
$$

descritos por um tempo curto $\tau_{1}$, um tempo longo $\tau_{2}$ e amplitudes $A_{1}$ e $A_{2}$. O tempo $\tau_{1}$ está associado a processos não radiativos no PFO que extinguem o éxciton com taxas rápidas $1 / \tau_{1}$ logo após a sua excitação. Os éxcitons que sobrevivem aos processos não radiativos decaem em tempos posteriores da ordem de $\tau_{2}$ próximas ao tempo de decaimento natural com taxas menores de $1 / \tau_{2}$. Porém, a Figura 4.27(c) mostra que tanto $\tau_{1}$ e $\tau_{2}$ dependem consideravelmente da espessura do filme. Os valores destes tempos serão apresentados com detalhes na discussão mais abaixo.

Além de $\tau_{1}$ e $\tau_{2}$, é possível obter um tempo de decaimento médio $\tau_{\mathrm{m}}$ para cada ponto da imagem FLIM, o que permite uma visualização das alterações nos tempos de vida sobre a área estudada. A Figura 4.27(d) faz a comparação entre as contagens normalizadas desse tempo de decaimento médio $\tau_{\mathrm{m}}$ calculadas para o filme de PFO espesso preparado $(5 \mathrm{~g} / \mathrm{L})$, assumido aqui como referência, e para o filme de PFO mais fino $(0.3 \mathrm{~g} / \mathrm{L})$. As distribuições de $\tau_{\mathrm{m}}$ associadas ao PFO sobre o substrato de quartzo são mostradas por linhas brancas e aquelas associadas ao PFO sobre o $\mathrm{TiO}_{2}$ por linhas vermelhas. Nota-se, primeiramente, que as distribuições de $\tau_{\mathrm{m}}$ para os filmes depositados sobre a superfície de $\mathrm{TiO}_{2}$ se deslocam para tempos de decaimentos menores, sugerindo que processos não radiativos rápidos estão atuando de forma eficiente sobre essa superfície e concorrendo com os processos envolvendo tempos mais longos medidos sobre os filmes sobre o quartzo tomados como referência. Além disso, a distribuição se estreita consideravelmente para a amostra fina sobre a superfície de $\mathrm{TiO}_{2}$, sugerindo que processos com tempos longos estão sendo praticamente suprimidos nessas amostras. Estes processos rápidos que extinguem os éxcitons logo após eles serem criados e estão associados com aqueles que promovem a dissociação eficiente destes éxcitons na interface. Considerando a posição das distribuições apresentadas acima, podemos associar o tempo de decaimento médio medido sobre a superfície de quartzo para o filme espesso (5 $\mathrm{g} / \mathrm{L})$ ao tempo de decaimento natural do éxciton $\tau_{\mathrm{o}}$, ou seja, $\tau_{\mathrm{m}}=4,5 \mathrm{~ns} \sim \tau_{\mathrm{o}}$. Já o decaimento médio avaliado para o filme fino $(0,3 \mathrm{~g} / \mathrm{L})$ sobre a superfície de $\mathrm{TiO}_{2}$ pode ser associado basicamente ao processo não radiativo de dissociação $\tau_{\mathrm{d}}$ do éxciton na interface, ou seja, $\tau_{\mathrm{m}}=0,5 \mathrm{~ns} \sim \tau_{\mathrm{d}}$. Assim, a eficiência de dissociação $E_{d}$ pode ser escrita por 


$$
E_{d}=\left(1+\frac{\tau_{d}}{\tau_{o}}\right)^{-1}
$$

ou seja, a eficiência de dissociação do éxciton na região próxima à interface (espessura < 13 $\mathrm{nm})$ pode ser estimada como sendo em torno de $90 \%$. Conforme foi mostrado na Figura 4.25 acima, as fortes quedas da intensidade na região escura $\left(\mathrm{I} / \mathrm{I}_{\mathrm{o}} \sim 0.02\right)$ sugerem que este valor está subestimado e que a eficiência de dissociação do éxciton pelo $\mathrm{TiO}_{2}$ deve ser próxima de (1$\left.\mathrm{I} / \mathrm{I}_{\mathrm{o}}\right)=98 \%$.

É interessante também conhecer a dependência de $\tau_{1}$ e $\tau_{2}$ com a espessura do filme de PFO. A Figura 4.28 faz uma comparação entre estes dois tempos de decaimento dentro de uma faixa de tempo que abrange quase duas ordens de grandezas (escala log) em função da concentração do PFO em clorofórmio sobre a superfície de quartzo (linha preta) e sobre o $\mathrm{TiO}_{2}$ (linha vermelha). Os decaimentos da emissão foram tomados para a faixa espectral $\lambda>490 \mathrm{~nm}$. Primeiramente, pode-se observar a grande diferença entre de $\tau_{1}$ e $\tau_{2}$. O primeiro varia na região de subnanosegundos e $\tau_{2}$ na faixa de tempos de nanosegundos. Tempos medidos da ordem de nanosegundos são associados ao decaimento radiativo natural $\tau_{\mathrm{o}}$ do éxcitons em polímeros (SHAW et al., 2010). Já tempos de decaimento menores $\tau$ estão associados a processos não radiativos $\tau_{\text {nr }}$ pela relação

$$
\frac{1}{\tau}=\frac{1}{\tau_{o}}+\frac{1}{\tau_{n r}} .
$$

se $\tau_{\text {nr }}$ é muito menor que $\tau_{0}$, então o tempo de decaimento medido $\tau \sim \tau_{\mathrm{nr}}$. Portanto, vale a aproximação $\tau_{1} \sim \tau_{\mathrm{nr}}$. Em nosso equipamento, o limite inferior para $\tau$ está condicionado à resposta do detector de aproximadamente $0,15 \mathrm{~ns}$, como é mostrado pela linha tracejada na Figura 4.28. Assim, os decaimentos rápidos na faixa de tempo de subnanosegundos devem estar associados à processos não radiativos que extinguem o éxciton eficientemente, como é o caso da sua dissociação na interface de $\mathrm{TiO}_{2}$. Já os tempos longos de decaimento dependem fortemente da região espectral medida para o PFO. Esta dependência do tempo de decaimento com o comprimento de onda é tema de estudos recentes (ARIU et al., 2003; SHAW et al., 2010). No caso da Figura 4.28, a região espectral detectada corresponde a $\lambda>490 \mathrm{~nm}$, que é dominada por transições ópticas envolvendo complexos excitônicos exciplex, estão associados a tempos de decaimento relativamente longos ( $\geq 5 \mathrm{~ns}$ ). Intrigantemente, estes complexos também sofrem o efeito da interface de $\mathrm{TiO}_{2}$. Este comportamento espectral, bem como os efeitos da fase $\beta$, estão sendo estudados atualmente em nossos laboratórios. 


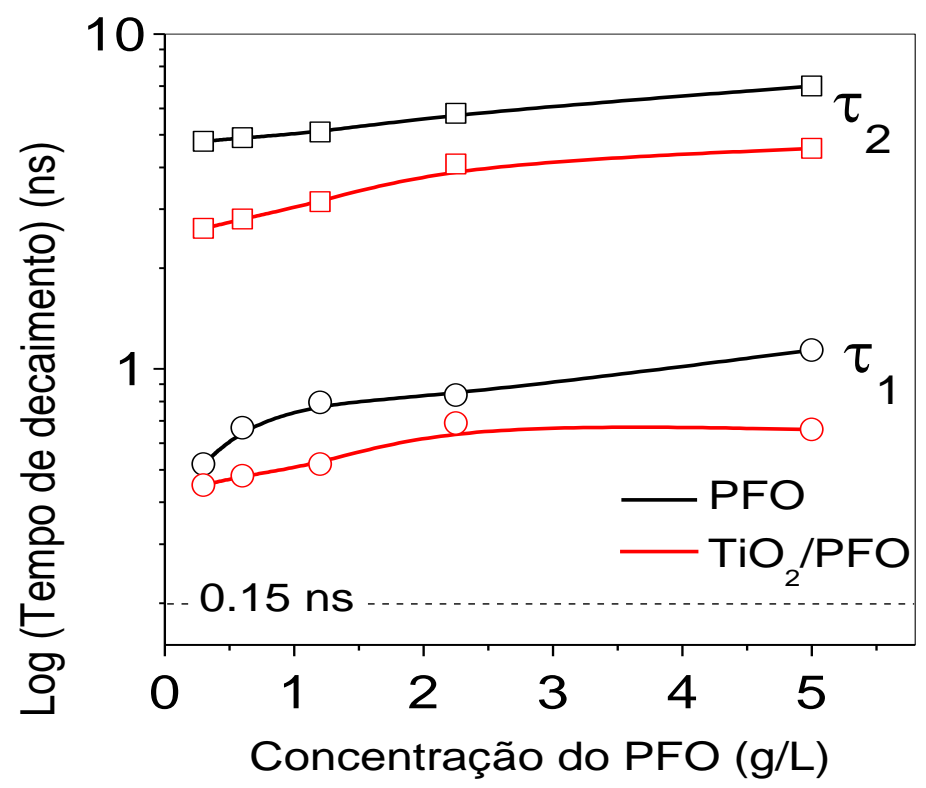

Figura 4.28: Dependência de $\tau_{1}$ e $\tau_{2}$ com a espessura do filme de PFO (com a concentração do PFO em clorofórmio) sobre as superfícies de quartzo (linha preta) e sobre o $\mathrm{TiO}_{2}$ (linha vermelha).

Em segundo lugar, a Figura 4.28 mostra que os tempos de decaimento $\tau_{1}$ e $\tau_{2}$ aumentam com o aumento da espessura (concentração) da amostra. Sugerimos que este comportamento está associado com processos de autoaniquilação do éxciton nesses filmes extremamente finos. Vimos na seção 4.3, a fluência utilizada na microscopia confocal é muito alta e que, nessas condições, é muito provável excitar dois éxcitons próximos na mesma cadeia ou em cadeias adjacentes dentro do tempo de vida do éxciton. Esta probabilidade aumenta muito com o decréscimo da espessura do filme. Processos de autoaniquilamento do éxciton são observados em sistemas como pontos quânticos semicondutores e em polímeros conjugados (SHAW et al., 2010; HUANG et al., 2010). Ainda estamos estudando os efeitos da fase $\beta$ nos processos de autoaniquilamento do éxciton no PFO.

Um processo que precede a transferência de carga é a migração do éxciton até a interface com o semicondutor inorgânico. A migração do éxciton é influenciada fortemente pela organização molecular do polímero (regiões amorfas e ordenadas, por exemplo) e temperatura. Como foi apresentado na seção 4.2, o PFO pode apresentar a fase $\beta$ inserida numa matriz amorfa. Através da PL, ambas as regiões são bem discriminadas (Figura 4.10). Portanto, este polímero é ideal para investigar a influência da organização molecular no processo de TC e temperatura na migração do éxciton no PFO.

A Figura 4.29 compara os espectros de emissão de um filme de PFO preparado por spin-coating sobre o quartzo (linha preta) e sobre o $\mathrm{TiO}_{2}$ (linha vermelha) medidos a $5 \mathrm{~K}$ (a) e 
a 297 K (b) utilizando-se para excitação um laser de $\mathrm{HeCd}$ em $325 \mathrm{~nm}$. A fase $\beta$ nesse filme foi gerada utilizando o solvente tolueno como discutido na seção 4.2.

Como pode ser observado nas Figuras 4.29(a) e (b), a emissão oriunda da fase amorfa (componente espectral mais larga e de maior energia) é totalmente eliminada quando medida sobre a interface $\mathrm{TiO}_{2} / \mathrm{PFO}$ tanto para baixa como para temperatura ambiente. Para $5 \mathrm{~K}$, a PL característica da região de fase $\beta$ (pico estreito em $443 \mathrm{~nm}$ e as réplicas provenientes da estrutura vibracional em mais baixa energia) não sofrem mudanças significativas na intensidade em relação aos mesmos picos na PL do filme de PFO sobre o quartzo (linha preta). Ou seja, as emissões provenientes de éxcitons presentes na fase $\beta$ não sofrem influência da interface contendo o $\mathrm{TiO}_{2}$ e, portanto, não são dissociados nessa interface. $\mathrm{O}$ mesmo efeito não ocorre para o mesmo filme de PFO à temperatura ambiente. Pose-se notar na Figura 4.29(b) que a PL proveniente da fase $\beta$ sofre uma forte redução da intensidade para o filme na interface com o $\mathrm{TiO}_{2}$.

Vários aspectos devem ser considerados para o entendimento dos resultados discutidos acima, já que para o PFO deve-se considerar o processo migração do éxciton em uma matriz amorfa contendo domínios da fase $\beta$ de menor energia. Primeiramente, pode-se dizer que a luz do laser em $325 \mathrm{~nm}$ não excita o PFO da fase $\beta$, já que a banda de absorção dessas moléculas é muito estreita e se localiza em torno de $435 \mathrm{~nm}$ (veja seção 4.2). Assim, a emissão proveniente dessa região é basicamente oriunda de éxcitons excitados na região amorfa contendo estados de maior energia e que migram até os domínios da fase $\beta$, onde são transferidos para moléculas de maior tamanho de conjugação dessa região e, portanto, de menor energia. A diferença de energia entre a fase amorfa e a fase $\beta$ é de $300 \mathrm{meV}$, o que é suficiente para produzir o confinamento dos éxcitons nesse domínio de menor energia. Assim, éxcitons gerados na fase amorfa em filmes com espessura da ordem de seu raio de migração $(\sim 13 \mathrm{~nm})$ têm grande probabilidade de terminar antecipadamente sua jornada migratória ou capturados em estados da fase $\beta$, ou dissociados por transferência de carga na interface com o $\mathrm{TiO}_{2}$, dentro do seu tempo de vida radiativo. No primeiro caso o processo final poderá ser radiativo e o segundo é estritamente não-radiativo. Isso explica a dissociação do éxciton, ou seja, a forte redução da emissão provinda da fase amorfa sobre o $\mathrm{TiO}_{2}$ tanto a $5 \mathrm{~K}$ quanto a 297 K. 

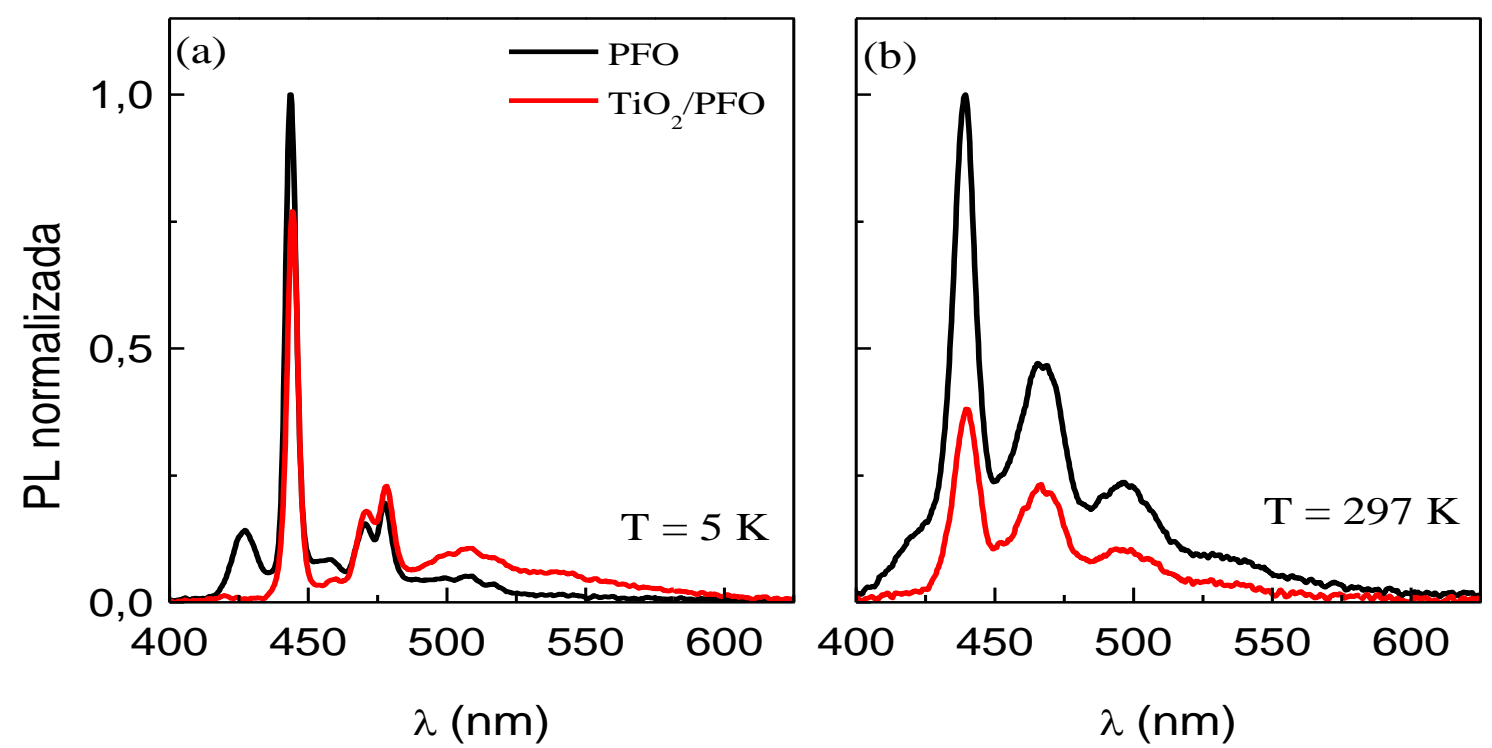

Figura 4.29: Fotoluminescência do filme de PFO contendo fase $\beta$ sobre o quartzo (linha preta) e sobre o $\mathrm{TiO}_{2}$ (linha vermelha). Medida realizada a (a) $5 \mathrm{~K}$ e (b) $297 \mathrm{~K}$. Excitação em $325 \mathrm{~nm}$ utilizando laser de $\mathrm{He}-\mathrm{Cd}$.

O segundo ponto a se considerar é o efeito da temperatura. A razão entre as intensidades de pico $I_{a} / I_{\beta}=0,14$ da fase $\beta\left(I_{\beta}\right)$ e da fase desordenada $\left(I_{a}\right)$ sobre o substrato de quartzo é praticamente a mesma tanto a baixas temperaturas quanto à temperatura ambiente. Isto significa que o processo de migração entre as fases amorfa e $\beta$ não foi muito alterado pela temperatura. Sobre o $\mathrm{TiO}_{2}, I_{a} / I_{\beta}=0,006$ é praticamente o mesmo a $5 \mathrm{~K}$ e a $297 \mathrm{~K}$ e se deve a dissociação do éxciton na interface $\mathrm{TiO}_{2} / \mathrm{PFO}$. Porém, a intensidade da emissão do PFO na fase $\beta$ diminui substancialmente (mais que duas vezes) a $297 \mathrm{~K}$ quando comparado à emissão provinda da mesma fase a $5 \mathrm{~K}$. Nossos estudos mostram que a dependência da intensidade de emissão com a temperatura não é muito diferente para a fase $\beta$ sobre o quartzo e sobre o $\mathrm{TiO}_{2}$.

Não existe também a possibilidade do éxciton capturado na fase $\beta$ a $5 \mathrm{~K}$ retorne à fase amorfa à temperatura ambiente por excitação térmica. A temperatura ambiente $(297 \mathrm{~K})$ a energia térmica fornecida para o sistema é $k_{B} \mathrm{~T}=26 \mathrm{meV}$ e a diferença de energia das moléculas da fase amorfa e da fase $\beta$ que estão emitindo, ou seja, diferença entre as transições puramente eletrônica $426 \mathrm{~nm}$ e $443 \mathrm{~nm}$, respectivamente, é igual a $110 \mathrm{meV}$. A energia térmica a temperatura ambiente não é suficiente para que os éxcitons capturados na fase $\beta$ sejam transferidos para as regiões amorfas.

Já a simulação da dinâmica do éxciton em sistemas amorfos (FACETO, 2012), mostra que o seu raio (volume) de difusão aumenta duas (oito) vezes com o aumento da temperatura de 5 a $297 \mathrm{~K}$. Isso pode indicar que o correspondente aumento da temperatura favorece a 
migração dos éxcitons para a interface e, consequentemente, sua dissociação pelo $\mathrm{TiO}_{2}$, explicando a forte diminuição da luminescência dos filmes de $\mathrm{PFO}$ sobre o $\mathrm{TiO}_{2}$ a $297 \mathrm{~K}$.

Um estudo de simulação computacional de um sistema semelhante ao investigado nessa seção foi realizado por Faceto (2012). Nesse estudo, a migração do estado excitado em filmes poliméricos contendo regiões ordenadas (similares às regiões de fase $\beta$ investigadas no presente trabalho) com uma interface com o $\mathrm{TiO}_{2}$ foram realizadas utilizando o método Monte Carlo e a integração da equação mestra. Essa simulação é feita considerando uma rede (100x 100) sítios com parâmetro de rede $a=0,37 R_{0}$ com condições de contorno periódicas, onde $R_{0}$ é o raio de transferência de energia característico e que está associado com a densidade molecular assumida no problema. Cada sítio possui um valor de energia que é escolhida de forma randômica com base em uma distribuição de estados gaussiana.

Com base nessa configuração, é possível obter o mapa de migração que corresponde ao deslocamento médio quadrático $\left(\left\langle r^{2}\right\rangle\right)$ do éxciton entre o ponto de sua fotogeração e o de sua emissão. Também, com essa simulação, é possível ter acesso aos eventos de emissão que corresponde a intensidade de emissão por sítio após a excitação simultânea de todos os sítios da rede. Entendemos que os resultados obtidos por Faceto (2012) contribuem para elucidação dos processos investigados nessa seção e, portanto, serão discutidos a seguir.

Esses resultados estão apresentados na Figura 4.30 que mostra o mapa de migração na coluna esquerda (Figura 4.30(a), (c) e (e)) e os eventos de emissão na coluna direita (Figura 4.30 (b), (d) e (f)) para as respectivas configurações dos mapas de migração apresentados no lado esquerdo. Na Figura 4.30(a), as regiões que possuem alto valor de $\left\langle r^{2}\right\rangle$ (sítio P2 na região vermelha do diagrama, por exemplo) o éxciton possui de alta difusividade $\left\langle r^{2}\right\rangle / \tau_{0}$ uma vez que não existe uma molécula de baixa energia nas proximidades, fazendo com que a excitação precise caminhar muito antes de encontrar um sítio de baixa energia onde ocorre a recombinação radiativa. Já uma região próxima a uma molécula de baixa energia (sítio P1 na região em azul escuro, por exemplo), o éxciton possui baixo valor de $\left\langle r^{2}\right\rangle$, portanto baixo coeficiente de difusão $\left\langle r^{2}\right\rangle / \tau_{0}$. Apenas um sítio de baixa energia já é suficiente para capturar os éxcitons de toda a região, fazendo com que o entorno deste sítio de baixa energia seja uma região de baixa migração.

Um plano de nanopartículas de $\mathrm{TiO}_{2}$ foi introduzido na região central da rede mantendo a mesma configuração molecular anterior (Figuras 4.30(c) e (d)). Porém, a dissociação do éxciton por transferência de carga na interface com as nanopartículas de $\mathrm{TiO}_{2}$ é descrita por $\exp \left(-\mathrm{r} / \mathrm{R}_{\mathrm{CT}}\right)$, onde $\mathrm{R}_{\mathrm{CT}}=0,5 a$ é o raio de interação e $a$ o parâmetro de rede da 


\section{Capítulo 4 - Resultados e Discussão}

matriz do polímero. Na Figura 4.30(c), nota-se que próximo da interface com o $\mathrm{TiO}_{2}$ há pouca migração (região azul escura, $\left\langle r^{2}\right\rangle$ pequeno), isso ocorre porque os éxcitons fotogerados dentro de seu raio migração próximos da interface com o $\mathrm{TiO}_{2}$ são dissociados. Essa região escura (ver Figuras 4.30(d)) se estende por uma distância de aproximadamente $10 \mathrm{a}\left(3,7 \mathrm{R}_{\mathrm{o}}\right)$ da interface, que é muito maior que o raio de transferência de carga $(0,5 a)$. De acordo com Faceto (2012), a região escura corresponde a exatamente ao raio médio de migração do éxciton avaliado no seu tempo de vida $\tau_{0}$. Nesta seção, avaliamos uma extensão da região escura de $(13 \pm 3) \mathrm{nm}$ para o PFO nas proximidades da interface com o $\mathrm{TiO}_{2}$. De acordo com as previsões de Faceto (2012), podemos assumir que o raio de transferência de energia para o PFO é $\mathrm{Ro}=(3,5 \pm 0,5) \mathrm{nm}$, o que está próximo do valor igual a $3 \mathrm{~nm}$ reportado na literatura (MESKERS, et al.,2001).

Como mencionada anteriormente, a influência de domínios ordenados na migração do éxciton no sistema polímero conjugado contendo interface de $\mathrm{TiO}_{2}$ também foi investigada por Faceto (2012). Dois domínios de dimensão 5x5, ou 25 segmentos conjugados com energia HOMO-LUMO de 1 eV foram inseridos na matriz 100x100 no diagrama anterior, mantendo a mesma configuração molecular das simulações anteriores, conforme mostrado nas Figuras 4.30(e) e (f). Esse valor da energia foi escolhido para que o éxciton não tenha energia para sair desse domínio de fase $\beta$ por excitação térmica à temperatura ambiente. Um domínio foi inserido dentro da região escura e outro em uma região de máxima migração (setas). 


\section{Capítulo 4 - Resultados e Discussão}
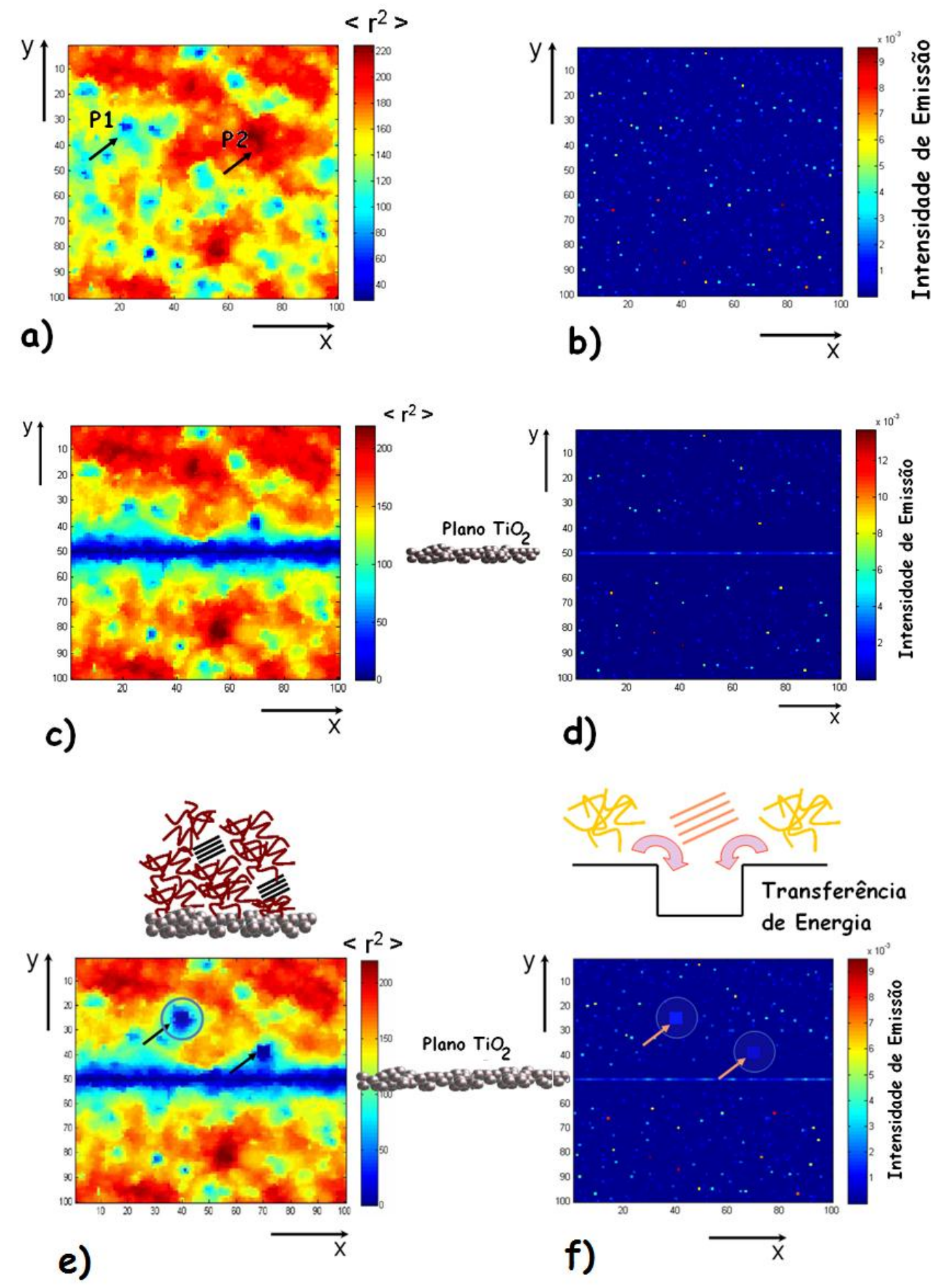

Figura 4.30: Simulações de sistema polimérico obtidos utilizando o método de Monte Carlo realizado por Faceto (2012). (a), (c) e (e) são mapas de migração do éxciton em um polímero amorfo, amorfo com interface de $\mathrm{TiO}_{2}$ e amorfo com domínios ordenados e interface de $\mathrm{TiO}_{2}$, respectivamente. Em (a) as posições P1 e P2 indicam regiões de baixa e alta migração, respectivamente. (b), (d) e (f) são os eventos de emissão para a mesma configuração de (a), (c) e (f) respectivamente. Em (e) e (f) as setas indicam os domínios ordenados. 
Pode-se notar no diagrama da Figura 4.30(e) que a migração é pequena próxima aos domínios de fase $\beta$ há pouca migração, o que significa que éxcitons nessa região são transferidos eficientemente para estes domínios. Esta região escura em torno dos domínios (ver Figura 4.30(f)) corresponde à faixa de transferência de energia radiativa regida pelo parâmetro $\mathrm{R}_{0}$. É interessante notar que a região dos domínios apresenta eventos de emissão de alta intensidade em toda a sua extensão mesmo próximo da interface com o $\mathrm{TiO}_{2}$, indicando que os éxcitons que são capturados pelas moléculas da fase $\beta$ estão desacopladas com a matriz amorfa e não podem migrar ate a interface de $\mathrm{TiO}_{2}$. Os detalhes das Figuras 4.30(e) e (f) ilustram estes processos.

A Figura 4.31 mostra o perfil de migração $\left(<r^{2}>\right)$ correspondendo à Figura 4.30(c), ou seja, do sistema contendo um plano de $\mathrm{TiO}_{2}$ no meio da matriz 100x100. É interessante notar que o diagrama de migração é profundamente afetado pela presença do $\mathrm{TiO}_{2}$, mesmo a distâncias muito maiores que o raio de migração de 3,7 $\mathrm{R}_{0}$. Além disso, o perfil de migração perpendicular ao plano de $\mathrm{TiO}_{2}$ é da forma sigmoidal, como foi visto na Figura 4.25.

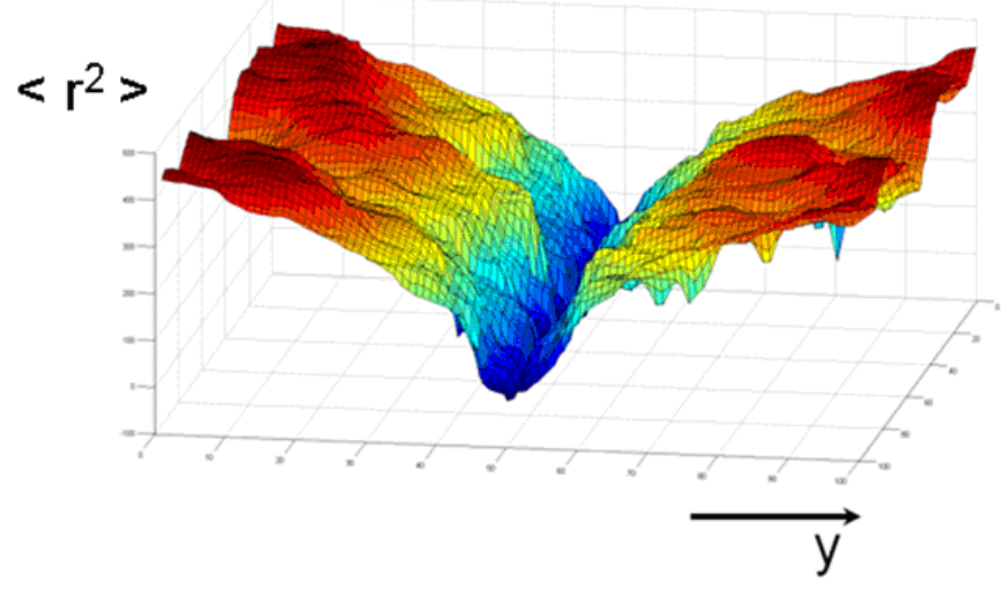

Figura 4.31: Perfil de migração do éxciton em um sistema polimérico contendo uma interface de $\mathrm{TiO}_{2}$ obtida a partir do método Monte Carlo (FACETO, 2012). 


\section{CONCLUSÕES}

Neste trabalho realizamos uma caracterização espectroscópica em filmes finos e ultrafinos (espessuras menores que o raio de migração do éxciton de $10 \mathrm{~nm}$ ) de PFO amorfo e contendo fase $\beta$. Também investigamos os processos de migração e dissociação do éxciton próximo a interface desses filmes de polifluoreno (amorfos e com fase $\beta$ ) com nanopartículas de $\mathrm{TiO}_{2}$. Métodos espectroscópicos, tais como, microscopia confocal de fluorescência, microscopia de imagem do tempo de vida (FLIM), fotoluminescência de onda contínua e resolvida no tempo, bem como espectroscopia de absorção foram utilizadas neste trabalho.

Em relação à caracterização espectroscópica de filmes de PFO amorfo, investigamos a propriedades espectrais de emissão de filmes de PFO através da intensidade da transição puramente eletrônica $I$, largura da linha a meia altura $\Gamma_{\mathrm{o}}$, energia da transição puramente eletrônica $E$ e do parâmetro de Huang-Rys $S$. Verificamos que todos estes parâmetros dependem indiretamente da energia térmica do sistema. A intensidade $I$ é influenciada pela migração do éxciton que por sua vez depende da temperatura. Observamos que a intensidade de emissão é máxima para temperaturas próximas de $5 \mathrm{~K}$ o que é explicado pelo volume de migração do éxciton ser oito vezes menor do que à temperatura ambiente, ou seja, a probabilidade do éxciton ser capturado por um centro não radiativo é muito reduzida à baixa temperatura. Já os parâmetros $\Gamma_{\mathrm{o}}, E$ e $S$ dependem fortemente do comprimento efetivo do segmento conjugado do polímero que é influenciado pela energia térmica fornecida ao sistema. A partir do comportamento de $\Gamma_{\mathrm{o}}, E$ e $S$ com a temperatura obtivemos as energias de ativação térmica em que cada um desses parâmetros que estão associados com a excitação de fônons longitudinais.

Por outro lado, filmes spin-coating de PFO preparados em tolueno apresentaram domínios associados à fase $\beta$. Segundo os procedimentos de produção dos filmes adotados neste trabalho, solução polimérica de concentração igual a $0,6 \mathrm{~g} / \mathrm{L}$ e parâmetros de spincoating igual a $3000 \mathrm{rpm}$ por $60 \mathrm{~s}$, estimamos que $8,6 \%$ das moléculas estão na fase $\beta$. Porém, verificamos que esta fase não está distribuída uniformemente na matriz amorfa, mas sim em forma de domínios que contém em média 50 segmentos altamente conjugados devido ao alinhamentos dos anéis aromáticos.

Filmes de PFO preparados por spin-coating a partir de uma solução de PFO em clorofórmio foram preparados com sucesso com espessuras menores que o raio típico de migração do éxciton $(10 \mathrm{~nm})$. Os filmes apresentaram apenas a fase amorfa para espessuras maiores que $10 \mathrm{~nm}$. O uso da técnica de microscopia confocal de fluorescência possibilitou a 
investigação de um ensamble pequeno da ordem $10^{6}$ moléculas de PFO nestes filmes. Utilizando essa técnica combinada com a microscopia de força atômica realizamos uma caracterização dos filmes ultrafinos de PFO (espessuras < $10 \mathrm{~nm}$ ) demonstrando que estes filmes possuem recobrimento total, aderência e homogeneidade sobre o substrato, características desejáveis para o estudo de processos fotofísicos. Também a partir dos resultados de microscopia confocal de fluorescência, observamos que nestes filmes ultrafinos a forte interação filme/substrato induz um ordenamento dos meros dos segmentos conjugados do polímero que leva a formação camadas de fase $\beta$.

Além das duas maneiras de geração de fase $\beta$ descrita acima, também induzimos esta fase utilizando métodos bem conhecidos na literatura tais como, ciclos de aquecimento/resfriamento e tratamento de vapor de tolueno. Este último método se mostra o mais interessante por proporcionar um controle de frações de fase $\beta$ através do tempo de tratamento. Utilizando esse método, verificamos que para um filme de PFO produzido com solvente clorofórmio e com espessura de $41 \mathrm{~nm}$ há uma estabilidade da formação da fase $\beta \mathrm{a}$ partir de 10 minutos de tratamento. Essa fração de fase $\beta$ é suficiente para que todos os éxcitons fotogerados na região amorfa migrem para as regiões de fase $\beta$. Com relação ao mecanismo de indução de fase $\beta$ por ciclos de aquecimento/resfriamento, propomos que o mecanismo de geração dessa fase esta relacionada com as tensões sofridas pela cadeia molecular devido a forte aderência entre o filme e o substrato e aos diferentes coeficientes de dilatação térmica do quartzo e do polímero, que produz um alongamento por tensão dos segmentos conjugados.

Os processos de migração e dissociação do éxciton próximos da interface do $\mathrm{TiO}_{2} / \mathrm{PFO}$ foram investigados utilizando as técnicas de microscopia confocal de fluorescência, FLIM e fotoluminescência de onda contínua e decaimento temporal da luminescência. A emissão foi totalmente suprimida para filmes spin- coating de PFO preparados em solução de clorofórmio quando depositado sobre $\mathrm{TiO}_{2}$. Utilizando a razão da intensidade do PFO sobre o $\mathrm{TiO}_{2}$ (I) pela intensidade sobre a superfície de quartzo tomada como referência (Io) em função da espessura dos filmes, obtivemos que o raio de migração do éxciton é de (13 \pm 3$) \mathrm{nm}$, dentro do erro esse valor está próximo do raio de migração típico de polímeros luminescentes (10 $\mathrm{nm})$. A partir dos tempos de decaimento radiativo estimamos que a eficiência dos processos de dissociação do éxciton na interface com o $\mathrm{TiO}_{2}$ está acima de $90 \%$ para filmes com espessura menores que o raio de migração do éxciton. Além disso, observamos que os tempos de decaimento diminuem com a redução da espessura da amostra. Por utilizarmos uma fluência 
alta nas medidas de microscopia confocal, há uma grande possibilidade de excitar dois éxcitons vizinhos na mesma cadeia ou em cadeias adjacentes dentro do tempo de vida do éxciton. Nossos resultados sugerem que processos de autoaniquilamento desses éxcitons são responsáveis por este comportamento. Atualmente nosso grupo está investigando o autoaniquilamento de éxcitons em filmes ultrafinos de PFO.

Já filmes de PFO contendo fase $\beta$ depositados sobre o $\mathrm{TiO}_{2}$, observamos que somente os éxcitons da região amorfa conseguem migrar até interface e serem eficientemente dissociados por ela. Verificamos que a energia térmica à temperatura ambiente não é suficiente para transferir os éxcitons capturados pela da fase $\beta$ novamente para as regiões amorfas. Porém, nessa temperatura a migração do éxciton até a interface com o $\mathrm{TiO}_{2}$ é favorecida e, portanto, a dissociação é mais eficiente em temperatura ambiente do que a baixas temperaturas. No entanto, mesmo à temperatura ambiente, há uma fotoluminescência proveniente dos éxcitons capturados pela fase $\beta$. Ou seja, a fase $\beta$ inserida na matriz amorfa atua como um centro de captura de éxciton que compete com a dissociação dos éxcitons pela interface com o $\mathrm{TiO}_{2}$. A partir do raio de migração do éxciton no PFO e resultados obtidos por Faceto (2012) o raio de transferência de energia de $(3,5 \pm 0,5) \mathrm{nm}$ foi estimado para o PFO. 


\section{REFERÊNCIAS}

AKIRA, et al. (1995). Optical properties of two-dimensional dye aggregate. Journal of Chemical Physics, v. 102, p. 5109-5117.

ATKINS, P.; PAULA, J. (2004). Físico-Química. 7ª Ed. vol. 2. Rio de Janeiro: LTC - Livros técnicos e científicos Editora S.A. 593 p.

ALONSO, M. \& FINN, E. J. (1968). Quantum and statistical physics. v. 3. Canada: Addison-Wesley, $598 \mathrm{p}$.

ALVARADO, S.; SEIDLER, P.; LIDZEY, D.; BRADLEY, D. (1998). Direct Determination of the Exciton Binding Energy of Conjugated Polymers Using a Scanning Tunneling Microscope. Physical Review Letters, v. 81, p. 1082-1085.

ANTONIADIS, H., et al. (1994). Photovoltaic and photoconductive properties of aluminum/poly(p-phenylene vinylene) interfaces. Synthetic Metals, v. 62, p. 265-271.

ARIU, M. et al. (2001). A study of the different structural phase of the polymer poly $\left(9,9^{\prime}\right.$ dioctyl fluorene) using Raman spectroscopy. Synthetic Metals, v.116, p. 271-221.

ARIU, M. et al. (2002). The effect of morphology on the temperature-dependent photoluminescence quantum efficiency of the conjugated polymer poly(9,9-dioctylfluorene).

Journal of Physics: Condensed Matter, v. 14, p. 9975-9986.

ARIU, M. et al. (2003). Exciton migration in $\beta$-phase poly(9,9-dioctylfluorene). Physical Review B, v. 67, p. 1-11.

BARFORD, W. (2005). Electronic and Optical Properties of Conjugated Polymers. $1^{\mathrm{a}} \mathrm{ed}$. Nova York: Oxford University Press, 262 p.

BERNÈDE, J. C. (2008). Organic Photovoltaic Cells: History, Principle and Techniques. Journal of the Chilean Chemical Society, v. 53, p. 1549-1564.

BORGES, C. A. M. (2001). Processos radiativos e não radiativos em polímeros conjugados emissores de luz. 124 p. Dissertação (Mestrado). Instituto de Física de São Carlos, Universidade de São Paulo.

BORGES, C. A. M.; RODRIGUES, C. A.; FARIA, R. M. \& GUIMARÃES, F. E. G. (2005). Strong luminescence intensity modulation near a metal-organic interface. Synthetic Metals, v.154, p.133-136.

BORGES, C. A. M. (2005). Efeitos de interface sobre as propriedades ópticas de polímeros conjugados. 142 p. Tese (Doutorado). Instituto de Física de São Carlos, Universidade de São Paulo.

CALlister, Jr. W. D. (2008). Ciência e engenharia de materiais: uma introdução. Tradução Sérgio Murilo Stamile Soares. Rio de Janeiro: Livros Técnicos e Científicos Editora S.A./LTC. 
CAZATI, T. (2003). Correlação entre a polarização da luz emitida e a morfologia de filmes luminescentes de poli(fenileno vinileno) e derivados. 124 p. Dissertação (Mestrado). Escola de Engenharia de São Carlos, Instituto de Química de São Carlos e Instituto de Física de São Carlos, Universidade de São Paulo.

CHANG, R. et al. (2000). Experimental and theoretical investigations of absorption and emission spectra of the light-emitting polymer MEH-PPV in solution. Chemical Physics Letters, v. 317, p. 142-152.

CHEN, S. H.; SU, A. C. \& CHEN, S. A. Noncrystalline Phases in Poly(9,9-di-n-octyl-2,7fluorene). Journal of Physical Chemistry B, v.109, p. 10067-10072, 2005.

CHEN, X.; MAO, S. S. (2007). Titanium dioxide nanomaterials: synthesis, properties, modifications, and applications. Chemical Reviews, v. 107, p. 2891-959.

CLARKE, T. M. \& DURRANT, J. R. (2010). Charge photogeneration in organic solar cells. Chemical Reviews, v. 110, p. 6736-6767.

DA SILVA, M. A. T., et al. (2008). Identification of the optically active vibrational modes in the photoluminescence of MEH-PPV films. The Journal of Chemical Physics, v. 128, p. 094902/1-7.

FACCHETTI, A. (2011). $\pi$-Conjugated Polymers for Organic Electronics and Photovoltaic Cells Applications. Chemistry of Materials, v.23, p.733-758.

FACETO, A. D. (2007). Simulação dos processos de migração e relaxação energética em sistemas orgânicos $\pi$-conjugados emissores de luz. 115 f. Dissertação (Mestrado). Instituto de Física de São Carlos, Universidade de São Paulo, São Carlos, 2007.

FACETO, A. D. (2012). Simulação da dinâmica do estado excitado em semicondutores orgânicos. 112 p. Tese (Doutorado). Instituto de Física de São Carlos, Universidade de São Paulo.

FAVARIM, H. R. (2006). Estudos dos processos fotofísicos em heteroestruturas orgânicas que utilizam chaveamento de luz por fotoalinhamento molecular. 127 p. Dissertação (Mestrado). Instituto de Física de São Carlos, Universidade de São Paulo.

FAVARIM, H. R., et al. (2007). Energy-Modulated Heterostructures Made with Conjugated Polymers for Directional Energy Transfer and Carrier Confinement. Advanced Functional Materials, v. 17, p. 2862-2868.

FORSTER, T. (1959). 10th Spiers Memorial Lecture - Transfer Mechanisms of Electronic Excitation. Discussions of the Faraday Society, v. 27, p. 7-17.

GIERSCHNER, J. et al. (2002). Fluorescence and absorption spectra of oligophenylenevinylenes: Vibronic coupling, band shapes, and solvatochromism. Journal of Chemical Physics, v. 116, p. 8596-8609.

GOBATO, Y. G. et al. (2002). Photoinduced photoluminescence intensity enhancement in 
poly(p-phenylene vinylene) films. Applied Physics Letters, v. 81, p. 942-944.

GRELL, M. et al. (1998). Chain geometry, solution aggregation and enhanced dichroism in the liquid-crystalline conjugated polymer poly(9,9-dioctylfluorene). Acta polym, v. 49, p. 439-444.

GRELL, M.; BRADLEY, D.D.C.; UNGAR, G.; HILL, J.; WHITEHEAD, K.S. (1999). Interplay of Physical Structure and Photophysics for a Liquid Crystalline Polyfluorene. Macromolecules, v. 32, p. 5810-5817.

HAINS, A. W. et al. (2010). Molecular semiconductors in organic photovoltaic cells. Chemical reviews, v. 110, p. 6689-735.

HAGLER, T. W.; PAKBAZ, K.; VOSS, K. F. \& HEEGER, A. J. (1991). Enhanced order and electronic delocalization in conjugated polymers oriented by gel processing in polyethylene. Physical Review B, v. 44, p. 8652-8666.

HEUN, S. et al. (1993). Conformational effects in poly(p-phenylene vinylene)s revealed by low-temperature site-selective fluorescence. Journal of Physics: Condensed Matter, v. 5, p. 247-260.

HIBBS, A. R. (2004). Confocal Microscopy for Biologist. New York: Springer. 467 p.

HOFFMANN, S. T., et al. (2010). Spectral diffusion in poly(para-phenylene)-type polymers with different energetic disorder. Physical Review B, v. 81, p. 1-8.

HONG, H., et al. (1996). Possible evidence for quantum-size effects in self-assembled ultrathin films containing conjugated copolymers. Journal of Applied Physics, v. 79, p. 3082-3088.

HUANG, et al. (2010). Multiple exciton dissociation in CdSe quantum dots by ultrafast electron transfer to adsorbed methylene blue. Journal of the American Chemical Society, p. 132, v. 4858-4864.

IBALDO, A. P. (2010). Estudo de materiais, estruturas de dispositivos e fenômenos de transporte em sistemas fotovoltaicos híbridos orgânico-inorgânico. 192p. Tese (Doutorado) - Escola de Engenharia de São Carlos, Instituto de Química de São Carlos e Instituto de Física de São Carlos, Universidade de São Paulo.

KAWAMURA, T. et al. Crystalline thin films of b-phase poly(9,9-dioctylfluorene). Thin Solids Films, v. 519, p. 2247-2250, 2011.

KENNED, S. P.; GARRO, N. and PHILIPPS, R. T. (2001). Time-resolved site-selective spectroscopy of poly( $p$-phenylene vinylene). Physical Review B, v. 64, p. 115206.

KIESS, H. (org.). (1992). Conjugated Conducting Polymers. v. 102. Nova York: SpringerVerlag, $310 \mathrm{p}$.

KIROVA, N.; BRAZOVISKII, S. \& BISHOP, A.R. (1999). A systematic theory for optical properties of phenylene-based polymers. Synthetic Metals, v.100, p. 29-53. 
KHAN, A. L .T.; BANACH, M. J.; KÖHLER, A. Control of $\beta$-phase formation in polyfluorene thin films via Franck-Condon analysis. Synthetic Metals, v.139, p. 905-907, 2003.

KNUPFER, M. (2003). Exciton binding energies in organic semiconductors. Applied Physics A: Materials Science \& Processing, v. 77, p. 623-626.

LIST, E. J. W.; GUENTNER, R.; SCANDUCCI DE FREITAS, P. \& SCHERF, U. (2002). The Effect of Keto Defect Sites on the Emission Properties of Polyfluorene-Type Materials. Advanced Materials, v. 14, p. 374-378.

LOBO, R. F. M. et al. (2003). The morphology of layer-by-layer films of polymer/ polyelectrolyte studied by atomic force microscopy. Nanotechnology, v. 101, p. 101-108.

LIAO, L. S. et al. (2000). Electronic structure and energy band gap of poly $(9,9-$ dioctylfluorene) investigated by photoelectron spectroscopy. Applied Physics Letters, v. 76, p. 3582-3584.

MAIA, F. C. B. (2006). Correlação entre polarização da luminescência e orientação molecular em polímeros conjugados. 142 p. Dissertação (Mestrado). Instituto de Física de São Carlos, Universidade de São Paulo.

MAIA, F. C. B. (2011). Estudo da interação entre polímeros semicondutores e metais ou surfactantes. 209 p. Tese (Doutorado). Instituto de Física de São Carlos, Universidade de São Paulo, São Carlos, 2011.

MATWEB.<.http://www.matweb.com/reference/ tensilestrengthaspx>. Acesso: 11 de Julho de 2012.

MCBRANCH, D.; CAMPBELL, I. H.; SMITH, D. L. \& FERRARIS, J. P. (1995). Optical determination of chain orientation in electroluminescent polymer films. Applied Physics Letters, v. 66, p. 1175-1177.

MESKERS, S. \& HÜBNER, J. (2001). Dispersive relaxation dynamics of photoexcitations in a polyfluorene film involving energy transfer: experiment and Monte Carlo simulations. The Journal of Physical Chemistry B, v. 105, p. 9139-9149.

MOKARIAN-TABARI, P. et al. (2010). Quantitative evaluation of evaporation rate during spin-coating of polymer blend-films: Control of film structure through defined-atmosphere solvent-casting. The European Physical Journal E, v. 33, p. 283-289.

MOLITON, A. (2006). Optoelectronics of Molecules and Polymers. v. 104. Nova York: Springer, $497 \mathrm{p}$.

QUILES, M. C. et al. (2005). Ellipsometric characterization of the optical constant of polyfluorene gain media. Advanced Functional Materials, v.15, p.925-933. 
REEJA-JAYAN, B. \& MANTHIRAM, A. (2010). Influence of polymer-metal interface on

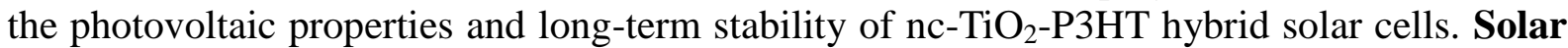
Energy Materials and Solar Cells, v. 94, p. 907-914.

RIESS, W.; KARG, S. \& DYAKONOV, V. (1994). Electroluminescence and photovoltaic effect in PPV Schottky diodes. Journal of Luminescence, v. 60-61, p. 906-911.

ROMANER, L. et al. (2003). The Origin of Green Emission in Polyfluorene-Based Conjugated Polymers: On-Chain Defect Fluorescence. Advanced Functional Materials, v. 13 , p. 597-601.

SESSOLO, M. \& BOLINK, H. J. (2011). Hybrid Organic-Inorganic Light-Emitting Diodes. Advanced Materials, v.23, p.1829-1845.

SIMS, M. et al. (2004). Understanding the Origin of the 535nm Emission Band in Oxidized Poly(9,9-dioctylfluorene): The Essential Role of Inter-Chain/Inter-Segment Interactions. Advanced Functional Materials, v. 14, p. 765-781.

SCHOLES, G. D \& RUMBLES, G. (2006). Excitons in nanoscale systems. Nature Materials, v. 5, p. 683-696.

SHAW, B. P. E. et al. (2010). Exciton - Exciton Annihilation in Mixed-Phase Polyfluorene Films. Advanced Functional Materials, v. 20, p. 155-161.

SHI, Y.; DENG, Z.; XU, D.; CHEN, Z. \& LI, X. (2007). Quantum well organic light emitting diodes with ultra thin Rubrene layer. Displays, v. 28, p. 97-100.

SRIWICHITKAMOL, K.; SURAMITR, S.; POOLMEE, P. \& HANNONGBUA, S. (2006). Structures, absorption spectra, and electronic properties of polyfluorene and its derivatives: A theoretical study. Journal of Theoretical and Computational Chemistry, v. 5, p. 595-608.

TADMOR, R. (2004). Line Energy and the Relation between Advancing, Receding, and Young Contact Angles. Langmuir, v. 20, p. 7659-7664.

VETTEGREN, V. I.; SLUTSKER, A. I. \& KULIK, V. B. (2009). Stresses induced in polymer crystals by the atomic-molecular internal dynamics. Physics of the Solid State, v. 51, p. $212-$ 220.

WU, B. C. (2012). Thinking small for solar. MRS Bulletin, v.37, p. 194-195.

YU, G.; HUMMELEN, J.C.; WUDL, F. \& HEEGER, A. J. (1995). Polymer Photovoltaic Cells: Enhanced Efficiencies via a Network of Internal Donor-Acceptor Heterojunctions. Science, v. 270, p. 1789-1791.

YU, J. et al. (1995). Experimental an theoretical studies of absorption and photoluminescence excitation spectra of $\operatorname{poly}(p-$ phenylene vinylene). Synthetic Metals, v.74, p. 7-13. 